\title{
MATHEMATICAL TREATMENT OF OPTIMAL OCEAN SHIP ROUTEING
}




\title{
MATHEMATICAL TREATMENT OF OPTIMAL OCEAN SHIP ROUTEING
}

\author{
PROEFSCHRIFT \\ TER VERKRIJGING VAN DE GRAAD VAN DOCTOR IN DE \\ TECHNISCHE WETENSCHAPPEN AAN DE TECHNISCHE \\ HOGESCHOOL DELFT OP GEZAG VAN DE RECTOR \\ MAGNIFICUS DR. IR. C.J.D.M. VERHAGEN, \\ HOOGLERAAR IN DE AFDELING DER TECHNISCHE \\ NATUURKUNDE, VOOR EEN COMMISSIE UIT DE SENAAT \\ TE VERDEDIGEN OP WOENSDAG 20 NOVEMBER 1968 \\ TE 14 UUR
}

DOOR

\section{CORNELIS DE WIT}

DOCTORANDUS WIS- EN NATUURKUNDE

GEBOREN TE ROTTERDAM

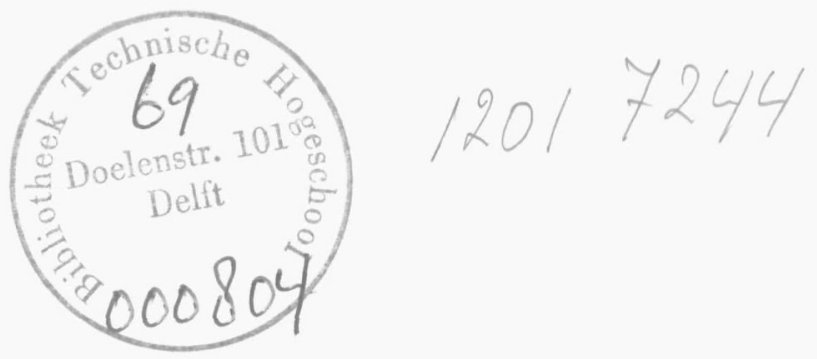


Dit proefschrift is goedgekeurd door de promotor PROF. DR. R. TIMMAN. 


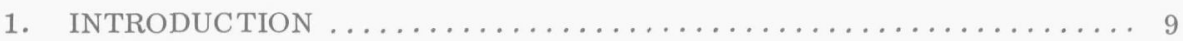

1.1 The stage preceding ship routeing $\ldots \ldots \ldots \ldots \ldots \ldots \ldots \ldots \ldots .9$

1.2 The K.N.M.I. ship routeing department $\ldots \ldots \ldots \ldots \ldots \ldots \ldots \ldots$

1.3 Description of the dynamical system $\ldots \ldots \ldots \ldots \ldots \ldots \ldots \ldots \ldots \ldots$

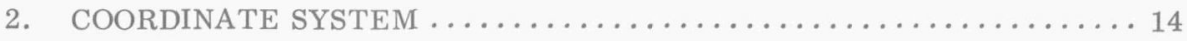

3. ANALYSIS OF THE CONSTRUCTION OF AN OPTIMAL TRACK $\ldots \ldots 19$

3.1 Controlled dynamical systems $\ldots \ldots \ldots \ldots \ldots \ldots \ldots \ldots \ldots \ldots \ldots \ldots \ldots \ldots \ldots \ldots \ldots \ldots$

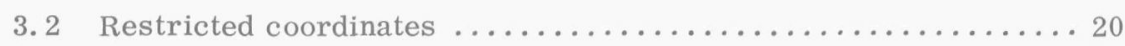

3.3 The unrestricted problem ........................ 20

3.4 Extremals, optimal controls, timefronts .............. 24

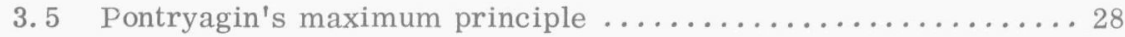

3.6 Behaviour of the tangent and the normal to a timefront along an extremal ............................... 31

3.7 Construction of the solution. Examples .............. 39

3. 8 Remarks on the occurrence of more than one solution ....... 46

3.9 Modifications in case of coordinate restrictions $\ldots \ldots \ldots \ldots \ldots 50$

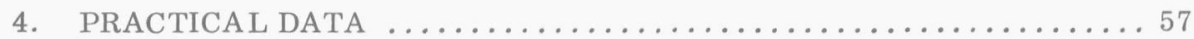

4.1 The wave prediction problem .................... 57

4.2 Some basic elements of ocean wave theory $\ldots \ldots \ldots \ldots \ldots \ldots \ldots 7$

4.3 The Sverdrup-Munk wave forecasting method ............ 59

4.4 The Pierson-Neumann theory $\ldots \ldots \ldots \ldots \ldots \ldots \ldots \ldots \ldots \ldots \ldots \ldots \ldots \ldots \ldots \ldots \ldots \ldots \ldots$

4. 5 The performance of a ship in a given wave field $\ldots \ldots \ldots \ldots \ldots 70$ 
4.5.1 Practical approach ................... 70

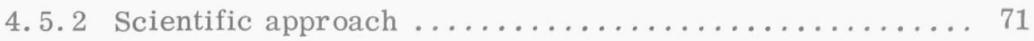

5. EVALUATION $Q F$ THE LEAST TIME TRACK $\ldots \ldots \ldots \ldots \ldots \ldots \ldots .75$

5.1 Oceanographic and meteorological data .............. 75

5.2 Evaluating the timefronts $\ldots \ldots \ldots \ldots \ldots \ldots \ldots \ldots \ldots \ldots \ldots \ldots$

5.3 Revision of the timefronts $\ldots \ldots \ldots \ldots \ldots \ldots \ldots \ldots \ldots \ldots \ldots \ldots$

5.4 Determination of the trajectory and the time gain .......... 79

5.5 The Algol program to compute the least time track ......... 80

5. 6 Considerations regarding data incertainties and practical use. 


\section{A THE M T T A L TREATMENT OF O P T M A L OCEAN SHIP ROUTEING}

\section{I N T RO D U C T I O N}

This chapter contains a description of the practical data, that formed the basis of ocean navigation for merchant ships in the past.

The foundation of a Ship Routeing Department at the Royal Dutch Weather Institute (K. N.M.I.) in 1960 can be seen as an end of this period for two reasons. In the first place the issue to a ship of navigational advices by a shore station was an important renewal in navigation history, while secondly this was a serious attempt to furnish ships with information regarding the sea conditions to be expected, which was never but occasionally done before.

This chapter concludes with the description of a suitable mathematical model of the ship's movement with respect to the earth's surface, suitable in the sense that it can be used for solving the problem of constructing the shortest i. e. least time - track between two fixed points.

1.1. The stage preceding ship routeing.

The entirely autonomous navigation of merchant ships across the North Atlantic Ocean in either East or West direction was committed on the following basis:

a. Statistical information regarding the occurrence of bad weather and rough sea furnished by books, called "Ocean Pilots" and by Pilot Charts, issued by the U.S. Hydrographic Office.

b. Information regarding areas to be avoided on account of iceberg danger.

c. Determination of a great circle track and computation of the intersections of this track with meridians of $10^{\circ} \mathrm{W}, 20^{\circ} \mathrm{W}$ etc.

d. Meteorological information from a weather forecast for a period of one to five days ahead.

This meteo information contained little or nothing regarding the sea conditions to be expected. The ship's master was compelled to draw his conclusions from these weather forecasts all by himself, led by his experience and by his common sense. Therefore, the deviations from the predetermined track seldomly were 
more than occasional and for low powered ships, this procedure not rarely resulted in a considerable delay of the time of arrival.

\subsection{The K.N.M.I. Ship Routeing Department.}

Seeking to avoid these delays and the high costs they implied, two Dutch shipping companies studied the possibility of furnishing their ships with more detailed information on the sea to be expected, such as height and direction of sea waves, direction and period of swell.

For this purpose, the K. N. M. I. established a special "Ship Routeing Department" with the assignment of predicting sea conditions for and giving navigational advices to ships "under treatment".

This routeing office was thus confronted with various problems of which no systematical study had been made so far.

To start with, a reliable picture of the weather situation was needed, not only for the present and the past, but also for the next (at most) eight days to come. In the case of an obviously stable weather situation, this stability was extrapolated over the period the crossing was expected to take and a least time track was constructed in accordance with it.

In the more frequently occurring case of a rapidly changing weather picture, no assumptions were made at all for more than two days ahead. Here the routeing department confined itself to pilot the ship through the dangers of the next two days to come. Working this way, disappointments still occur, although with considerably less frequency than in the preceding period with no shore based navigating control.

The second difficulty was the prediction of the sea conditions as a result of a given weather situation. Although many aspects of this problem are still subject to serious studies, the routeing department has by now attained a satisfying degree of reliability regarding these forecasts.

Thirdly the ship's response to the sea and swell waves had to be considered. As this response depended upon various characteristic properties of the routed ship, such as its draught, shape, length, longships and thwartships stability, the routeing was started on a strictly voluntary basis with two ships of the Holland America Line. After some experience, obtained with these trial models, the service was extended to other ships of the same general cargo type, while nowadays also tankers and container carriers are frequently accompanied by the K. N. M. I. routeing office on their way across the North Atlantic. 
1.3. Description of the dynamical system.

It is the aim of this thesis to indicate a construction of the least time track on a mathematical basis, mainly formed by Pontryagin's theory of optimally controlled processes.

To start with, the weather and sea situation will be assumed to be known in the entire navigating area and for a time last, that covers the average trip's duration. From a mathematical point of view it seems perhaps most appropriate to describe the ship's movement in a two-dimensional manyfold - the earth's surface - by means of complete equations of motion. However, practical navigation methods as well as some numerical facts regarding the motion of an ocean vessel necessitate some simplifying assumptions.

In the first place ocean navigation is carried out with the aid of a conformal ocean chart of a small scale with such a slight scale alteration, that a straight line between two points on this chart can be taken as a good enough approximation of the shortest distance between these points. A chart with these properties would be Kahn's oblique cilindrical projection. This chart will be treated more closely in the second chapter.

For the time being, it will be assumed that the ship's position and movement can be accurately enough described with the aid of an orthonormal 2-dimensional coordinate system.

The dynamical system, describing the horizontal movement of the vessel, calls for the following notations:

$\mathrm{x}, \mathrm{y} \quad$ : Ship's position coordinates. (It is customary to neglect the ship's dimensions in sea navigation)

$\mathrm{u}, \mathrm{v} \quad$ : Components of the ship's speed in the $\mathrm{X}^{+}$and $\mathrm{Y}^{+}$directions, relative to water.

$\mathrm{n}^{\prime} \quad$ : Number of ship's engine rotations per time unit.

Y $\quad$ : Steering angle, i.e. the sharp angle between the rudder plane and the plane of keel and stems.

(The numbers $\mathrm{n}$ and $\gamma$ could be regarded as control parameters)

l, $\mathrm{d} \quad$ : Longships and thwartships directions of the driving power per mass unit, excited by propellor and/or rudder.

$\mathrm{w}_{1}, \mathrm{w}_{\mathrm{d}} \quad$ : Resistance force components per mass unit in 1- and d-directions as a result of ship's speed and situation of sea and swell. 
$\mathrm{t}_{\mathrm{a}}, \mathrm{t}_{\mathrm{b}} \quad$ : Times of departure and arrival.

$\mathrm{c}^{1}, \mathrm{c}^{2} \quad: \mathrm{X}^{+}$and $\mathrm{Y}^{+}$components of the sea current, assumed to be stationary.

$\dot{\mathrm{x}}, \dot{\mathrm{y}}, \dot{\mathrm{u}}, \dot{\mathrm{v}} \quad$ : Time derivatives of $\mathrm{x}, \mathrm{y}, \mathrm{u}, \mathrm{v}$.

$\xi_{i}, i=1(1) \mathrm{m}$ : Sea resistance parameters.

With these notations, the equations of motion are:

$$
\begin{aligned}
& \dot{\mathrm{u}}=\left(\mathrm{l}-\mathrm{w}_{\mathrm{l}}\right) \cos \alpha-\left(\mathrm{d}-\mathrm{w}_{\mathrm{d}}\right) \sin \alpha \\
& \dot{\mathrm{v}}=\left(\mathrm{l}-\mathrm{w}_{\mathrm{l}}\right) \sin \alpha+\left(\mathrm{d}-\mathrm{w}_{\mathrm{d}}\right) \cos \alpha \\
& \dot{\mathrm{x}}=\mathrm{u}+\mathrm{c}^{1} \\
& \dot{\mathrm{y}}=\mathrm{v}+\mathrm{c}^{2}
\end{aligned}
$$

The driving force component 1 is a function of $n$ and $\gamma$, while $d$ is dependent of $\mathrm{n}, \gamma, \mathrm{u}$ and $\mathrm{v}$, so

$$
\text { (1. 3. 2) } \quad l=1(n, \gamma) ; d=d(n, \gamma, u, v)
$$

The controls $\mathrm{n}$ and $\gamma$ are limited: $|\mathrm{n}| \leqslant \mathrm{N} ;|\gamma| \leqslant \Gamma$.

The resistance components $w_{1}$ and $w_{d}$ depend on the longships speed $\left(u^{2}+v^{2}\right)^{\frac{1}{2}}$ and the rudder angle $\gamma$ as well as on the parameters $\xi_{i}$, which are functions of $\mathrm{x}, \mathrm{y}$ and $\mathrm{t}$.

The problem to be solved would now be to find a trajectory satisfying (1.3.1)

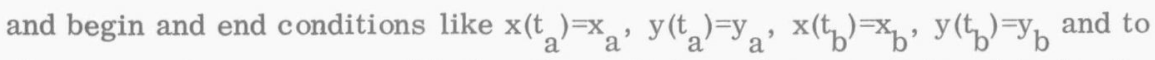
choose $n$ and $\gamma$ as measurable functions of $t$ in such a way as to minimize the time $t_{b}$ for a given value of $t_{a}$.

This system, however, is unfit for practical use for two reasons:

a. On account of safety considerations regarding the ship's oscillations the necessity to reduce $n$ in heavy weather frequently occurs. Thus $n$ no longer satisfies the requirements of a freely choosable control.

b. The practical result of (1.3.1) always consists of long periods (12 hours) of ultimately slightly changing $\mathrm{u}$ and $\mathrm{v}$, interrupted by short time intervals of a few minutes, during which $u$ and $v$ change to another value as a result of a pulse type alteration of $\gamma$ and possibly of $n$.

On account of the fact, that the influence of the sea parameters $\xi_{i}$ such as height and direction of the sea waves, direction and period of swell - on the ship's resistance is by now far from exactly known for one thing, while on the other hand one has good reasons to expect errors in these parameters, the values of $u$ and $v$, obtained from integrating (1.3.1) can hardly be expected to have any proctical use. 
It is for these reasons, that another model will be adopted.

Given certain sea conditions in a point $(x, y)$ at a time $t$, the maximum attainable speed relative to water can be regarded as a function of the course angle $\alpha$. Denoting $s=\left(u^{2}+v^{2}\right)^{\frac{1}{2}}$, the equations of motion are:

$$
\begin{aligned}
& \dot{x}=s(x, y, \alpha, t) \cos \alpha+c^{1}(x, y) \\
& \dot{y}=s(x, y, \alpha, t) \sin \alpha+c^{2}(x, y)
\end{aligned}
$$

The problem is now to find a trajectory satisfying (1.3.3) and the starting condition:

(1. 3. 4) (Given $\left.t_{a}\right):\left(x_{a}\left(t_{a}\right), y\left(t_{a}\right)\right)=\left(x_{a}, y_{a}\right)$

while for some, yet undetermined time $t_{b}$ the condition

(1. 3. 5) $\quad\left(\mathrm{x}_{\mathrm{b}}\left(\mathrm{t}_{\mathrm{b}}\right), \mathrm{y}\left(\mathrm{t}_{\mathrm{b}}\right)\right)=\left(\mathrm{x}_{\mathrm{b}}, \mathrm{y}_{\mathrm{b}}\right)$

must hold. Furthermore $\alpha$ as a function of time is to be chosen so that it minimizes $t_{b}$.

This system is fairly in accordance with the practical case.

The way s depends on $\alpha$ can in some occasions be very peculiar. In heavy sea, the highest attainable speed can for certain value intervals of $\alpha$ be extremely small or even zero, meaning that a value of $\alpha$ in that interval is highly unadvisable or even forbidden.

This is the main reason, why an analogy with the air navigation problem, studied and treated by H.M. de Jong (K. N. M.I. publ. 64) was not possible. In that case $\mathrm{s}$ was entirely independent of $\alpha$, which made the problem solvable as a direct application of the classical calculus of variations.

It must be noticed that the course angle $\alpha$ is to be considered as a "course made good". It differs from the steering course $\alpha_{\mathrm{S}}$ by the drift angle $d$, as shown in figure 1.3.a.

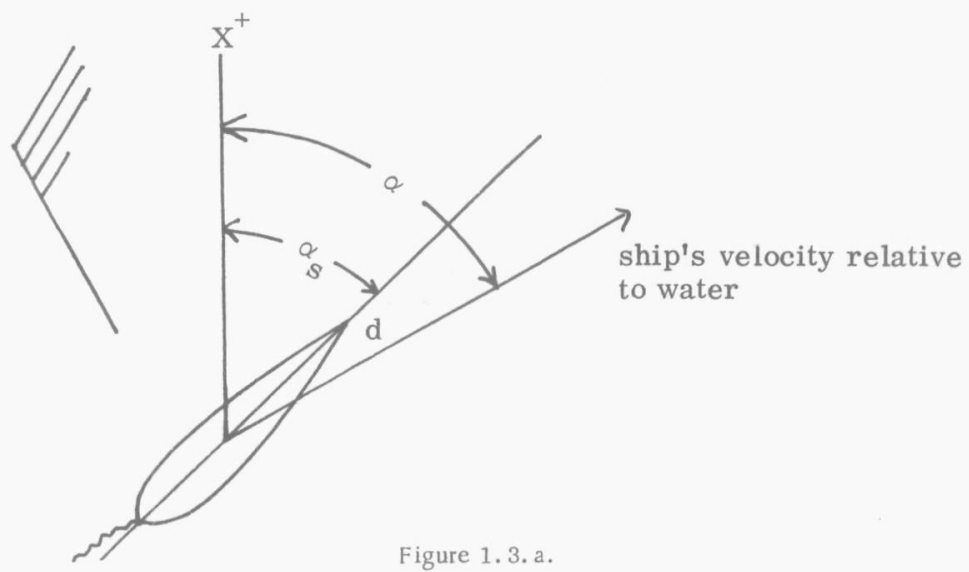




\section{C O O R D I N A T E S Y S T E M}

System (1.3. 3) supposes a plane orthonormal coordinate system. Crossing the North Atlantic involves an area of the geoid of $4000 * 1200$ square nautical miles, that must be scanned to find the best ship's route.

As it is a practical habit of navigators to work with a conformal sea chart - to avoid tedious corrections of measured or plotted angles, like courses, sight and radio bearings - it is most convenient to construct a plane conformal mapping of this area with very slight scale alteration.

Considering the length/width ratio of the area, amounting to about 3.3 , it seems most appropriate to make an oblique Mercator projection.

In a Mercator projection the equator is mapped as the $\mathrm{X}$-axis and the mapping of some meridian is the $\mathrm{Y}$-axis. The isometric grid of parameter lines, that is being mapped as the net of lines parallel to the $\mathrm{X}$ - and $\mathrm{Y}$-axis, is formed by parallel circles of equal geographic latitude and meridians. It would imply quite a few computational difficulties to construct such an isometric system on an arbitrary part of the geoid.

In order to avoid these difficulties, one can make a conformal mapping of the earth's surface onto a sphere by way of intermediate step. Beside being conformal, this mapping must have a practically constant scale.

Denoting the spherical mappings of A and B - the vertices of the ship's ocean route - as $A^{\prime}$ and $B^{\prime}$, we can consider the great circle over $A^{\prime}$ and $B^{\prime}$ as an oblique equator, while the collection of great circles through the poles of this great circle over $A^{\prime}$ and $B^{\prime}$ serve as skew meridians. The conformal mapping with this basis is called a Kahn projection.

\section{Notations:}

$\varphi, \lambda \quad$ : geographical latitude and longitude.

a : radius of the equator.

e : excentricity of an elliptic meridian.

$\rho \quad$ : curvature radius of a meridian.

$\mathrm{N} \quad$ : curvature radius of the prime vertical.

$\Downarrow, \mathrm{L} \quad$ : latitude and longitude of the spherical mapping of a point $(\varphi, \lambda)$.

$\mathrm{R} \quad$ : radius of the sphere.

o : index, referring to the projection centre, when mapping the (Hayford) 
ellipsoid onto a sphere.
n : longitude scale $\frac{\mathrm{dL}}{\mathrm{d} \lambda}$.
$\mathrm{k} \quad$ : distance scale sphere/ellipsoid.
$\alpha_{\mathrm{PQ}} \quad$ : great circle distance from $\mathrm{P}$ to $\mathrm{Q}$.
$\mathrm{v}_{\mathrm{PQ}} \quad$ : maximal latitude of the great circle over $\mathrm{P}$ and $\mathrm{Q}$.
$\mathrm{m} \quad$ : angle between $\mathrm{P}^{\prime} \mathrm{S}$ and the normal equator.
s : scale Kahn chart/sphere.
$\mathrm{s}_{\mathrm{o}} \quad$ : value of $\mathrm{s}$ for $\delta=0$.

$\delta \quad:$ spherical distance from a point $\mathrm{P}^{\prime}$ of the sphere to the oblique equator.

$\gamma \quad$ : angle between the oblique meridians of $\mathrm{P}^{\prime}$ and $\mathrm{S}$, the intersection of the oblique and normal equator closest to the projection centre.

Adopting the Hayford ellipsoid as a suitable approximation of the earth's surface, we work with:

$$
\begin{aligned}
& \mathrm{a}=6378388 \text { meters } \\
& \mathrm{e}=0.08226889 \\
& \rho=\frac{\mathrm{a}\left(1-\mathrm{e}^{2}\right)}{\sqrt{\left(1-\mathrm{e}^{2} \sin ^{2} \varphi\right)^{3}}} \\
& \mathrm{~N}=\frac{\mathrm{a}}{\sqrt{\left(1-\mathrm{e}^{2} \sin ^{2} \varphi\right)}}
\end{aligned}
$$

The transformation of $(\varphi, \lambda)$ to $(\psi, L)$ will now be described.

Taking $\psi=\psi(\varphi)$ and $L=L(\lambda)$, a conformal mapping requires the equality:

$$
k=\frac{R d \psi}{\rho d \varphi}=\frac{R \cos \psi d L}{N \cos \varphi d \lambda}
$$

Taking $n=\frac{d L}{d \lambda}$ constant and $L_{o}=\lambda_{0}$, this gives:

$$
\begin{array}{r}
L=\lambda_{0}+n\left(\lambda-\lambda_{0}\right) \text { and } \\
\int_{0}^{\varphi_{0}} \sec p d p=n \int_{\varphi_{0}}^{\varphi_{0}} \frac{\left(1-e^{2}\right) \sec f}{1-e^{2} \sin ^{2} f} d f .
\end{array}
$$

The apparent freedom to select the constants $\psi_{0}$ and $n$ is now used to make $\frac{d k}{d \varphi}$ and $\frac{d^{2} k}{d \varphi}{ }^{2}$ equal to zero for $\varphi=\varphi_{0}$. The results are: 


$$
\begin{aligned}
\psi_{0} & =\operatorname{arctg}\left(\operatorname{tg} \varphi_{0} \sqrt{ }\left(\rho_{0} / N_{0}\right)\right) \\
n & =\sin \varphi_{0} / \sin \psi_{0} \\
R & =\sqrt{ }\left(\rho_{0} N_{0}\right)
\end{aligned}
$$

The coordinates $(\psi, L)$ of the spherical mapping of a point on the earth $(\varphi, \lambda)$ follow from:

$$
\begin{gathered}
\sigma_{\varphi}=\ln \left\{\operatorname{tg}(\pi / 4+\varphi / 2)\left(\frac{1-\mathrm{e} \sin \varphi}{1+\mathrm{e} \sin \varphi}\right)^{\frac{\mathrm{e}}{2}}\right\} \\
\psi=2 \operatorname{arctg}\left(\exp \left(\ln \left(\operatorname{tg}\left(\pi / 4+\psi_{\mathrm{o}} / 2\right)\right)+\mathrm{n}\left(\sigma_{\varphi}-\sigma_{\varphi_{0}}\right)\right)\right)-\pi / 2 \\
\mathrm{~L}=\lambda_{\mathrm{o}}+\mathrm{n}\left(\lambda-\lambda_{\mathrm{o}}\right)
\end{gathered}
$$

In order to demonstrate the slight scale alteration, $\mathrm{k}$ was computed, with $\varphi_{\mathrm{o}}=46^{\circ}$, for $\varphi=15^{\circ}\left(1^{\circ}\right) 60^{\circ}$ :

$(\varphi)$

$\begin{array}{ll}15^{\circ} & 1.00029868 \\ 20^{\circ} & 1.00017889 \\ 25^{\circ} & 1.00009431 \\ 30^{\circ} & 1.00004036 \\ 40^{\circ} & 1.00000025 \\ 50^{\circ} & 1.00000086 \\ 55^{\circ} & 0.99999470 \\ 60^{\circ} & 0.99997084\end{array}$

Taking $\mathrm{k}=1$ implies an error over a 2000 miles stretch from the edge to the centre of less than 0.5 mile. For navigational practice this is negligible. Taking the great circle on the sphere as an approximation of the geodesic on the ellipsoid introduces another error of a still smaller magnitude. The small value of $\frac{\mathrm{dk}}{\mathrm{d} \varphi}$ keeps this error smaller than $2 * 10^{-7}$ miles over a 100 miles stretch. 


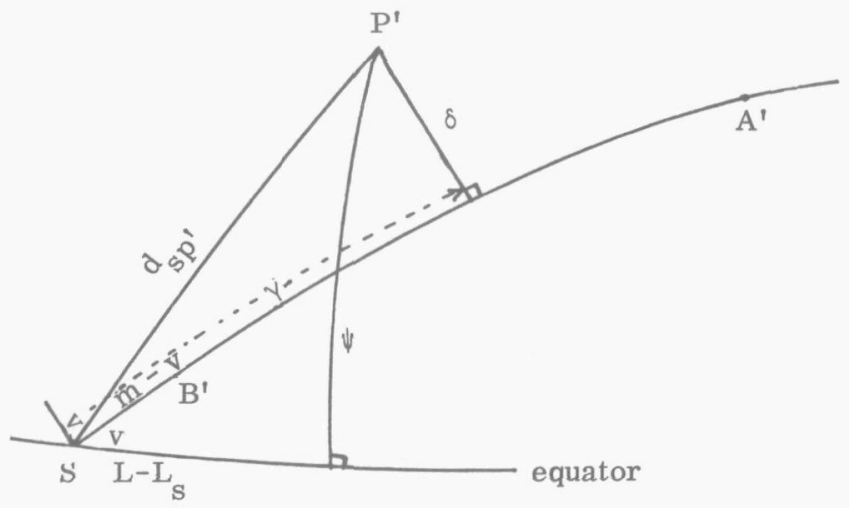

Figure 2. a.

Concentrating now on the transformation of $(\psi, L)$ to $(\delta, \gamma)$, the quantities $v$ and $\mathrm{L}_{\mathrm{S}}$ are computed by:

$$
\begin{aligned}
& \frac{\mathrm{d}_{\mathrm{A}^{\prime} \mathrm{B}^{\prime}}}{\mathrm{R}}=\arccos \left(\cos \psi_{\mathrm{A}^{\prime}} \cos \psi_{\mathrm{B}^{\prime}}+\sin \psi_{\mathrm{A}^{\prime}} \sin \psi_{\mathrm{B}^{\prime}} \cos \left(\mathrm{L}_{\mathrm{A}^{\prime}}-\mathrm{L}_{\mathrm{B}^{\prime}}\right)\right) \text {, }
\end{aligned}
$$

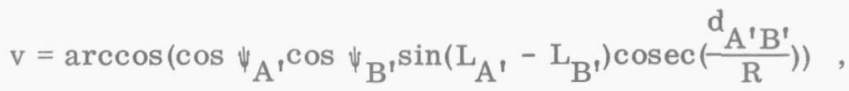

$$
\begin{aligned}
& \mathrm{L}_{\mathrm{S}}=\mathrm{L}_{\mathrm{A}^{\prime}}-\arcsin \left(\operatorname{cotg} \mathrm{v} \operatorname{tg} \psi_{\mathrm{A}^{\prime}}\right) \text {. }
\end{aligned}
$$

Then the angle $m$ follows from $m=\operatorname{arctg}\left(\operatorname{tg} \psi \operatorname{cosec}\left(L-L_{s}\right)\right)$.

Finally, $\delta$ and $\gamma$ can be computed:

$$
\begin{aligned}
\frac{\mathrm{d}_{\mathrm{SP}}}{\mathrm{R}} & =\arccos \left(\cos \left(\mathrm{L}-\mathrm{L}_{\mathrm{S}}\right) \cos \psi\right), \\
\delta & =\arcsin \left(\sin \left(\frac{\mathrm{d}_{\mathrm{SP}}}{\mathrm{R}}\right) \sin (\mathrm{m}-\mathrm{v})\right), \\
\gamma & =\operatorname{arctg}\left(\operatorname{tg}\left(\frac{\mathrm{d}_{\mathrm{SP}}}{\mathrm{R}}\right) \cos (\mathrm{m}-\mathrm{v})\right) .
\end{aligned}
$$

The $\mathrm{x}$ - and $\mathrm{y}$-components of the mapping $\mathrm{P}^{\prime \prime}$ of $\mathrm{P}^{\prime}$ into the oblique Mercator projection can be computed by means of:

$$
\begin{aligned}
\gamma_{B^{\prime}} & =\arcsin \left(\sin \psi_{B^{\prime}} \operatorname{cosec} v\right), \\
x & =s_{0} R\left(\gamma-\gamma_{B^{\prime}}\right),
\end{aligned}
$$




$$
\begin{aligned}
& \mathrm{y}=\mathrm{s}_{\mathrm{o}} \mathrm{R} \ln (\operatorname{tg}(\pi / 4+\delta / 2), \\
& \mathrm{s}=\mathrm{s}_{\mathrm{o}} \cdot \sec \delta .
\end{aligned}
$$

One can take account of the scale alteration by multiplying a line element $\mathrm{ds}=\left(\mathrm{dx}{ }^{2}+\mathrm{dy}^{2}\right)^{\frac{1}{2}}$ with the factor $\sec \delta$, where $\delta$ follows from $\mathrm{y}$ according to $\delta=2 \operatorname{arctg}\left(\exp \left(y / s_{0} R\right)\right)-\pi / 2$.

Another possible error source is the fact, that a straight line segment is taken as the shortest track between two points.

For a distance $\mathrm{d}$ between two points $\mathrm{P}$ and $\mathrm{Q}$, measured along a straight line in the Kahn chart, the difference with the great circle distance between $\mathrm{P}$ and $\mathrm{Q}$ is maximal if $\delta_{\mathrm{P}}=\delta_{\mathrm{Q}}$, namely:

$$
\mathrm{d}-2 \arcsin \left(\cos \delta \sin \left(\frac{\mathrm{d} \sec \delta}{2 \mathrm{R}}\right)\right) .
$$

With $|\delta| \leqslant 10^{\circ}$ and working with distance steps of at most 200 miles, the error per step never exceeds 0.06 miles, so the relative error is at most $0.03 \%$. On a 4000 miles stretch, this could accumulate to 1.2 miles, which is negligible for navigational practice. 
3. A N A L Y I S O F THE C O N T R U C TION OFA N O P T I M A L T R A C K

Optimal ship routeing can be incorporated into the class of optimal control problems. These problems were investigated and analyzed by a group of Russian mathematicians, directed by Pontryagin, while Halkin later published a more generalized theory. It was Pontryagin's merit to effectuate something much like a breakthrough from the classical variation calculus into modern applied mathematics by announcing his maximum principle. Halkin gave the problem statement and the adjacent theory in a somewhat different and more general form. His concept of the "set of reachable events" can be seen as a continuation of Hamilton's wave front theory. It also opens pracical possibilities for an actual solution of the problem.

With this basis, the third chapter has no other pretentions than to be an explanation of this application of the general theory.

\subsection{Controlled dynamical systems.}

Consider a ship, starting in $\mathrm{A}:\left(\mathrm{x}_{\mathrm{a}}^{1}, \mathrm{x}_{\mathrm{a}}^{2}\right)$ at a time $\mathrm{t}_{\mathrm{a}}$, following a course $\alpha$, which is a given function of the time $t$, and arriving in $\mathrm{B}:\left(\mathrm{x}_{\mathrm{b}}^{1}, \mathrm{x}_{\mathrm{b}}^{2}\right)$ at a time $\mathrm{t}_{\mathrm{b}}$. This sequence of events can be conceived as a dynamical system. The events $y=(x, t)$ are elements of the event space, which is the Cartesian product of the two dimensional space $\mathrm{X}$ - with points $\mathrm{x}=\left(\mathrm{x}^{1}, \mathrm{x}^{2}\right)$ - and the real time axis $\mathrm{T}=\left\{\mathrm{t} \mid \mathrm{t}_{\mathrm{a}} \leqslant \mathrm{t}\right\}$. So $\mathrm{y}=(\mathrm{x}, \mathrm{t}) \in \mathrm{X} * \mathrm{~T}$.

A dynamical system is specified by the fact that the various elements $(x, t)$ are mutually connected by a binary relation $\mathrm{R}$ on $\mathrm{X} * \mathrm{~T}$ :

(a) $y^{r} \mathrm{Ry}$ for all $\mathrm{y}$ in $\mathrm{X} * \mathrm{~T}$.

(b) if $\mathrm{y}_{1} \mathrm{Ry}_{2}$ and $\mathrm{y}_{2} \mathrm{Ry} \mathrm{y}_{3}$ then $\mathrm{y}_{1} \mathrm{Ry_{3 }}$.

(c) if $\mathrm{y}_{1} \mathrm{Ry}_{2}$ and $\mathrm{y}_{2} \mathrm{Ry}_{1}$ then $\mathrm{y}_{1}=\mathrm{y}_{2}$.

(d) if $\mathrm{y}_{1} \overline{\mathrm{Ry}}_{2}$ and $\mathrm{y}_{1} \mathrm{Ry}{ }_{3}$ then either $\mathrm{y}_{2} \mathrm{Ry}{ }_{3}$ or $\mathrm{y}_{3} \mathrm{Ry} \mathrm{y}_{2}$.

This relation $R$ is caused by a system of differential equations

$$
\dot{x}=f(x, \alpha(t), t) \quad \text { almost everywhere on } \mathrm{T} \text {. }
$$

As $\alpha(t)$ is a given function of $t$, this equation can be written as

$$
\dot{\mathrm{x}}=\mathrm{f}^{*}(\mathrm{x}, \mathrm{t}) \text {. }
$$

However, by varying $\alpha(t)$, the solution of (3.1.1) will in general vary as well. 
System (3.1.1) can therefore be seen as a controlled dynamical system - or "control system" for short - and the, yet to be chosen, function $\alpha(t)$ is called a control or steering function for the obvious reason that it can vary the solution of (3.1.1) to a certain extent.

The optimal control problem now consists of choosing $\alpha(t)$ so that the arrival time at $B$ is not greater than any other $\tilde{t}_{b}$, generated by some $\tilde{\alpha}(t)$.

\subsection{Restricted coordinates.}

Before studying this control system more precisely, the fact that the coordinates $x^{1}$ and $x^{2}$ of the ship's position are limited, cannot remain unmentioned, because it might play a part when determining the least time track.

In practice, the only restrictions of importance are the 10,20 or 30 fathoms depth lines - dependent of the ship's draught - and the boundaries of iceberg danger areas.

These restrictions can be expressed mathematically by the requirement, that the coordinate vector $\mathrm{x}$ is an element of $\mathrm{G}$, a bounded subset of $\mathrm{X}$, determined by the condition $G=\{x \mid \varphi(x) \leqslant 0\}$, where $\varphi(x)$ is a scalar function of $x$. As the coordinate restrictions appear to be working as slight modifications of the general maximum principle, this problem will be taken into consideration later in this chapter.

3. 3. The unrestricted problem.

Consider the following data:

(1) The initial point $A: x_{a}=\left(x_{a}^{1}, x_{a}^{2}\right)$, from where the ship starts at a time $t_{a}$.

(2) The time halfline $T:\left\{t \mid t_{a} \leqslant t\right\}$.

(3) The point of destination $B: x_{b}=\left(x_{b}^{1}, x_{b}^{2}\right)$.

(4) A collection $\mathrm{C}$ of available courses $\alpha$. What this collection consists of, may depend on the ship's position $(\mathrm{x})$ as well as on the time (t) the ship is at that position, so $\mathrm{C}=\mathrm{C}(\mathrm{x}, \mathrm{t})$.

In a field of low waves $C$ is the entire interval $[0,2 \pi)$.

However, if the wave heights exceed 4 meters, some course intervals may become prohibited.

For a wave direction $\beta, \mathrm{C}(\mathrm{x}, \mathrm{t})$ can thus be the union of the intervals $[0, \beta+a],[\pi+\beta-b, \pi+\beta+b]$ and $[2 \pi+\beta-a, 2 \pi)$. 


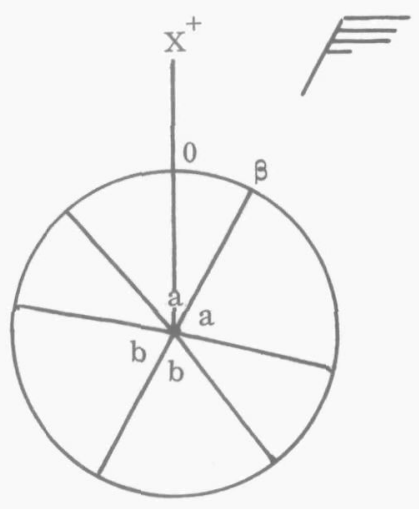

Figure 3. 3. a.

(5) Thinking of a certain trajectory with points $x(t)=\left(x^{1} \cdot(t), x^{2}(t)\right)$, the values of $\alpha$, chosen in these points, must be elements of $\mathrm{C}(\mathrm{x}(\mathrm{t}), \mathrm{t})$. Following some track, $\alpha$ can thus be seen as a function of $t$.

For practical reasons, we confine ourselves to control functions $\alpha(t)$ that are piecewise differentiable, piecewise continuous with a finite number of discontinuous jumps.

(6) The actual motor of the control system is the vector valued function

$$
f(x, \alpha, t)=\left(f^{1}\left(x^{1}, x^{2}, \alpha, t\right), f^{2}\left(x^{1}, x^{2}, \alpha, t\right)\right) .
$$

$f^{i}$ and $\frac{\partial f^{i}}{\partial x^{j}}$ - with $i, j=1,2$ - are assumed to be bounded, continuously differentiable with respect to $x^{1}, x^{2}$ and $t$ and differentiable with respect to $\alpha$.

(7) A special study will be made of functions $\alpha(t)$, as mentioned in (5), with the property that the differential system

$$
\dot{x}=f(x, \alpha(t), t) \text { with the initial condition }
$$

$$
x\left(t_{a}\right)=x_{a} \text { and the end condition }
$$

$$
x\left(t_{b}\right)=x_{b} \text { for some } t_{b} \geqslant t_{a} \text { has a unique and continuous }
$$
solution.

The arrival time $t_{b}$ obviously depends on the choice of the function $\alpha(t)$. The problem can now be formulated as to find a function $\alpha(t)$, defined in (7) so that the arrival time $t_{b}$, determined by $\alpha(t)$, is not greater than any other $\tilde{t}_{b}$, generated by some $\widetilde{\alpha}(\mathrm{t})$. 
Some additional remarks have to be made concerning the components of $\mathrm{f}(\mathrm{x}, \alpha, \mathrm{t})$. According to (1.3.3) we have

$$
\mathrm{f}^{\mathrm{i}}\left(\mathrm{x}^{1}, \mathrm{x}^{2}, \alpha, \mathrm{t}\right)=\mathrm{s}\left(\mathrm{x}^{1}, \mathrm{x}^{2}, \alpha, \mathrm{t}\right) \sin (\pi \mathrm{i} / 2-\alpha)+\mathrm{c}^{\mathrm{i}}\left(\mathrm{x}^{1}, \mathrm{x}^{2}\right) .
$$

Considering a fixed point $P$ with coordinates $\left(x^{1}, x^{2}\right)$ at a time $t$, the values of $f^{1}$ and $\mathrm{f}^{2}$ can be plotted out into the $\mathrm{x}^{1}$ - and $\mathrm{x}^{2}$-direction respectively for all possible values of $\alpha$ in $\mathrm{C}(\mathrm{x}, \mathrm{t})$, using arbitrary, but equal units for $\dot{\mathrm{x}}^{1}$ and $\dot{\mathrm{x}}^{2}$.

The curve, that is thus obtained, will be called the "original velocity indicatrix". In a field of low to moderate waves, $\alpha$ can vary continuously from 0 to $2 \pi$. The scalar function $\mathrm{s}(\mathrm{x}, \alpha, \mathrm{t})$, indicating the maximum attainable speed for a true course $\alpha$, is in that case differentiably dependent of $\alpha$. The indicatrix is now a closed curve with a continuous tangent, but not necessarily convex, as it may be necessary to reduce speed in certain courses to avoid too heavy rolling or pitching.

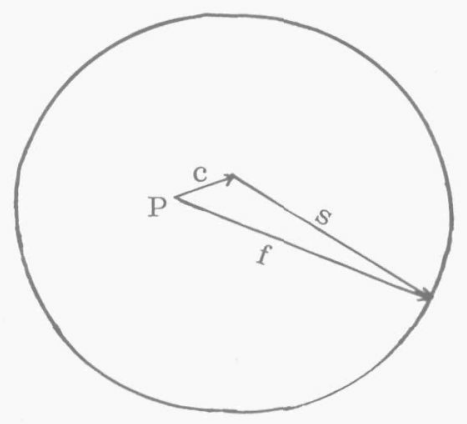

Figure 3. 3. b.

As the scalar value of the sea current c never exceeds 1.5 miles per hour, while $\mathrm{s}$ is not less than 8 miles per hour, the centre P, from where the vectors $\mathrm{f}$ were plotted out, always lies well inside the original velocity indicatrix. It is clear that in this case, the ship is able to make headway from $\mathrm{P}$ into all directions.

Considering the case, that there are prohibited sectors for $\alpha$, the original indicatrix consists of separate arcs ( $\mathrm{AB}$ and $\mathrm{CD}$ in fig. 3. 3. c).

At first hand the possibilities for a ship to proceed from $\mathrm{P}$ seem to be limited to the sectors APB and CPD. However, it is still possible to make headway into a direction, that lies within one of tile gaps BPC or DPA. To explain this, let us replace the velocity indicatrix by a position indicatrix, meaning that from $P$, the values of $f^{1}(x, \alpha, t) \delta t$ and $f^{2}(x, \alpha, t) \delta t$ are plotted out 


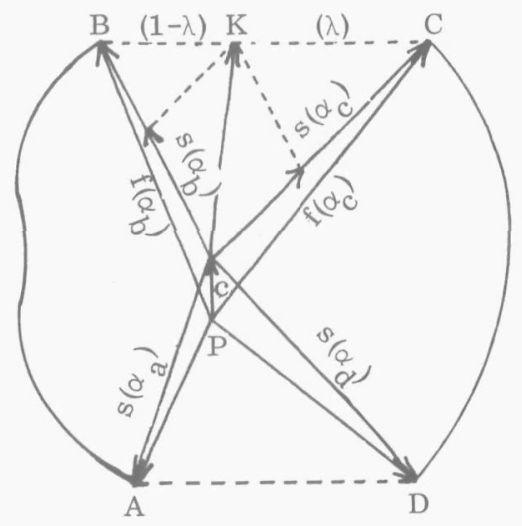

Figure 3. 3.c.

into the $\mathrm{x}^{1}-$ and $\mathrm{x}^{2}$-directions, with $\delta t>0$ and using the adopted units for $\mathrm{x}^{1}$ and $x^{2}$.

As $\mathrm{f}^{1}$ and $\mathrm{f}^{2}$ are assumed to be partially differentiable with respect to $\mathrm{x}^{1}, \mathrm{x}^{2}$ and $t$, we have for some fixed $\alpha$ :

$$
\begin{aligned}
x^{i}(t+\delta t) & =x^{i}(t)+\int_{t}^{t+\delta t} f^{i}(x, \alpha, \tau) d \tau \\
& =x^{i}(t)+f^{i}(x, \alpha, t) \delta t+o(\delta t),
\end{aligned}
$$

where $o(\delta t)$ has the property: $\lim _{\delta t \rightarrow 0} \frac{o(\delta t)}{\delta t}=0$.

The end points of the vectors

$$
\mathrm{x}(\mathrm{t})+\mathrm{f}(\mathrm{x}, \alpha, \mathrm{t}) \delta \mathrm{t}
$$

can thus be considered as approximations of the furthest attainable points from $\mathrm{P}$ at time $t$ after a small time interval $\delta$. The errors in the coordinates of these points can be made arbitrarily small by taking $8 \mathrm{t}$ small enough. If one thinks of figure 3.3. c to be constructed this way, it is clear that all points of the straight line segment $\mathrm{BC}$ are now attainable by taking linear combinations of the courses $\alpha_{b}$ and $\alpha_{c}$ during the $\delta$ t-time interval. The point $\mathrm{K}$ for instance is attainable by taking course $\alpha_{\mathrm{b}}$ during a time $\lambda \delta \mathrm{t}$ and course 
$\alpha_{c}$ during the interval $(t+\lambda \delta t, t+\delta t)$, where $\lambda$ follows from $\mathrm{KC}=\lambda * \mathrm{BC}$.

Points of AD can be reached by tacking between the courses $\alpha_{a}$ and $\alpha_{d}$ in a proper time ratio.

The objection to this idea could be made, that it is practically impossible for a ship to tack on two zonsiderably different courses during a small time interval. However, practical data reveal, that in wave fields on the North Atlantic circumstances are changing very slightly, so that one hour is a small enough choice of $\delta$ to obtain a practically negligible error in the sense mentioned above.

In 3.5 it will be shown, that it is the (smallest possible) convex envelope of the original indicatrix, that plays an important part in the constructional procedure of the least time track. This envelope will be called the "effective velocity indicatrix".

As a result of practical experience it can be asserted, that for the merchant ships that were routed on the North Atlantic, every point P lies inside its own effective indicatrix, so that the foregoing considerations justify the conclusion, that it is always and everywhere possible to make headway from $\mathrm{P}$ into all horizontal directions from 0 to $2 \pi$.

3.4. Extremals, optimal controls, timefronts.

If a trajectory from A to B, satisfying (3.3.1) for some control function $\alpha(\mathrm{t})$, generates an arrival time $\mathrm{t}_{\mathrm{b}}$ not greater than any other $\mathrm{t}_{\mathrm{b}}$, caused by some $\widetilde{\alpha}(\mathrm{t})$, the control $\alpha(\mathrm{t})$ is called "optimal" and the corresponding trajectory is called an "extremal".

Given the initial event $\left(\mathrm{x}_{\mathrm{a}}, \mathrm{t}_{\mathrm{a}}\right)$ and the system (3.3.1), the set of reachable points $\mathrm{H}^{+}\left(t ; x_{a}, t_{a}\right)$ can be defined as the collection of points $x(t)$ that can be reached at the instant $t$, by starting from $A$ at a time $t_{a}$ and then following a trajectory, governed by (3.3.1) for all possible control functions $\alpha(t)$. So $\mathrm{H}^{+}\left(\mathrm{t} ; \mathrm{x}_{\mathrm{a}}, \mathrm{t}_{\mathrm{a}}\right)=\left\{\mathrm{x}(\mathrm{t}) \mid \mathrm{x}\left(\mathrm{t}_{\mathrm{a}}\right)=\mathrm{x}_{\mathrm{a}}, \dot{\mathrm{x}}=\mathrm{f}(\mathrm{x}, \alpha(\tau), \tau), \tau \in\left(\mathrm{t}_{\mathrm{a}}, \mathrm{t}\right]\right\}$. This point collection, shortly denoted as $\mathrm{H}^{+}(\mathrm{t})$, is everywhere dense, closed and bounded.

The boundedness is an evident consequence of the fact that $\mathrm{f}^{1}$ and $\mathrm{f}^{2}$ are bounded. The density of $\mathrm{H}^{+}(\mathrm{t})$ means to express that, given a trajectory $\mathrm{x}=\mathrm{x}(\tau ; \alpha(\tau))$, we can always find a control function $\beta(\tau)$, different from $\alpha(\tau)$, with the property that, given an arbitrary $\epsilon>0$, every point $x^{*}(\tau)$ of the 
trajectory, produced by this control function $\beta(\tau)$, has a distance to $x(\tau)$ less than $\epsilon .\left(\mathrm{t}_{\mathrm{a}}<\tau \leqslant \mathrm{t}\right)$.

This property, proved extensively by Halkin ${ }^{1}$ ), is guaranteed by the boundedness of $\mathrm{f}^{1}$ and $\mathrm{f}^{2}$ and of their partial derivatives to $\mathrm{x}^{1}$ and $\mathrm{x}^{2}$. It is, for instance, possible to choose $\beta(\tau)$ arbitrarily different from $\alpha(\tau)$ during the interval $\left(t_{a}, t_{a}+\delta t\right)$, while taking $\beta(\tau)=\alpha(\tau)$ for $t_{a}+\delta t \leqslant \tau \leqslant t$. By taking $\delta$ t sufficiently small, we can always find $x^{*}(\tau)$ in an $\varepsilon$-vicinity of $x(\tau)$.

A consequence of these two properties is the possibility of covering $\mathrm{H}^{+}(\mathrm{t})$ by a finite number of these $\epsilon$-circles, which means that $\mathrm{H}^{+}(\mathrm{t})$ is compact and - by virtue of this - closed.

I now wish to consider the boundary of $\mathrm{H}^{+}(\mathrm{t})$, called the timefront $\mathrm{S}^{+}(\mathrm{t})$.

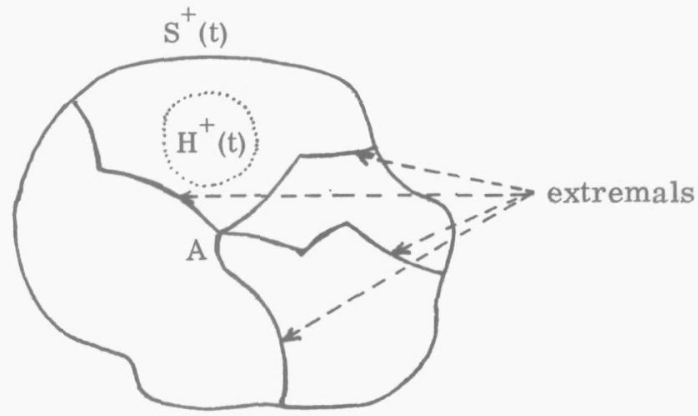

Figure 3.4.a.

In what follows I assume, as is plausible from topological considerations, that $\mathrm{S}^{+}(\mathrm{t})$ is a continuous closed curve with an almost everywhere continuous tangent. As this boundary of $\mathrm{H}^{+}(t)$ can be seen as the collection of ultimately reachable points at a time $t$, every trajectory from $A$ to a point of $S^{+}(t)$ is an extremal.

An important property of these boundaries follows from the considerations and practical data regarding $f(x, \alpha, t)$, mentioned in 3.3 .

Consider the points of $S^{+}(t)$ for some $t \geqslant t_{a}$. As all these points lie inside their own effective indicatrix, a ship is able to move away from such a point into all directions. This implies that for every $\delta \mathrm{t}>0$, the boundary $\mathrm{S}^{+}(\mathrm{t}+\delta \mathrm{t})$ of $\mathrm{H}^{+}(\mathrm{t}+\delta \mathrm{t})$ lies wholly "outside" $\mathrm{S}^{+}(\mathrm{t})$, i.e. two $\mathrm{S}^{+}$-timefronts never have points in common.

1) Journal d'Analyse Mathénatique, Vol. XII, Jérusalem Acad.Press. 
Another useful concept is the set of initial points $\mathrm{H}^{-}\left(t ; \mathrm{x}_{\mathrm{b}}, \mathrm{t}_{\mathrm{b}}\right)$. This set can be defined as the collection of points, from where, starting at a time $t, B$ can be reached at a given time $t_{b}$, following (3.3.1) for some proper $\alpha(\tau)$. So we can write

$\mathrm{H}^{-}\left(\mathrm{t} ; \mathrm{x}_{\mathrm{b}}, \mathrm{t}_{\mathrm{b}}\right)=\left\{\mathrm{x}(\mathrm{t}) \mid \mathrm{x}\left(\mathrm{t}_{\mathrm{b}}\right)=\mathrm{x}_{\mathrm{b}}, \mathrm{t} \leqslant \mathrm{t}_{\mathrm{b}}, \dot{\mathrm{x}}=\mathrm{f}(\mathrm{x}, \alpha(\tau), \tau), \tau \in\left(\mathrm{t}, \mathrm{t}_{\mathrm{b}}\right)\right\}$.

This set, shortly denoted as $\mathrm{H}^{-}(\mathrm{t})$, has the same properties as $\mathrm{H}^{+}(\mathrm{t})$, while its boundary $\mathrm{S}^{-}(\mathrm{t})$ has the same properties as those, that were mentioned for $\mathrm{S}^{+}(\mathrm{t})$.

I now wish to state and prove a fundamental property of extremals:

Lemma 3.4. $\alpha$ : If a trajectory from $A$ to $B$ is an extremal and $P$ is an arbitrary point of this trajectory, then the arcs AP and PB of this extremal are "extremals" as well.

The extremal arc AP is an extremal in the sense that, starting from A a time $t_{a}$ and following the extremal $A B$, one arrives at $P$ at a time $t \leqslant t^{*}$, where $\mathrm{t}^{*}$ is the arrival time at $\mathrm{P}$ for an arbitrary trajectory from A to P and governed by $\dot{x}=f\left(x, \alpha^{*}(\tau), \tau\right)$.

The extremal arc PB is to be considered an extremal in such a way, that every other trajectory from $\mathrm{P}$ to $\mathrm{B}$ with arrival time $\mathrm{t}_{\mathrm{b}}$, following (3.3.1), demands a starting time $\bar{t} \leqslant \mathrm{t}$.

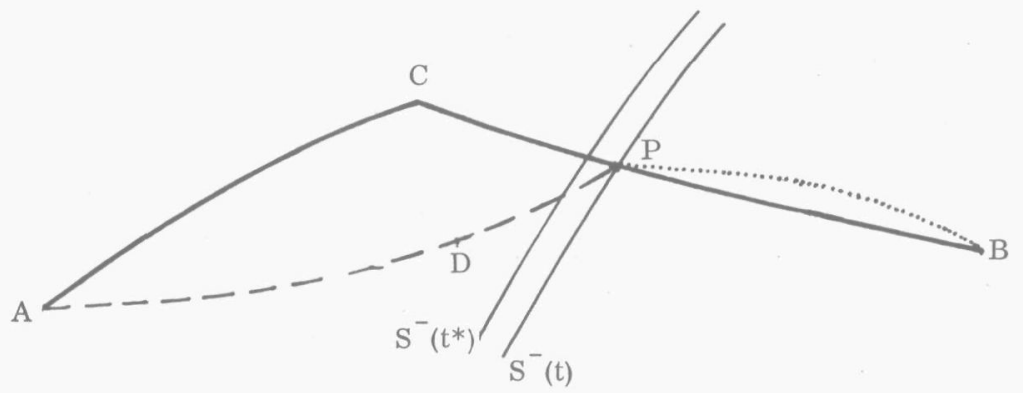

Figure 3. 4. b.

To prove this lemma, let us assume that - fig. $3.4 . \mathrm{b}$ - the fully drawn curve $\mathrm{AB}$ is an extremal from $\mathrm{A}$ (at $\mathrm{t}_{\mathrm{a}}$ ) to $\mathrm{B}$. (Whenever a part of this curve, say from $\mathrm{C}$ to $\mathrm{P}$, is considered, it will be indicated as $\mathrm{CP}_{\mathrm{e}}$ ).

Taking an arbitrary point of this curve, let us first suppose that $\mathrm{PB}_{\mathrm{e}}$ is not an extremal. This would mean, that a moving point $\mathrm{M}^{\prime}$, starting from $\mathrm{A}$ at 
time $t_{a}$, following $\mathrm{ACP}_{\mathrm{e}}$, arriving at $\mathrm{P}$ at a time $\mathrm{t}$, could then reach $\mathrm{B}$ in a shorter last of time than $t_{b}-t$ by following some other track - the dotted line for instance - and would thus arrive in B at a time $t_{b}^{\prime}<t_{b}$. This would contradict the assumption that $\mathrm{t}_{\mathrm{b}}$ was optimal, so $\mathrm{PB}_{\mathrm{e}}$ must be an extremal.

As for the proof, that $\mathrm{AP}_{\mathrm{e}}$ is an extremal, suppose it is not and assume, that the dashed arc ADP leads from A (at time $t_{a}$ ) to $P$ at a time $t^{*}<t$. Consider now two points $\mathrm{M}$ and $\mathrm{M}^{*}$, moving from $\mathrm{A}$ to $\mathrm{B}$.

$M$ takes track $\mathrm{ACPB}_{\mathrm{e}}$, arrives at $\mathrm{P}$ at time $\mathrm{t}$ and is in $\mathrm{B}$ at time $\mathrm{t}_{\mathrm{b}}$, not later than any other point, going from $\mathrm{A}$ to $\mathrm{B}$.

$M^{*}$ starts from A at the same moment $t_{a}$, but follows the dashed curve ADP, which brings it in $\mathrm{P}$ at an earlier moment $\mathrm{t}^{*}$. Then $\mathrm{M}^{*}$ goes to $\mathrm{B}$ along track $\mathrm{PB}_{\mathrm{e}}$.

For the arrival time $\mathrm{t}_{\mathrm{b}}^{*}$ of $\mathrm{M}^{*}$ there are now two possibilities, merely thinking of the fact that $\mathrm{M}^{*}$ leaves $\mathrm{P}$ earlier than $\mathrm{M}$ :

(1) $\mathrm{t}_{\mathrm{b}}^{*}<\mathrm{t}_{\mathrm{b}}$. This is in contradiction with the optimality assumption regarding $t_{b}$ and therefore impossible.

(2) $\mathrm{M}^{*}$ is being overhauled by $\mathrm{M}$ somewhere on the way between $\mathrm{P}$ and $\mathrm{B}$, say in $Q$. Let this overhauling take place at a time $t^{\prime}$. Q may even coincide with $\mathrm{B}$, so for $\mathrm{t}^{\prime}$ the inequality $\mathrm{t}<\mathrm{t}^{\prime} \leqslant \mathrm{t}_{\mathrm{b}}$ holds.

From that moment on, the positions of $\mathrm{M}$ and $\mathrm{M} *$ coincide permanently until $\mathrm{t}_{\mathrm{b}}$, so they arrive in $\mathrm{B}$ at the same moment.

Consider now the sets $\mathrm{H}^{-}\left(\mathrm{t}^{*} ; \mathrm{x}_{\mathrm{b}}, \mathrm{t}_{\mathrm{b}}\right)$ and $\mathrm{H}^{-}\left(\mathrm{t} ; \mathrm{x}_{\mathrm{b}}, \mathrm{t}_{\mathrm{b}}\right)$ with $\mathrm{S}^{-}\left(\mathrm{t}^{*}\right)$ and $\mathrm{S}^{-}(\mathrm{t})$ as their respective boundaries.

As $t^{*}$ was assumed to be smaller than $t$, the boundary $\mathrm{S}^{-}\left(\mathrm{t}^{*}\right)$ must be wholly outside $\mathrm{S}^{-}(\mathrm{t})$ and these two curves have no common points. Now, as $\mathrm{M}$, starting in $\mathrm{P}$ at time $t$, follows an extremal to $\mathrm{B}$, this starting point $\mathrm{P}$ is situated on $\mathrm{S}^{-}(\mathrm{t})$, the boundary of $\mathrm{H}^{-}(\mathrm{t})$. This implies that $\mathrm{P}$ is an interior point $\mathrm{H}^{-}\left(\mathrm{t}^{*}\right)$. Now the conclusion is justified, that $\mathrm{PB}_{\mathrm{e}}$ is not an extremal for $\mathrm{M}^{*}$ to reach $\mathrm{B}$. In other words, $M^{*}$ could reach $B$ at an instant $t_{b}^{*}<t_{b}$, if some other track would be taken from $\mathrm{P}$ to $\mathrm{B}$. This however contradicts the optimality assumption of $t_{b}$ once more.

So the supposition, that $\mathrm{P}$ could be reached at an earlier time than $\mathrm{t}$, is erroneous. This completes the proof of lemma 3.4. $\alpha$.

The main reason for giving this lemma some more attention is, that it indicates a possibility of constructing the least time track from A to B by means of the $\mathrm{S}^{+}$-timefronts.

Construction of these fronts for various values of $t$ leads to the final timefront 
$\mathrm{S}^{+}\left(\mathrm{t}_{\mathrm{b}}\right)$, on which $\mathrm{B}$ is located. The other points $\mathrm{x}(\mathrm{t})$ of the extremal from $A$ to $B$ are subsequently located on the $S^{+}(t)$-fronts. Working backwards from $\mathrm{B}$, all these points can be traced and thus the track can be determined. The way, this "working backwards" as well as finding $\mathrm{S}^{+}\left(\mathrm{t}_{\mathrm{b}}\right)$ takes place, will be indicated after having treated some properties regarding the relation between timefronts and extremals. These properties will be discussed in the following paragraphs.

\subsection{Pontryagin's Maximum Principle.}

Reconsidering the result of the preceding paragraph, it can be stated that a (total) extremal from A to B is an extremal all the way through. In other words: Every line element of an extremal between the times $t$ and $t+\epsilon \delta t-$ with $\epsilon$ and st positive - is optimal when it comes to crossing the lane between the two consecutive timefronts $\mathrm{S}^{+}(\mathrm{t})$ and $\mathrm{S}^{+}(\mathrm{t}+\epsilon \delta \mathrm{t})$.

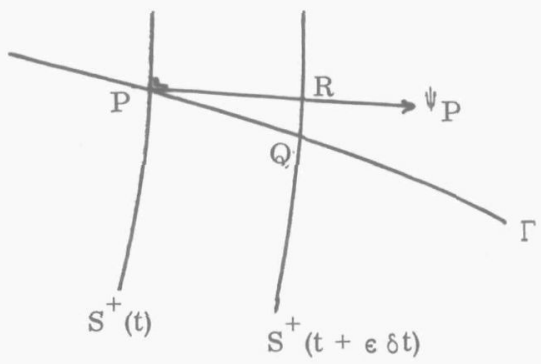

Figure 3.5.a.

This optimal crossing characterizes the extremal's direction.

Let $\Gamma$ be an extremal, intersecting the fronts $S^{+}(t)$ and $S^{+}(t+\epsilon \delta t)$ in $P$ and $Q$ respectively. The width $\mathrm{PR}$ of the lane between these two fronts, measured perpendicular to $\mathrm{S}^{+}(\mathrm{t})$ in $\mathrm{P}$, is proportional to $\epsilon \delta \mathrm{t}+o(\epsilon)$, with $\lim _{\epsilon \rightarrow 0} \frac{o(\epsilon)}{\epsilon}=0$. As the vector $\overrightarrow{\mathrm{PQ}}$ is equal to

$$
\begin{aligned}
x(t+\epsilon \delta t)-x(t) & =\int_{t}^{t+\epsilon \delta t} f\left(x(\tau), \alpha e^{(\tau), \tau) d \tau=}\right. \\
& =f\left(x(t), \alpha_{e}(t), t\right) \varepsilon \delta t+o(\varepsilon),
\end{aligned}
$$


we see that, with the extremal's velocity $f\left(x(t), \alpha_{e}(t), t\right)$ at $P$, this width is covered faster than with any other velocity $f(x(t), \alpha, t)$.

Neglecting terms of $o(\epsilon)$, it turns out that the projection of this velocity vector onto the vector $\psi_{\mathrm{P}}$, drawn in $\mathrm{P}$ perpendicular to $\mathrm{S}^{+}(\mathrm{t})$, has to be greater than or at least equal to the projection of any other vector $f(x(t), \alpha, t)$ onto $\Downarrow_{P}$. Maximum principle. Analytically, this means that in every point of an extremal the control parameter $\alpha$ must be so chosen, that it maximizes the inner product

$$
(\psi, f(x, \alpha, t))=H(\alpha ; x, \psi, t)
$$

for given values of the vectors $x$ and $\downarrow$ and the parameter $t$.

So for all $t \geqslant t_{a}$ the control function $\alpha_{e}(t)$ that belongs to an extremal, must satisfy the requirement

$$
\left(\psi(t), f\left(x(t), \alpha_{e}(t), t\right)\right) \geqq(\psi(t), f(x(t), \alpha, t))
$$

for all possible values of $\alpha$.

This requirement is the formulation of Pontryagin's maximum principle in this case.

Transversality. The special crossing of the time fronts by the extremals is called "transversal intersection".

In this case it may be useful to point out the possibility of a discontinuous jump of the velocity $\mathrm{x}$ along an extremal as a result of a continuous change of $\psi$. This can occur, whenever the maximum value of $\mathrm{H}(\alpha, \mathrm{x}, \psi, t)$, denoted as $\mathrm{M}(\psi, \mathrm{x}, \mathrm{t})$ is attained for two different values of $\alpha$, say $\alpha_{1}$ and $\alpha_{2}$, with $\alpha_{1}<\alpha_{2}$, while for all $\tilde{\alpha}$ between these values, $\mathrm{H}$ is smaller. In such a case $\alpha$ jumps instantaneously from $\alpha_{1}$ to $\alpha_{2}$ or reversely. This means that the extremal trajectory makes an abrupt bend.

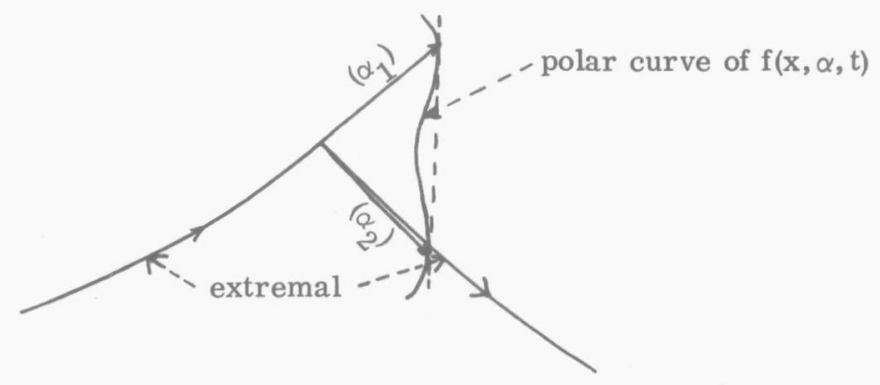

Figure 3.5.b. 
These bending points are allowed for in Pontryagin's theory, as (3.3.1) was to hold almost everywhere on $\mathrm{T}$, which practically means, that a finite number of discontinuous jumps of $\alpha$ - and therewith of $\dot{x}$ - is permitted. Let us once more consider the original velocity indicatrix, as described in 3. 3 .

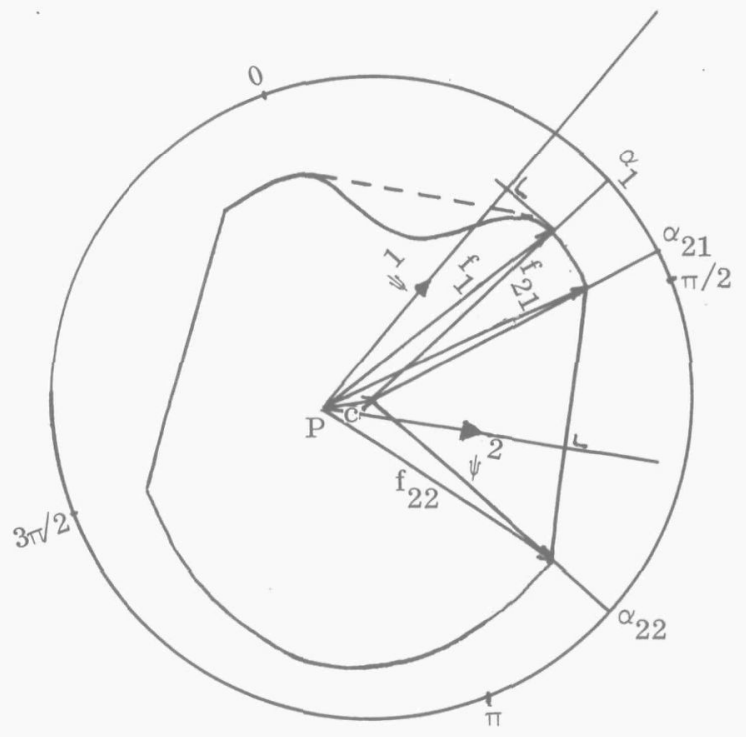

Figure 3.5.c.

The true course $\alpha_{e}$, for which the inner product

$$
(\psi, f)=(\psi, c)+\sum_{1}^{2} \psi_{i} s \sin (\pi i / 2-\alpha)
$$

is maximized, can be graphically determined with the aid of the original indicatrix:

Draw a line perpendicular to the given $\psi$-direction, denoted by $\varphi$, so that at least one point of the indicatrix lies on this line, while all other points are located on the same side of it as the centre P.

Letting $\varphi$ vary from 0 to $2 \pi$, we find the optimal course $\alpha_{e}$ as a function of $\varphi$. This function $\alpha e^{(\varphi)}$ turns out to be piecewise continuously differentiable.

Discontinuous jumps can be expected in two cases:

1. $\psi$ is perpendicular to a tangent of the indicatrix with two or more touching points. 
2. $\psi$ is perpendicular to a straight line, that covers a gap in the original indicatrix.

As for the determination of $\alpha_{e}$, it is now clear that the original indicatrix can be replaced by its convex closure, for which the name "effective indicatrix" seems suitable.

Figure 3.5.d shows the graph of $\alpha_{e} e^{(\varphi)}$, following from the indicatrix of figure 3. 5 . c.

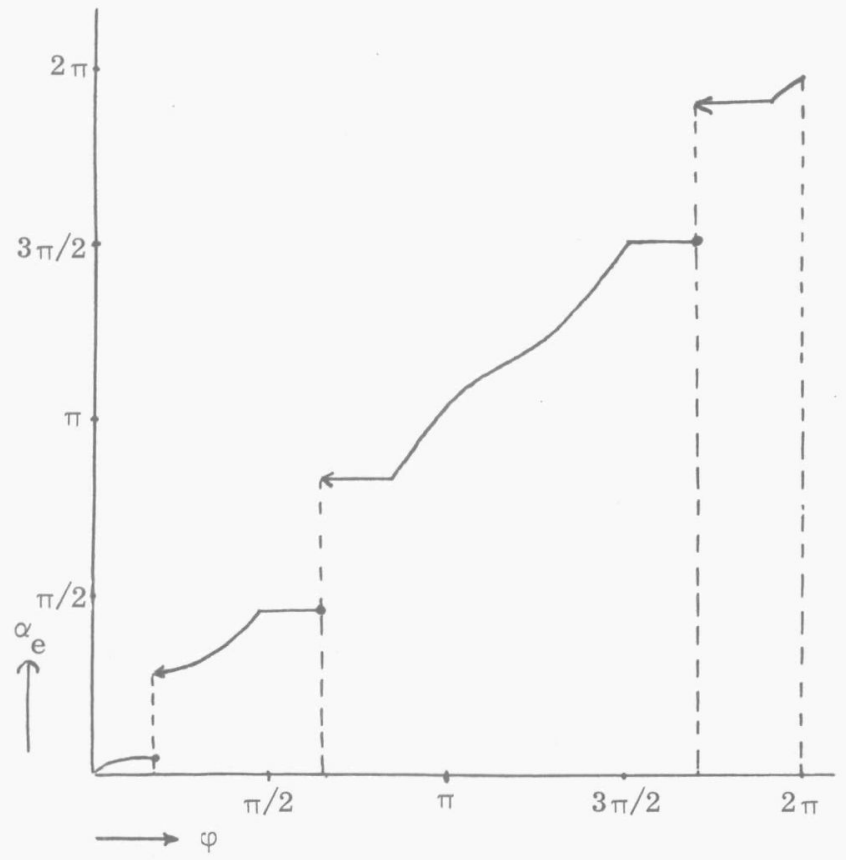

Figure 3.5.d.

3.6. Behaviour of the tangent and the normal to a timefront along an extremal.

Let $\{\Gamma\}$ be the collection of all extremals from A to a point of $S^{+}(\tau)$, with $\tau>t_{a}$. Stated more precisely, $\{\Gamma\}$ is the collection of solutions of $\dot{x}=f(x, \alpha, t)$ with initial value $\left.\mathrm{x}_{(\mathrm{a}}\right)=\mathrm{x}_{\mathrm{a}}$ and $\mathrm{x}(\tau)$ on $\mathrm{S}^{+}(\tau)$. 


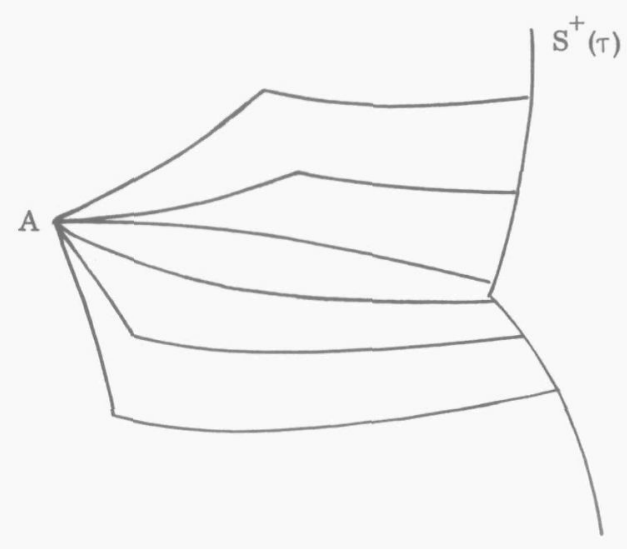

Figure 3.6.a.

A subcollection $\mathrm{C}$ of $\{\Gamma\}$ is formed by a field of extremals - i. e. a family of extremals with no mutual intersection points but A - with the additional property that the timefronts $\mathrm{S}^{+}(\mathrm{t})$ are differentiable curves as long as they are drawn in relation with elements of $\mathrm{C}$.

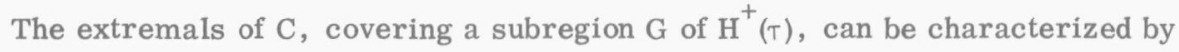
attaching a real number $\mathrm{s}$ to each specimen.

Thus the coordinates of a point of $\mathrm{G}$ are functions of $t$ and $s$ :

$$
x^{i}=x^{i}(t, s) \text { with } i=1,2 \text {, or in vector notation } x=x(t, s) \text {. }
$$

In view of the assumptions regarding $\mathrm{C}$, these functions are partially differentiable with respect to s everywhere in $\mathrm{G}$, except of course in the edge points, where there is only left or right differentiability.

Let $\Gamma_{0}$ be an extremal of $\mathrm{C}$ with $\mathrm{s}=\mathrm{s}_{\mathrm{o}}$, generated by the control function $\alpha_{0}(\mathrm{t})$. Take $t_{1}$ and $t_{2}$ so that $t_{a}<t_{1}<t_{2} \leqq \tau$.

$\Gamma_{0}$ intersects the timefronts $\mathrm{S}^{+}\left(\mathrm{t}_{1}\right)$ and $\mathrm{S}^{+}\left(\mathrm{t}_{2}\right)$ in $\mathrm{P}_{1}$ and $\mathrm{P}_{2}$ respectively.

So $\quad x_{P_{j}}^{i}=x^{i}\left(t_{j}, s_{0}\right) \quad$ with $i, j=1,2$.

Analogously $Q_{1}$ and $Q_{2}$ are points of another extremal $I_{\varepsilon}$ of $C$, generated by $\alpha_{\epsilon}(t)$, so that $x_{Q_{j}}^{i}=x^{i}\left(t_{j}, s_{o}+\epsilon\right)$. This situation is exposed in figure 3.6.b. The components of the tangent vector $\delta x(t)$, touching $S^{+}(t)$ in a point of $\Gamma_{0}$, are defined by:

$$
\delta x^{i}(t)=\frac{\partial x^{i}\left(t, s_{0}\right)}{\partial s}, \quad(i=1,2)
$$

so that 


$$
x^{i}\left(t, s_{0}+\epsilon\right)=x^{i}\left(t, s_{0}\right)+\epsilon \delta x^{i}(t)+o(\epsilon)
$$

where $o(\epsilon)$ has again the property: $\lim _{\epsilon \rightarrow 0} \frac{o(\epsilon)}{\epsilon}=0$.

For what follows a lemma is needed regarding the optimal steering functions $\alpha_{0}(t)$ and $\alpha_{\epsilon}(t)$. I first want to prove:

Lemma 3.6. $\alpha$ : If $\mathrm{f}(\mathrm{x})$ is a Lebesque-integrable function, defined on $[\mathrm{a}, \mathrm{b}]$ with the property $\int_{a}^{x} f(t) d t=0$ for $x \in[a, b]$ then $f(x)=0$ almost everywhere on $[a, b]$.

To prove this, I introduce the collections $B, B_{1}$ and $B_{2}$ :

$B=\{x \mid f(x) \neq 0, x \in[a, b]\}, B_{1}=\{x \mid f(x)>0, x \in[a, b]\}$,

$\mathrm{B}_{2}=\{\mathrm{x} \mid \mathrm{f}(\mathrm{x})<0, \mathrm{x} \in[\mathrm{a}, \mathrm{b}]\}$.

Then $B=B_{1}+B_{2}, B_{1}$ and $B_{2}$ are disjoint, so $\mu(B)=\mu\left(B_{1}\right)+\mu\left(B_{2}\right)$. Now $B_{1}$ and $\mathrm{B}_{2}$ can be sequentially covered by a finite or countably infinite number of measurable sets:

$$
B_{i} \subset \sum_{(j)} B_{i j} \text { so } \mu\left(B_{i}\right)=\inf \sum_{(j)} \mu\left(B_{i j}\right)
$$

The sets $B_{i j}$ are so defined, that, with $a_{i j}=\lim \inf \left(x \mid x \in B_{i j}\right)$ and $b_{i j}=\lim \sup \left(x \mid x \in B_{i j}\right)$, it follows from $a_{i j} \leqq x \leqq b_{i j}$ that $x \in B_{i j}$, in other words: $B_{i j}$ is a closed interval.

From the assumption that $\int_{a}^{x} f(t) d t=0$ it follows that

$$
\int_{i j}^{b_{i j}} f(t) d t=\int_{a}^{b_{i j}} f(t) d t-\int_{a}^{a_{i j}} f(t) d t=0
$$

As $f(t)>0$ for $i=1$ and $f(t)<0$ for $i=2$, it is clear, that $\mu\left(B_{i j}\right)=0$.

Now from the choice of $B_{i j}$ we see that $B_{i j}$ and $B_{i k}$ are disjoint for $j \neq k$, so that

$$
\mu\left(B_{i}\right)=\sum_{(j)} \mu\left(B_{i j}\right)=0 \text { while } \mu(B)=\mu\left(B_{1}\right)+\mu\left(B_{2}\right),
$$

so $\mu(B)=0$, which means that $f(x)=0$ almost everywhere on $[a, b]$.

We are now in a position to state and prove: 
Lemma 3.6. $\beta: \lim _{\epsilon \rightarrow 0} f\left(x\left(t, s_{0}+\epsilon\right), \alpha_{\epsilon}(t), t\right)=f\left(x\left(t, s_{0}\right), \alpha_{o}(t), t\right)$ almost everywhere on $\left[\mathrm{t}_{\mathrm{a}}, \tau\right]$.

As we are dealing with a field of extremals, it is obvious, that for $t \in\left[t_{a}, \tau\right]$ we have:

$$
\lim _{\epsilon \rightarrow 0} x\left(t, s_{0}+\epsilon\right)=x\left(t, s_{0}\right)
$$

(If $\Gamma_{0}$ is a boundary curve of $G$, then this " $\epsilon \rightarrow 0$ " should be replaced by " $\epsilon \downarrow 0$ " or " $€ \uparrow 0 "$ ")

Comparing now:

$$
\begin{aligned}
& x\left(t, s_{0}+\epsilon\right)=x_{a}+\int_{t_{a}}^{t}\left\{f\left(x\left(\xi, s_{0}+\epsilon\right), \alpha_{\epsilon}(\xi), \xi\right) d \xi \quad\right. \text { and } \\
& x\left(t, s_{0}\right) \quad=x_{a}+\int_{t_{a}}^{t} f\left(x\left(\xi, s_{0}\right), \alpha_{0}(\xi), \xi\right) d \xi \quad \text { it is now clear that } \\
& \lim _{\epsilon \rightarrow 0} \int_{t_{a}}^{t}\left\{f\left(x\left(\xi, s_{0}+\epsilon\right), \alpha_{\epsilon}(\xi), \xi\right)-f\left(x\left(\xi, s_{0}\right), \alpha_{0}(\xi), \xi\right)\right\} d \xi=0
\end{aligned}
$$

for $t \in\left[t_{a}, \tau\right]$, or written componentwise:

$$
\int_{t_{a}}^{t}\left\{\lim _{\epsilon \rightarrow 0} f^{i}\left(x\left(\xi, s_{0}+\epsilon\right), \alpha_{\epsilon}(\xi), \xi\right)-f^{i}\left(x\left(\xi, s_{0}\right), \alpha_{0}(\xi), \xi\right)\right\} d \xi=0 .
$$

According to lemma 3.6. $\alpha$ we may now conclude:

$$
\lim _{\epsilon \rightarrow 0} f^{i}\left(x\left(t, s_{0}+\epsilon\right), \alpha_{\epsilon}(t), t\right)=f^{i}\left(x\left(t, s_{0}\right), \alpha_{o}(t), t\right)
$$

almost everywhere on $\left[\mathrm{t}_{\mathrm{a}}, \mathrm{T}\right]$.

\section{Corollary:}

In regard of the assumption (6) in paragraph (3.3), that $\mathrm{f}^{1}$ and $\mathrm{f}^{2}$ were continuously differentiable with respect to $x^{1}$ and $x^{2}$ and as a result of this last lemma we may state, that 


$$
\lim _{\epsilon \rightarrow 0} \frac{\partial f^{i}\left(x\left(t, s_{0}+\epsilon\right), \alpha_{\varepsilon}(t), t\right)}{\partial x^{j}}=\frac{\partial f^{i}\left(x\left(t, s_{0}\right), \alpha_{0}(t), t\right)}{\partial x^{j}}(i, j=1,2)
$$

almost everywhere on $\left[t_{a}, \tau\right]$

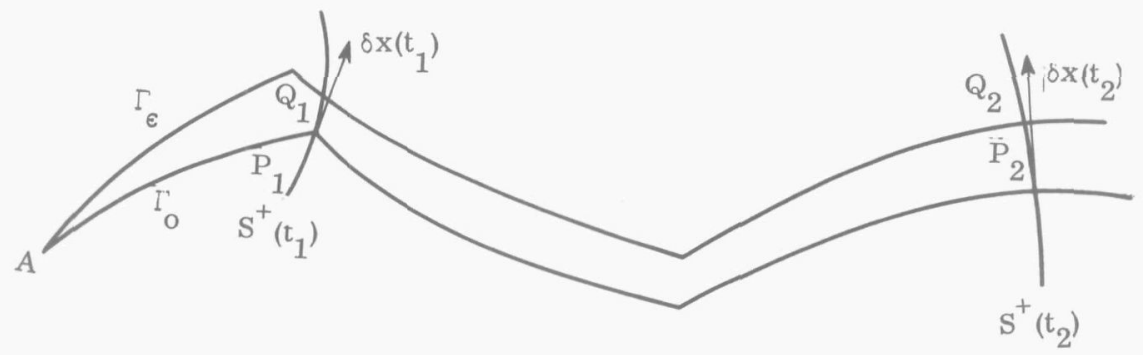

Figure 3.6.b.

Seeking now a relation between $\delta x\left(t_{1}\right)$ and $\delta x\left(t_{2}\right)$, we subtract:

(3.6. $\left.5^{\mathrm{a}}\right)$

$$
x\left(t_{2}, s_{0}+\epsilon\right)=x\left(t_{1}, s_{0}+\epsilon\right)+\int_{t_{1}}^{t_{2}} f\left(x\left(t, s_{0}+\epsilon\right), \alpha_{\epsilon}(t), t\right) d t \quad \text { and }
$$

(3. 6. $\left.5^{\mathrm{b}}\right)$

$$
x\left(t_{2}, s_{0}\right) \quad=x\left(t_{1}, s_{0}\right)+\int_{t_{1}}^{t_{2}} f\left(x\left(t, s_{0}\right), \alpha_{o}(t), t\right) d t \quad \text { and find, }
$$

in view of $(3.6 .2)$ :

$$
\epsilon \delta x\left(t_{2}\right)=\epsilon \delta x\left(t_{1}\right)+\int_{t_{1}}^{t_{2}}\left\{f\left(x\left(t, s_{0}+\epsilon\right), \alpha_{\epsilon}(t), t\right)-f\left(x\left(t, s_{0}\right), \alpha_{o}(t), t\right)\right\} d t
$$

where $o_{2}(\varepsilon)$ denotes a vector in $\mathrm{R}^{2}$ with components of the type o( $\left.{ }^{2}\right)$.

We can split up (3.6.6) in two ways:

(3.6.7)

$$
1^{\circ}: \epsilon \delta x\left(t_{2}\right)=\epsilon \delta x\left(t_{1}\right)+I+J+o_{2}(\varepsilon) \quad \text { with }
$$

(3.6. $\left.7^{\mathrm{a}}\right)$

$$
I=\int_{t_{1}}^{t_{2}}\left\{f\left(x\left(t, s_{0}+\epsilon\right), \alpha_{\epsilon}(t), t\right)-f\left(x\left(t, s_{0}+\epsilon\right), \alpha_{0}(t), t\right)\right\} d t
$$

and

$\left(3.6 .7^{\mathrm{b}}\right)$

$$
J=\int_{t_{1}}^{t_{2}}\left\{f\left(x\left(t, s_{0}+\epsilon\right), \alpha_{0}(t), t\right)-f\left(x\left(t, s_{0}\right), \alpha_{0}(t), t\right)\right\} d t .
$$


(3.6.8)

$$
2^{\mathrm{O}}: \epsilon \delta \mathrm{x}\left(\mathrm{t}_{2}\right)=\epsilon \delta \mathrm{x}\left(\mathrm{t}_{1}\right)+\mathrm{I}^{*}+\mathrm{J}^{*}+\mathrm{o}_{2}(\epsilon) \quad \text { with }
$$

$\left(3.6 .8^{\mathrm{a}}\right)$

$$
I^{*}=\int_{t_{1}}^{t_{2}}\left\{f\left(x\left(t, s_{0}\right), \alpha_{\epsilon}(t), t\right)-f\left(x\left(t, s_{0}\right), \alpha_{0}(t), t\right)\right\} d t
$$

(3.6. $\left.8^{\mathrm{b}}\right)$

$$
J^{*}=\int_{t_{1}}^{t_{2}}\left\{f\left(x\left(t, s_{0}+\epsilon\right), \alpha_{\epsilon}(t), t\right)-f\left(x\left(t, s_{0}\right), \alpha_{\epsilon}(t), t\right)\right\} d t .
$$

The expressions for $\mathrm{J}$ and $\mathrm{J} *$ can be written respectively as:

$$
\begin{aligned}
& J=\int_{t_{1}}^{t_{2}}\left\{\sum_{j=1}^{2} \frac{\partial f\left(x\left(t, s_{0}\right), \alpha_{o}(t), t\right)}{\partial x^{j}}\left(x^{j}\left(t, s_{o}+\epsilon\right)-x^{j}\left(t, s_{o}\right)\right)+o_{2}(\epsilon)\right\} d t, \\
& J^{*}=\int_{t_{1}}^{t_{2}}\left\{\sum_{j=1}^{2} \frac{\partial f\left(x\left(t, s_{0}+\epsilon\right), \alpha_{\epsilon}(t), t\right)}{\partial x^{j}}\left(x^{j}\left(t, s_{0}+\epsilon\right)-x^{j}\left(t, s_{o}\right)\right)+o_{2}(\epsilon)\right\} d t .
\end{aligned}
$$

In view of the corollary to lemma (3.6. $\beta$ ) we may conclude now, that

$$
\text { (3.6.9) } \lim _{\epsilon \rightarrow 0} J / \epsilon=\lim _{\epsilon \rightarrow 0} J * / \epsilon=\int_{t_{1}}^{t_{2}} \sum_{j=1}^{2} \frac{\partial f\left(x\left(t, s_{0}\right), \alpha_{o}(t), t\right)}{\partial x^{j}} \delta x^{j}(t) d t
$$

Concentrating on I and I*, we can remark two things:

a. From (3.6.7) and (3.6.8) it follows that

$$
\begin{aligned}
& \left(3.6 .7^{c}\right) \delta x\left(t_{2}\right)=\delta x\left(t_{1}\right)+\lim _{\epsilon \rightarrow 0} I / \epsilon+\lim _{\epsilon \rightarrow 0} J / \epsilon \quad \text { and } \\
& \left(3.6 .8^{c}\right) \quad \delta x\left(t_{2}\right)=\delta x\left(t_{1}\right)+\lim _{\epsilon \rightarrow 0} I^{*} / \epsilon+\lim _{\epsilon \rightarrow 0} J * / \epsilon .
\end{aligned}
$$

Considering (3.6.9) it can be asserted now that

$$
\lim _{\epsilon \rightarrow 0} I / \epsilon=\lim _{\epsilon \rightarrow 0} I^{*} / \epsilon=L \text {. }
$$

b. Writing L as $\int_{t_{1}}^{t_{2}} \lim _{\epsilon \rightarrow 0} \frac{f\left(x\left(t, s_{0}\right), \alpha_{\epsilon}(t), t\right)-f\left(x\left(t, s_{0}\right), \alpha_{0}(t), t\right)}{\epsilon} d t$

we may conclude that $\mathrm{L}$ is almost everywhere differentiable to its upper bound, 
so that $\frac{d L}{d t}$ exists almost everywhere on $\left[t_{1}, \tau\right]$.

From (3.6. $7^{\mathrm{a}}$ ) we see that

(3. 6.10) $\frac{\mathrm{dI}}{\mathrm{dt}}=\mathrm{f}\left(\mathrm{x}\left(\mathrm{t}, \mathrm{s}_{\mathrm{o}}+\epsilon\right), \alpha_{\epsilon}(\mathrm{t}), \mathrm{t}\right)-\mathrm{f}\left(\mathrm{x}\left(\mathrm{t}, \mathrm{s}_{\mathrm{o}}+\epsilon\right), \alpha_{\mathrm{o}}(\mathrm{t}), \mathrm{t}\right)$.

Remembering the maximum principle $(\rightarrow 3.5)$ and the assumption that $\alpha_{\epsilon}(\mathrm{t})$ was an optimal control function - as $\Gamma_{\varepsilon}$ is an extremal - it is clear that

$$
\left(\psi_{\epsilon}, f\left(x\left(t, s_{0}+\epsilon\right), \alpha_{\varepsilon}(t), t\right)\right) \geqq\left(\psi_{\epsilon}, f\left(x\left(t, s_{0}+\varepsilon\right), \alpha_{o}(t), t\right)\right)
$$

where $\psi_{\epsilon}$ is a normal vector to $S^{+}(t)$ in the point $x\left(t, s_{0}+\epsilon\right)$.

So according to (3.6.10) we have:

$$
\left(\psi_{\epsilon}, \frac{\mathrm{dI}}{\mathrm{dt}}\right) \geqq 0 \quad \text { and obviously }
$$

(3.6.12\& 13) for $\epsilon>0:\left(\psi_{\epsilon}, \frac{\mathrm{dI} / \epsilon}{\mathrm{dt}}\right) \geqq 0$ and for $\epsilon<0:\left(\psi_{\epsilon}, \frac{\mathrm{dI} / \epsilon}{\mathrm{dt}}\right) \leqq 0$.

Regarding $I^{*}$, we find from $\left(3.6 .8^{\mathrm{a}}\right)$ :

(3. 6. 14) $\frac{\mathrm{dI}^{*}}{\mathrm{dt}}=\mathrm{f}\left(\mathrm{x}\left(\mathrm{t}, \mathrm{s}_{\mathrm{o}}\right), \alpha_{\varepsilon}(\mathrm{t}), \mathrm{t}\right)-\mathrm{f}\left(\mathrm{x}\left(\mathrm{t}, \mathrm{s}_{\mathrm{o}}\right), \alpha_{\mathrm{o}}(\mathrm{t}), \mathrm{t}\right)$.

As $\alpha_{0}(t)$ is an optimal control function, generating the extremal $\Gamma_{0}$, the maximum principle reveals:

$$
\left(\psi_{0}, f\left(x\left(t, s_{0}\right), \alpha_{\epsilon}(t), t\right)\right) \leqq\left(\psi_{0}, f\left(x\left(t, s_{0}\right), \alpha_{o}(t), t\right)\right),
$$

so from (3.6.14) it follows that for $\epsilon>0$ :

(3.6.15\& 16) $\left(\psi_{0}, \frac{\mathrm{dI} * / \epsilon}{\mathrm{dt}}\right) \leqq 0$ and for $\epsilon<0$ : $\left(\psi_{0}, \frac{\mathrm{dI} * / \epsilon}{\mathrm{dt}}\right) \geqq 0$.

Letting $\epsilon$ descend to zero, $\psi_{\epsilon}$ tends to $\psi_{o}$ on every timefront $\mathrm{s}^{+}(\mathrm{t}), \mathrm{t} \in\left[\mathrm{t}_{\mathrm{a}}, \tau\right]$. From (3.6.12) it follows now, that $\left(\psi_{0}, \frac{d L}{d t}\right) \geqq 0$ almost everywhere on $\left[t_{a}, \tau\right]$, while (3.6.15) leads to $\left(\psi_{0}, \frac{d L}{d t}\right) \leqq 0$ a.e. on $\left[t_{a}, \tau\right]$. So for $\epsilon \downarrow 0$ we see that $\left(\psi_{0}, \frac{d L}{d t}\right)=0$ almost everywhere on $\left[t_{a}, \tau\right]$. For $\in \uparrow 0$ the arguments are analogous:

(3.6.13) gives $\left(\psi_{0}, \frac{d L}{d t}\right) \leqq 0 \quad$ a.e. on $\left[t_{a}, \tau\right]$ and 
(3.6.16) gives $\left(\psi_{0}, \frac{d L}{d t}\right) \geqq 0 \quad$ a.e. on $\left[t_{a}, \tau\right]$.

So the conclusion is that

$$
\left(\psi_{0}, \frac{d L}{d t}\right)=0 \quad \text { a.e. on }\left[t_{a}, \tau\right] .
$$

Differentiating $\left(3.6 .7^{\mathrm{c}}\right)$ to $\mathrm{t}_{2}$ and omitting the index $\left(\mathrm{t}_{2}:=\mathrm{t}\right)$ we find in view of (3.6.9):

$$
\frac{d(\delta x)}{d t}=\sum_{j=1}^{2} \frac{\partial f\left(x\left(t, s_{o}\right), \alpha_{o}(t), t\right)}{\partial x^{j}} \delta x^{j}(t)+\frac{d L}{d t} \text { a.e. on }\left[t_{a}, \tau\right] .
$$

Investigating the behaviour of a vector $\Downarrow(t)$ along an extremal, for which the relation $(\psi(t), \delta x(t))=0$ holds for all $t \in\left[t_{a}, t_{b}\right]$, we see that it has to satisfy the requirement

$$
\frac{d}{d t}(\psi(t), \delta x(t))=0
$$

In view of $(3.6 .18)$ we see that

$$
\sum_{i=1}^{2}\left(\psi_{i} \delta x^{i}+\psi_{i} \sum_{j=1}^{2} \frac{\partial f^{i}(x(t), \alpha(t), t)}{\partial x^{j}} \delta x^{j}+\psi_{i} \frac{d L^{i}}{d t}\right)=0
$$

Because of (3.6.17) and arranging this relation somewhat differently, the components $\psi_{1}$ and $\psi_{2}$ of the covariant vector $\psi$ are found to vary with $t$ according to:

$$
\dot{\psi}_{i}=-\sum_{j=1}^{2} \frac{\partial f^{j}(x(t), \alpha(t), t)}{\partial x^{i}} \psi_{j} \quad(i=1,2) \text { a. e. on }\left[t_{a}, t_{b}\right] .
$$

A vector $\psi$ with this property and the condition, that

$$
\left(\psi\left(t_{0}\right), \delta x\left(t_{o}\right)\right)=0
$$

for some $t_{0} \in\left[t_{a}, t_{b}\right]$ is called an adjoint vector to the trajectory $\mathrm{x}(\mathrm{t} ; \alpha(\mathrm{t}))$. 
3. 7. Construction of the solution. Examples.

Summarizing the foregoing paragraphs, a solution $\mathrm{x}=\mathrm{x}(\mathrm{t})$ was sought of the controlled dynamical system $\dot{x}=f(x, \alpha, t)$ with the initial condition $x_{(}\left(t_{a}\right)=x_{a}$ and for some - yet undetermined - value $t_{b}$ the requirement $x_{(}\left(t_{b}\right)=x_{b}$. Among all the real valued functions $\tilde{\alpha}(t)$, almost everywhere continuous, that generate a solution of this problem, an optimal control function $\alpha(t)$ was sought, generating a minimal arrival time $t_{b}$.

The trajectory that satisfies all these requirements, could be traced by carrying out the following procedure:

Select an arbitrary vector $\psi^{0}=\left(\psi_{1}^{0}, \psi_{2}^{0}\right)$. Select $\alpha\left(t_{\mathrm{a}}\right)$ so that it maximizes the inner product $\mathrm{H}(0)=\left(\psi^{0}, \mathrm{f}\left(\mathrm{x}_{\mathrm{a}}, \tilde{\alpha}\left(\mathrm{t}_{\mathrm{a}}\right), \mathrm{t}_{\mathrm{a}}\right)\right)$.

With $\psi\left(t_{a}\right)=\psi^{0}$, let the components of $\psi(t)$ vary according to $(3.6 .18)$, while $\mathrm{x}(\mathrm{t})$ changes as indicated by (3.3.1) and for all $\mathrm{t} \geqq \mathrm{t}_{\mathrm{a}}$, let $\alpha(\mathrm{t})$ maximize the inner product

$$
H(t)=(\psi(t), f(x(t), \widetilde{\alpha}(t), t) .
$$

Considering the maximum principle and the fact, that (3.6.18) is homogeneous in $\psi_{1}$ and $\psi_{2}$, it can be seen, that the initial choices $\psi^{0}$ and $\rho \psi^{0}$ - for some real $\rho>0$ - generate the same trajectory, so $\psi^{0}$ can be taken with unit length, say

$$
\psi^{0}=\left(\cos \varphi_{0}, \sin \varphi_{0}\right)
$$

The coordinates of points of the timefront $\mathrm{S}^{+}(\mathrm{t})$ are consequently functions of $t$ and $\varphi_{0}$, so $x^{i}=x^{i}\left(t, \varphi_{0}\right)$.

If analytical expressions for these functions can be deduced, $t_{b}$ and $\varphi_{0}$ can be solved from the equations

$$
\left\{\begin{array}{l}
x^{1}\left(t_{b}, \varphi_{o}\right)=x_{b}^{1} \\
x^{2}\left(t_{b}, \varphi_{o}\right)=x_{b}^{2}
\end{array} .\right.
$$

It should be remarked here, that these equations may very well have more than one set of solutions $\left(\mathrm{t}_{\mathrm{b}}^{*}, \varphi_{\mathrm{o}}^{*}\right)$. With the object of finding the least time track it is obvious, that of all solutions for $t_{b}$, we are only interested in the smallest value of it, providing it is greater than $t_{a}$. If $\varphi_{\mathrm{O}}^{*}$ is the solution of $\varphi_{\mathrm{O}}$, corresponding to this minimal arrival time $\mathrm{t}_{\mathrm{b}}^{*}$, then 
the extremal trajectory from A to B can be constructed by solving (3.3.1) and (3.6.18), using the maximum principle for the determination of $\alpha$ and taking $x^{i}\left(t_{a}\right)=x_{a}^{i}$ and $\psi\left(t_{a}\right)=\left(\cos \varphi_{0}^{*}, \sin \varphi_{0}^{*}\right)$ as initial conditions.

\section{Remark 1:}

Considering the effective indicatrix of fig. 3.7.a, drawn with respect to the starting point $A$, it appears that all initial values $\varphi_{0}$ with

$$
\varphi_{0}^{\prime} \leqq \varphi_{0} \leqq \varphi_{0}^{\prime \prime}
$$

generate the same initial course $\alpha_{0}$.

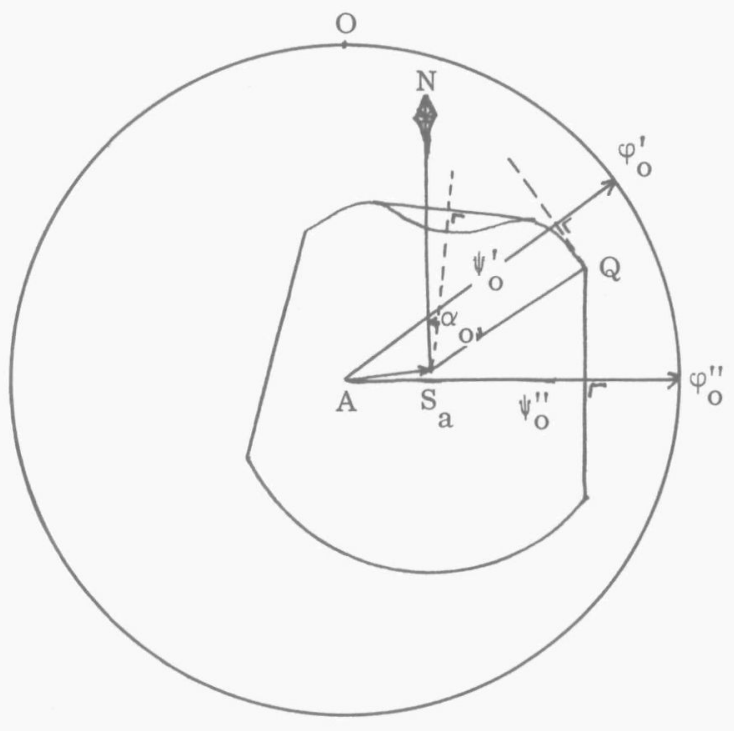

Figure 3. 7.a.

From this we can conclude, that the initial arcs of extremals, issuing from $A$, may partly coincide. This happens when $\mathrm{C}\left(\mathrm{x}_{\mathrm{a}}, \mathrm{t}_{\mathrm{a}}\right)$, the collection of possible courses in $\mathrm{A}$, does not consist of the entire interval $[0,2 \pi]$, so that the effective indicatrix has points where the tangent is not continuous.

Let, in figure 3.7.b, $\Gamma$ be such an arc of partly coinciding extremals. In a point $\mathrm{K}$ of that curve, the value of $\psi$ is not quite determined, because it depends on which neighbouring extremal $\Gamma$ is compared with. Let $\alpha_{\mathrm{k}}$ correspond with a bending point like $\mathrm{Q}$ in figure 3. 7. a and let $\psi^{\prime}$ and $\psi^{\prime \prime}$ 


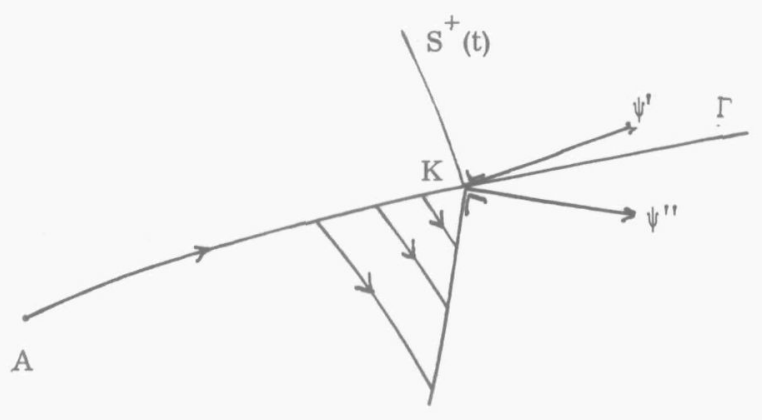

Figure 3. 7.b.

be the vectors perpendicular to the left and right tangents to the indicatrix of $\mathrm{K}$ in such a bending point.

If $\varphi^{\prime}$ and $\varphi^{\prime \prime}$ are the directions of $\psi^{\prime}$ and $\psi^{\prime \prime}$ respectively, it is clear that the tangent to the timefront $S^{+}(t)$ in $K$ bends abruptly from $\varphi^{\prime}+\pi / 2$ to $\varphi^{\prime \prime}+\pi / 2$.

\section{Remark 2:}

Along every extremal the maximum value of $\mathrm{H}(\alpha, \mathrm{x}, \psi, \mathrm{t})$, equal to $\mathrm{M}(\psi, \mathrm{x}, \mathrm{t})$ satisfies the relation

$$
\frac{d M}{d t}=\frac{\partial M}{\partial t} \quad \text { a.e. on }\left[t_{a}, \infty\right) .
$$

To prove this, consider the three possibilities for $\alpha$ in a point of an extremal trajectory:

a. $\alpha$ is continuously variable and $f$ is partially differentiable with respect to $\alpha$. We then know, that for $H=M$ :

$$
\begin{gathered}
\frac{\partial H}{\partial \alpha}=\sum_{i=1}^{2} \psi_{i} \frac{\partial f^{i}}{\partial \alpha}=0 \quad \text { and so: } \\
\frac{d M}{d t}=\sum_{i=1}^{2} \frac{d \psi_{i}}{d t} f^{i}+\sum_{i, j=1}^{2} \psi_{i} \frac{\partial f^{i}}{\partial x^{j}} \frac{d x^{j}}{d t}+\frac{\partial M}{\partial t} .
\end{gathered}
$$

With (3.3.1) and (3.6.17) we find that

$$
\frac{d M}{d t}=\sum_{i, j=1}^{2}\left(-\frac{\partial f^{j}}{\partial x^{i}} \psi_{j} f^{i}+\psi_{i} \frac{\partial f^{i}}{\partial x^{j}} f^{j}\right)+\frac{\partial M}{\partial t} \quad \text {, so } \frac{d M}{d t}=\frac{\partial M}{\partial t} .
$$


b. If $\alpha$ is constant - compare remark 1 - then there simply is no change in $\alpha$ as a result of a change of $t$, so the same relation holds.

c. If $\alpha$ jumps discontinuously from $\alpha_{1}$ to $\alpha_{2}$, we have the same maximum of $\mathrm{H}$ for $\alpha_{1}$ and $\alpha_{2}$, so in this case there is no change in $\mathrm{H}$ as a result of a continuous change in $\psi$ and $x$.

For an autonomous system: $\dot{x}=f(x, \alpha)$ it now follows that the maximum value of $\mathrm{H}$ is constant along an extremal.

\section{Remark 3:}

The Hamilton function $\mathrm{H}$ enables us to write (3.3.1) and (3.6.2) in a canonical form:

$$
\left\{\begin{array}{l}
\dot{x}^{i}=\frac{\partial H}{\partial \psi_{i}} \\
\dot{\psi}_{i}=-\frac{\partial H}{\partial x^{i}}
\end{array} \quad(i=1,2)\right.
$$

I now wish to enlighten this procedure by means of some elementary examples:

\section{Example 1:}

On the $\mathrm{X}$-axis a moving point has at a time $\mathrm{t}=\mathrm{t}_{\mathrm{o}}$ a position $\mathrm{x}_{\mathrm{o}}$ with respect to the origin and a velocity $\mathrm{y}_{0}$ along the $\mathrm{X}$-axis. The movement of this point along the $\mathrm{X}$-axis can be controlled by:

$$
\ddot{\mathrm{x}}=\alpha \quad \text { with the limitations } \quad-1 \leqq \alpha \leqq 1 .
$$

The assignment is to choose $\alpha$ as a function of $t$, so that the moving point arrives at the origin with velocity zero in the least possible time.

Introducing the velocity as a new variable $\mathrm{y}=\dot{\mathrm{x}}$, the equations of motion are:

(3. 7.1 .1$)$

$$
\left\{\begin{array}{l}
\dot{x}=y \\
\dot{y}=\alpha
\end{array}\right.
$$

Application of (3.3.1) and (3.6.2) gives 


$$
\left\{\begin{array}{l}
\dot{\psi}_{1}=0 \\
\dot{\psi}_{2}=-\psi_{1}, \text { while } \mathrm{H}=\psi_{1} \mathrm{y}+\psi_{2} \alpha .
\end{array}\right.
$$

$\mathrm{H}$ is maximized by taking $\alpha=\operatorname{sign}\left(\psi_{2}\right)$.

Taking the arrival time $t_{1}=0$ and putting $\psi(0)=\left(\cos \varphi_{0}, \sin \varphi_{0}\right)$, the solution of (3. 7.1.2) becomes

$$
\left\{\begin{array}{l}
\psi_{1}(t)=\cos \varphi_{0}, \\
\psi_{2}(t)=\sin \varphi_{0}-t \cos \varphi_{0} \quad(t \leqq 0) .
\end{array}\right.
$$

Concentrating on the $\mathrm{S}^{-}$-timefronts, various possibilities are considered:

a. $0 \leqq \varphi_{0} \leqq \pi / 2$.

For $\mathrm{t}<0$ we see that $\psi_{2}=\sin \varphi_{0}-\mathrm{t} \cos \varphi_{0}>0$, so $\alpha(\mathrm{t})=+1$. For this $\varphi_{0}$-sector, the $\mathrm{S}^{-}$-timefront consists of merely one point:

$\left(t^{2} / 2, t\right)$, solution of (3.7.1.1) for $\alpha=1$.

b. $\pi / 2<\varphi_{0}<\pi$.

Now $\psi_{2}=\sin \varphi_{0}-t \cos \varphi_{0}$ is positive for $\operatorname{tg} \varphi_{0}<t \leqq 0$ and negative for

$\operatorname{t}<\operatorname{tg} \varphi_{0}$. So, proceeding in time, we have:

$\alpha(t)=-1$ for $t<\operatorname{tg} \varphi_{0}$ and $\alpha(t)=+1$ for $\operatorname{tg} \varphi_{0}<t \leqq 0$.

Solving (3. 7.1.1), we find:

$\mathrm{x}=\mathrm{t}^{2} / 2, \mathrm{y}=\mathrm{t}$ for $\mathrm{t} \in\left[\operatorname{tg} \varphi_{0}, 0\right]$,

$x=-\operatorname{tg}^{2} \varphi_{0}+2 t \operatorname{tg} \varphi_{0}-t^{2} / 2, \quad y=2 \operatorname{tg} \varphi_{0}-t$ for $t \in\left[t, \operatorname{tg} \varphi_{0}\right]$.

Eliminating $\varphi_{0}$, we find the equation for $S^{-}(t): 4 x+(y-t)^{2}=2 t^{2}$.

At the time $\mathrm{t}^{*}=\operatorname{tg} \varphi_{\mathrm{O}}$, the switching from $\alpha=-1$ to $\alpha=+1$ takes place.

c. $\pi \leqq \varphi_{0} \leqq 3 \pi / 2$.

$\psi_{2}=\sin \varphi_{0}-t \cos \varphi_{0}$ is negative for $\mathrm{t}<0$. So $\alpha(\mathrm{t})=-1 \operatorname{maximizes} \mathrm{H}(\alpha, \mathrm{x}, \psi)$.

The trajectory is $\left(-\mathrm{t}^{2} / 2,-\mathrm{t}\right)$ and the $\mathrm{S}^{-}$-timefront is just this one point.

d! $3 \pi / 2<\varphi_{0}<2 \pi$.

As $\psi_{2}(t)=\sin \varphi_{0}-t \cos \varphi_{0}$ is negative for $\operatorname{tg} \varphi_{0}<t \leqq 0$ and $\psi_{2}(t)>0$ for $\mathrm{t}<\operatorname{tg} \varphi_{\mathrm{O}}$, we find:

$x(t)=\operatorname{tg}^{2} \varphi_{0}-2 t \operatorname{tg} \varphi_{0}+t^{2} / 2, y(t)=-2 \operatorname{tg} \varphi_{0}+t$ for $t_{0} \leqq t<\operatorname{tg} \varphi_{0}$.

The switching point is $\left(-\frac{1}{2} \operatorname{tg}^{2} \varphi_{0},-\operatorname{tg} \varphi_{0}\right)$, the switching time is $t^{*}=\operatorname{tg} \varphi_{0}$ and $\alpha$ jumps from +1 to -1 .

For $t \in\left[\operatorname{tg} \varphi_{0}, 0\right]$ we have $x=-\frac{1}{2} t^{2}, y=-t$.

The $\mathrm{S}^{-}$-timefront arc has the equation $4 \mathrm{x}-(\mathrm{y}+\mathrm{t})^{2}=2 \mathrm{t}^{2}$.

Figure 3.7. c shows the various possibilities. Taking $\left(\mathrm{x}_{0}, \mathrm{y}_{\mathrm{o}}\right)=(2,2)$, we 
find $t_{0}=-6, \operatorname{tg} \varphi_{0}=-2$, and the optimal track is:

$-6 \leqq \mathrm{t} \leqq-2:$

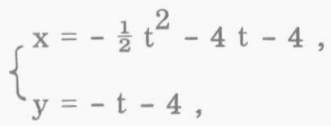

$-2 \leqq \mathrm{t} \leqq 0:$

$$
\left\{\begin{array}{l}
x=\frac{1}{2} t^{2} \\
y=t
\end{array}\right.
$$

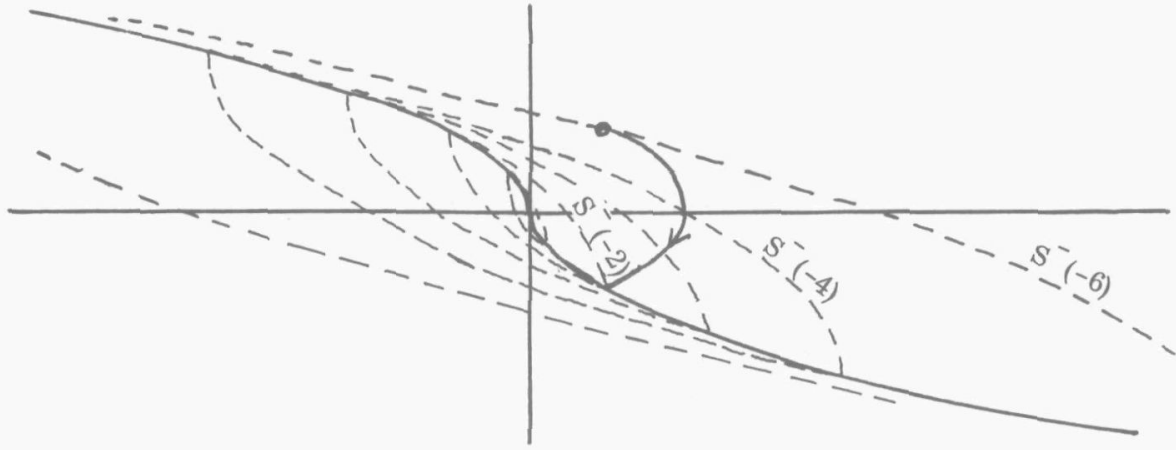

Figure 3.7.c.

\section{Example 2:}

In a 2-dimensional plane with an orthonormal coordinate system, the velocity field is defined as follows:

In a direction $\alpha$ with respect to the $\mathrm{x}^{+}$-direction the velocity is $\mathrm{v}_{\mathrm{o}}|\sin \alpha|$. $\left(v_{0}>0\right)$. The problem is to find the least time track from a given point $A$ to another given point $\mathrm{B}$.

The velocity components in the $\mathrm{X}^{+}$- and $\mathrm{Y}^{+}$-directions are:

$$
\left\{\begin{array}{l}
\dot{x}=v_{0}|\sin \alpha| \cos \alpha \\
\dot{y}=v_{0}|\sin \alpha| \sin \alpha
\end{array}\right. \text {, }
$$

The adjoint system is awfully simple: $\dot{\psi}_{1}=\dot{\psi}_{2}=0$ with solutions $\psi_{1}=\cos \varphi_{0}$, $\psi_{2}=\sin \varphi_{0}$, where $\varphi_{0}$ is a constant angle.

In this case we have to maximize

$\mathrm{H}=\mathrm{v}_{\mathrm{o}}|\sin \alpha| \cos \alpha \cos \varphi_{\mathrm{o}}+\mathrm{v}_{\mathrm{o}}|\sin \alpha| \sin \alpha \sin \varphi_{\mathrm{o}}=$

$=\mathrm{v}_{\mathrm{o}}|\sin \alpha| \cos \left(\alpha-\varphi_{\mathrm{O}}\right)$.

For various values of $\varphi_{0}$ we find: 
a. $\varphi_{0}=0: \mathrm{H}_{\max }=\frac{1}{2} \mathrm{v}_{0}$ for $\alpha=\pi / 4$ or $7 \pi / 4$.

b. $0<\varphi_{0}<\pi: H_{\max }=\frac{1}{2} v_{0}\left(1+\sin \varphi_{0}\right)$ for $\alpha=\pi / 4+\frac{1}{2} \varphi_{0}$.

c. $\varphi_{0}=\pi: H_{\max }=\frac{1}{2} \mathrm{v}_{\mathrm{o}}$ for $\alpha=3 \pi / 4$ or $5 \pi / 4$.

d. $\pi<\varphi_{0}<2 \pi: H_{\max }=\frac{1}{2} v_{0}\left(1-\sin \varphi_{0}\right)$ for $\alpha=3 \pi / 4+\frac{1}{2} \varphi_{0}$.

Taking the origin in $\mathrm{A}$, the $\mathrm{S}^{+}(\mathrm{t})$-timefronts can be described by:

a. $\varphi_{0}=0: x=\frac{1}{2} v_{0} t,-\frac{1}{2} v_{0} t \leqq y \leqq \frac{1}{2} v_{0} t$.

b. $0<\varphi_{0}<\pi: x=\frac{1}{2} v_{0} t \cos \varphi_{0}, y=\frac{1}{2} v_{0} t\left(1+\sin \varphi_{0}\right)$.

c. $\varphi_{0}=\pi: x=-\frac{1}{2} v_{0} t,-\frac{1}{2} v_{0} t \leqq y \leqq \frac{1}{2} v_{0} t$.

d. $\pi<\varphi_{0}<2 \pi: x=\frac{1}{2} v_{0} t \cos \varphi_{0}, y=\frac{1}{2} v_{0} t\left(\sin \varphi_{0}-1\right)$.
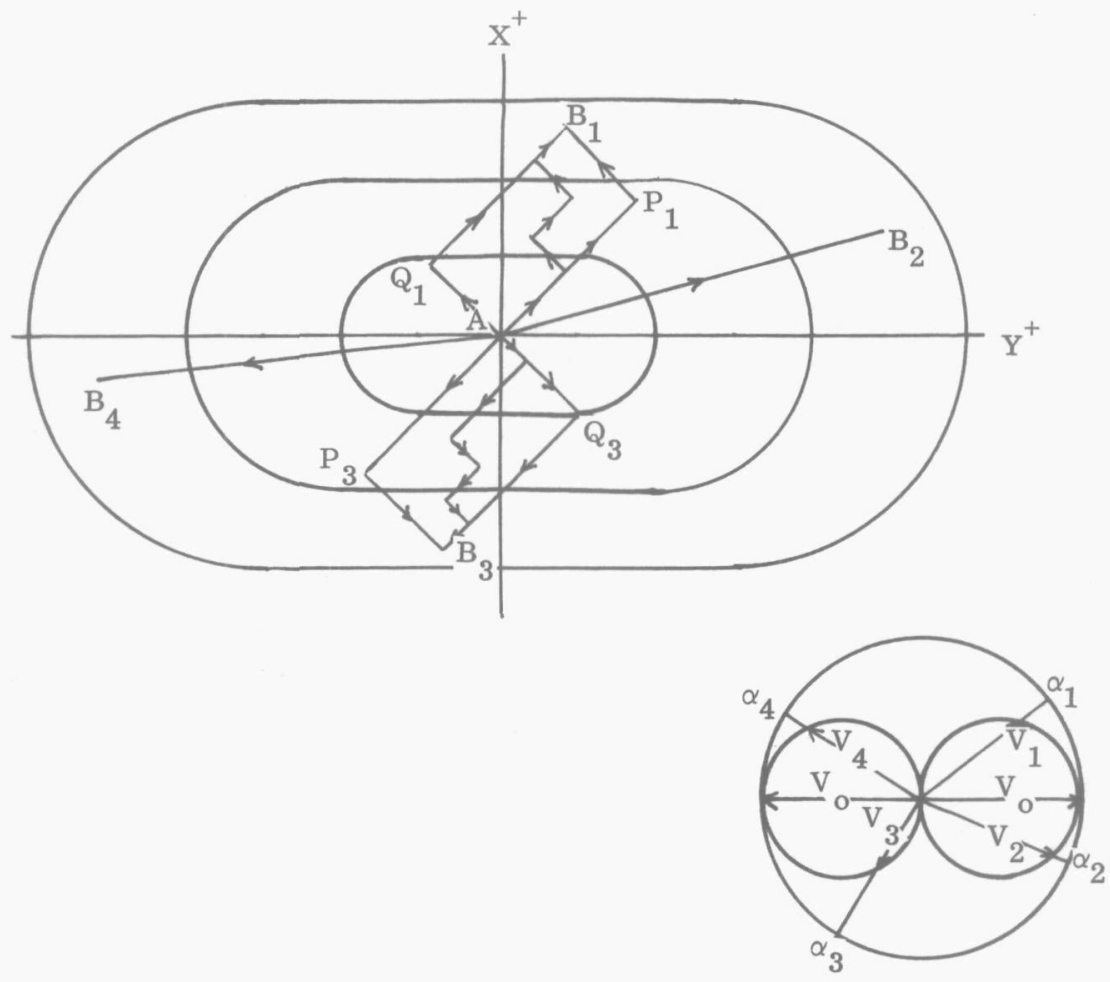

Figure 3.7.d.

Figure 3.7.d shows the extremal tracks for various cases. Denoting the direction of $A B$ as $\beta$, we find:

1. If $7 \pi / 4 \leqq \beta<2 \pi$ or $0 \leqq \beta \leqq \pi / 4$, then the extremal exists of a number of line segments with direction $\pi / 4$ and $7 \pi / 4$. The tracks $A P_{1} B_{1}$ and $A Q_{1} B_{1}$ 
give the same arrival time at $\mathrm{B}_{1}$ and so does any track along the periphery or inside the rectangle $A P_{1} B_{1} Q_{1}$, as long as it leads from $A$ to $B_{1}$ in courses of $45^{\circ}$ and $315^{\circ}$ alternatively.

2. If $\pi / 4<\beta<3 \pi / 4, \alpha=\beta$ and the track is one straight line.

3. For $3 \pi / 4 \leqq \beta \leqq 5 \pi / 4$, the extremal track consists of line segments with directions $135^{\circ}$ and $225^{\circ}$. The number of $90^{\circ}$-left or -right turns can be finite (one at least) or even countably infinite. This has the practical sense that this number of turns can be as large as one could possibly like.

4. If $5 \pi / 4<\beta<7 \pi / 4$ then $\alpha=\beta$. The extremal track is again a straight line.

This example can be applied with slight modifications to a head - to - wind sailing ship. It shows that a windward position can sometimes better be reached by tacking up against the wind than by steering a constant course.

3.8. Remarks on the occurrence of more than one solution.

In regions of small values of $|f|$ the speed decrease causes a decrease of the distance between two consecutive timefronts $\mathrm{S}^{+}(\mathrm{t})$ and $\mathrm{S}^{+}(\mathrm{t}+\delta \mathrm{t})$. As these regions, in the case of ship routeing, very frequently have a more or less elliptic structure, they also cause a convergence of the extremals. The result of these two phenomena often consists of a sector of ambiguity, i.e. more than one solution of the system of equations (3.3.1) and (3.6.17) combined with the maximum principle, with A as starting point and a point in this sector as point of arrival. This phenomenon will now be explained at the hand of an elementary example. Let the starting point A have coordinates $(-3,0)$ and let the velocity components be given by:

$$
\begin{aligned}
& \dot{x}=\left(2-\exp \left(-\frac{1}{2} \mathrm{x}^{2}-\frac{1}{2} \mathrm{y}^{2}\right)\right) \cos \alpha, \\
& \dot{\mathrm{y}}=\left(2-\exp \left(-\frac{1}{2} \mathrm{x}^{2}-\frac{1}{2} \mathrm{y}^{2}\right)\right) \sin \alpha, \quad \alpha \in[0,2 \pi] .
\end{aligned}
$$

This implies that in every point of the $\mathrm{X}-\mathrm{Y}-\mathrm{plane}$ the velocity indicatrix is a circle with radius $\mathrm{r}(\mathrm{x}, \mathrm{y})=2-\exp \left(-\frac{1}{2} \mathrm{x}^{2}-\frac{1}{2} \mathrm{y}^{2}\right)$. This radius has a minimal length in the origin,

$$
\operatorname{Min}_{(\mathrm{x}, \mathrm{y})} \mathrm{r}(\mathrm{x}, \mathrm{y})=\mathrm{r}(0,0)=1,
$$

and $\mathbf{r}$ is obviously constant on a circle with $(0,0)$ as centre.

Applying the maximum principle, the form 


$$
\mathrm{H}\left(\psi_{1}, \psi_{2}, \mathrm{x}, \mathrm{y}, \alpha\right)=\left(\psi_{1} \cos \alpha+\psi_{2} \sin \alpha\right) \mathbf{r}(\mathrm{x}, \mathrm{y})
$$

has to be minimized for given values of $\psi_{1}, \psi_{2}, x$ and $y$.

The adjoint variables $\psi_{1}$ and $\psi_{2}$ change with time according to:

$$
\left\{\begin{array}{l}
\dot{\psi}_{1}=-\mathrm{x}(2-\mathrm{r})\left(\psi_{1} \cos \alpha+\psi_{2} \sin \alpha\right) \\
\dot{\psi}_{2}=-\mathrm{y}(2-\mathrm{r})\left(\psi_{1} \cos \alpha+\psi_{2} \sin \alpha\right)
\end{array} .\right.
$$

Writing $\psi_{\mathbf{i}}=\mathrm{m} \sin (\pi \mathrm{i} / 2-\varphi)$ with $\mathbf{i}=1,2$, it follows that $\mathrm{H}$ is maximal for $\alpha=\varphi$. Thus the optimal dynamical system is described by:

(1) $\dot{\mathrm{x}}=\left(2-\exp \left(-\frac{1}{2} \mathrm{x}^{2}-\frac{1}{2} \mathrm{y}^{2}\right)\right) \cos \varphi$,

(2) $\dot{y}=\left(2-\exp \left(-\frac{1}{2} x^{2}-\frac{1}{2} y^{2}\right)\right) \sin \varphi$,

(3) $\dot{\varphi}=\exp \left(-\frac{1}{2} \mathrm{x}^{2}-\frac{1}{2} \mathrm{y}^{2}\right)(\mathrm{x} \sin \varphi-\mathrm{y} \cos \varphi)$,

(4) $\dot{\mathrm{m}}=-\mathrm{m} \exp \left(-\frac{1}{2} \mathrm{x}^{2}-\frac{1}{2} \mathrm{y}^{2}\right)(\mathrm{x} \cos \varphi+\mathrm{y} \sin \varphi)$.

with starting conditions $\mathrm{x}(0)=-3, \mathrm{y}(0)=0, \varphi(0)=\varphi_{\mathrm{o}}$ and $\mathrm{m}(0)=1 /\left(2-\exp \left(-4 \frac{1}{2}\right)\right)$ The fact that $\mathrm{H}=\left(2-\exp \left(-\frac{1}{2} \mathrm{x}^{2}-\frac{1}{2} \mathrm{y}^{2}\right)\right) \mathrm{m}$ is constant in this stationary velocity field, implies that

$$
m=\frac{H(0)}{2-\exp \left(-\frac{1}{2} x^{2}-\frac{1}{2} y^{2}\right)}=\frac{1}{2-\exp \left(-\frac{1}{2} x^{2}-\frac{1}{2} y^{2}\right)} .
$$

By taking various initial values, like $\varphi_{0}:=0(0.01) 1.20$ the equations $(3.8 .4)$ can be integrated numerically by means of a Runge-Kutta method with $\delta t=0.1$ as a sufficiently small step width. This was carried out with the aid of a TR-4 computer and for $\mathrm{t}=1(1) 12$ the values of $\mathrm{x}, \mathrm{y}, \varphi$ and $\mathrm{m}$ were printed out. The result is exposed in figure 3.8. a.

As for a qualitative explanation, it can be remarked that $m=|\psi|$ is constantly proportional to $|\operatorname{grad} S|$, where $S(x, y, t)=0$ is the equation of a timefront $S^{+}(t)$. According to (3.8.6), $m$ has a maximum value 1 for $(x, y)=(0,0)$. This means that the distance between two subsequent timefronts $\mathrm{S}^{+}(\mathrm{t})$ and $\mathrm{S}^{+}(\mathrm{t}+\delta \mathrm{t})$ is minimal in the origin. This explains that the timefronts become less convex near the $\mathrm{X}$-axis as $\mathrm{t}$ increases.

The overlapping of the timefronts can be explained by thinking of a timefront $\mathrm{S}^{+}(\mathrm{t}+\delta \mathrm{t})$ to originate from $\mathrm{S}^{+}(\mathrm{t})$ as the envelope of the $\delta \mathrm{t}$-position-indicatrices, drawn for all points of $\mathrm{S}^{+}(\mathrm{t})$.

Building up the subsequent timefronts this way and reminding that the radius of 


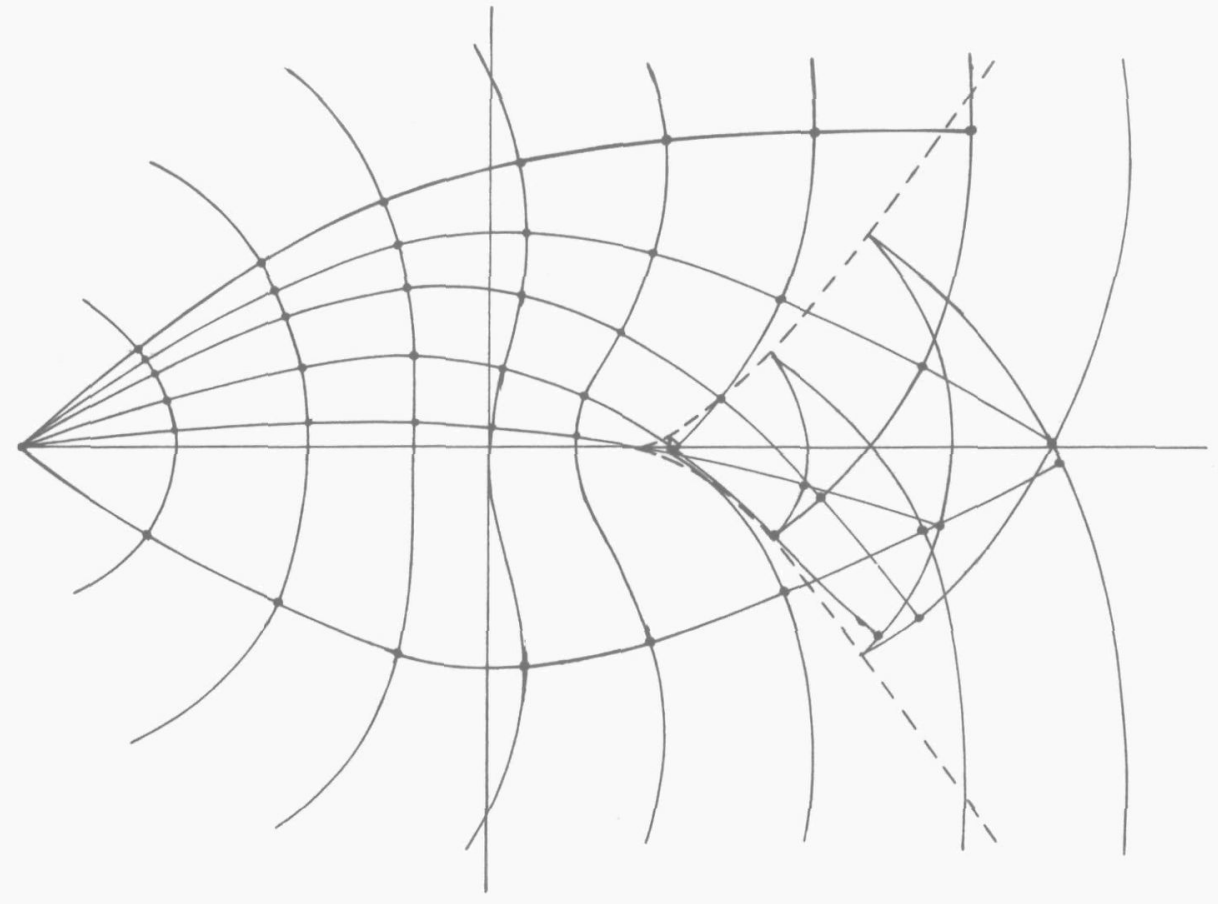

Figure 3.8.a.

Figure 3. 8. b.

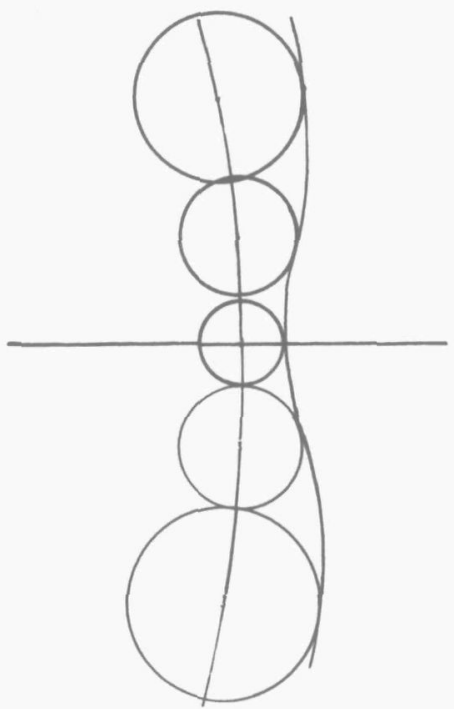


the indicatrix, $r(x, y) \delta$ t for a fixed value of $x$ is minimal for $y=0$, there is a fair possibility that the timefront through 0 has a zero curvature in 0 or even a concave part for $-\mathrm{y}_{0} \leqq \mathrm{y} \leqq \mathrm{y}_{0}$. In that case the next timefront has a deeper dent, which is symmetric with respect to the $\mathrm{X}$-axis.

Let us consider a small line element $\mathrm{P}^{*} \mathrm{PP} * *$ of $\mathrm{S}^{+}(\mathrm{t})$ near the $\mathrm{X}$-axis, with $\mathrm{P}$ on the $\mathrm{X}$-axis and the distance $\mathrm{PP}^{*}=\mathrm{PP}^{* *}$ small enough to be able to assume $\mathrm{r}(\mathrm{x}, \mathrm{y})$ equal in $\mathrm{P}, \mathrm{P} *$ and $\mathrm{P} * *$.

Now if the curvature radius of $\mathrm{S}^{+}(\mathrm{t})$ in $\mathrm{P}$ is equal to $\mathrm{r}\left(\mathrm{x}_{\mathrm{P}}, \mathrm{y}_{\mathrm{P}}\right) \delta \mathrm{t}$, the trajectories through $\mathrm{P}, \mathrm{P}^{*}$ and $\mathrm{P}^{* *}$ coincide in $\mathrm{Q}$, the curvature centre of $\mathrm{S}^{+}(\mathrm{t})$ for $\mathrm{P}$.

$\mathrm{Q}$ is known to be called the conjugate point to $\mathrm{A}$ for the central extremal, with $\varphi_{0}=0$.

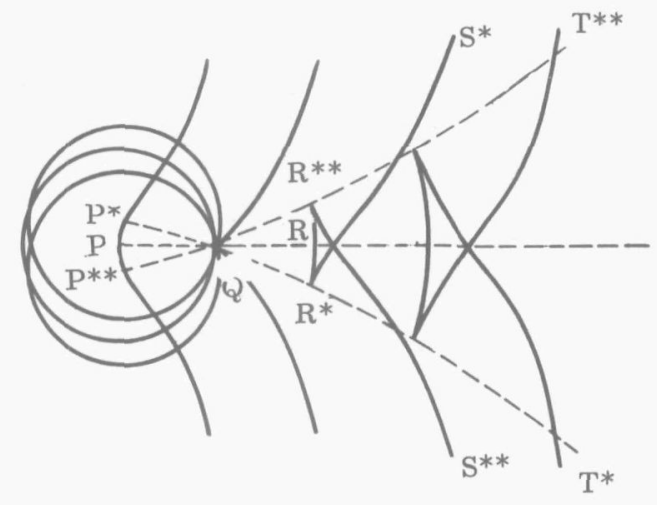

Figure 3.8.c.

The solutions of (3.8.4) with fixed $\mathrm{x}_{0}, \mathrm{y}_{\mathrm{o}}$ and variable $\varphi_{0}$ as starting values for $x(0), y(0)$ and $\varphi(0)$ are functions of $t$ and $\varphi_{0}$. In $Q$ the partial derivatives of $x$ and $\mathrm{y}$ with respect to $\varphi_{\mathrm{O}}$ are zero, while for all points on the line through $\mathrm{Q}$ parallel to the $\mathrm{Y}$-axis the derivative $\frac{\partial y}{\partial \varphi_{0}}$ is positive.

Turning back to the approximative construction, it is now obvious that the two parts of $\mathrm{S}^{+}(\mathrm{t}+\delta \mathrm{t})$ on each side of the $\mathrm{X}$-axis are transformed, by a next time increase $\delta \mathrm{t}$, to the intersecting fronts $\mathrm{R}^{*} \mathrm{~S} *$ and $\mathrm{R}^{* *} \mathrm{~S} * *$. The frontal arc between $\mathrm{R}^{*}$ and $\mathrm{R}^{* *}$ is formed by the "t $+2 \delta \mathrm{t}$-points" of extremals that intersected the timefront through $\mathrm{P}$ between $\mathrm{P}^{*}$ and $\mathrm{P} * *$.

If the curvature radius of $S^{+}(t+\delta t)$ in $Q$ is equal to $r\left(x_{Q}, y_{Q}\right) \delta t$, then $R^{*}$ and $\mathrm{R}^{* *}$ are the conjugate points to $\mathrm{A}$ for the extremals through $\mathrm{P}^{*}$ and $\mathrm{P}^{* *}$ respectively.

The further propagation of the timefronts is analogous. For $t^{*}>t+\delta t$ they appirently have a double point on the central "extremal" through $Q$ and turning 
points on the two dashed curves through Q, which form the locus of conjugate points to A for extremals with various starting values $\varphi_{0}$.

The practical importance of this phenomenon is, that for every point in the sector $\mathrm{T}^{* *} \mathrm{Q} \mathrm{T}^{*}$ we can find three solutions of (3.8.4) that lead to that point. Of these solutions only one is the absolute extremal, except when the point is located on the locus of double points of the timefronts, which is the continuation of the (3.8.4)-solution through Q. As these circular fields of low velocity frequently occur in ocean navigation, we can conclude from this example, that solving the problem of finding the least time track by means of some sort of a trial-and-error method has to be rejected, because such a procedure only leads to a trajectory, that is locally optimal. In order to find the real extremal from $A$ to $B$, it is necessary to construct the timefronts as far as possible, i. e. between the boundaries of the region G, mentioned in (3.2).

\subsection{Modifications in case of coordinate restrictions.}

The region G, within which the extremal from A to B has to be located, can in the case of a North Atlantic crossing between the English Channel and the U.S. East Coast be described by the requirements:

$$
\begin{aligned}
& 0 \leqq x \leqq 17, \\
&-2 \leqq y \leqq 3 \text { for } \quad 0 \leqq x<9 \\
&-1 \leqq y \leqq 3 \text { for } \quad 9 \leqq x<10 \\
&-1.5 \leqq y ~
\end{aligned},
$$

Assume the data, necessary to construct the complete figure of extremals and timefronts, to be known in a somewhat larger region $\hat{G}$, so that it is always possible to extend an extremal arc for a short stretch outside of $\mathrm{G}$.

If extremals, starting from $A$ on the basis of an initially chosen value of $\psi\left(t_{a}\right)$, intersect the boundary of $\mathrm{G}$ at a too early time $\mathrm{t}$ - meaning that the corresponding region $\mathrm{H}^{+}(\mathrm{t})$ does not contain the destination $\mathrm{B}-$ then these trajectories are immaterial and have to be cancelled. If such an extremal $\Gamma_{\mathrm{g}}$ touches the boundary - meaning that one point $\mathrm{R}$ of $\Gamma_{g}$ lies on the boundary, while all other points of $\Gamma_{g}$ in a not too large neighbourhood of $R$ lie inside $G$, the arc of $\Gamma_{g}$ for $t>t_{R}$ is an unwanted border of the field of extremals, with which the region $\mathrm{G}$ is being scanned until $\mathrm{B}$ is hit by $\mathrm{H}^{+}\left(\mathrm{t}_{\mathrm{b}}\right)$ for some $\mathrm{t}_{\mathrm{b}}>\mathrm{t}_{\mathrm{R}}$. For example, in figure 3.9.a the part of $G$ between the arc RP and the boundary part PQSTR 


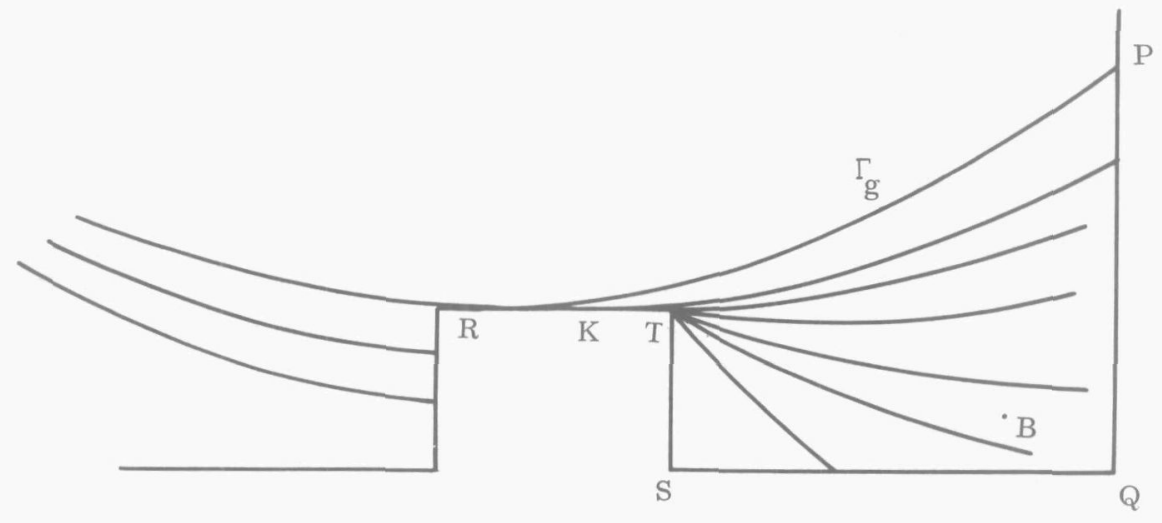

Figure 3.9. a.

would remain uncovered by extremals. In such a case, it is necessary to cover this shadow region with a collection of supplementary extremals, all starting from R.

Let the adjoint vector with respect to $\Gamma_{g}$ have the value $\psi_{R}$ for $t=t_{R}$.

If $\psi_{R}$ is left unchanged, then the procedure, described in (3.7) generates the trajectory $\Gamma_{\mathrm{g}}$.

The solution seems to be to turn $\psi_{\mathrm{R}}$ over some angle, varying for example from 0 to $-\pi / 2$, before the integrating procedure is continued. However, this normal procedure would generate extremals, that lead to points outside of G. The construction of extremal arcs from $R$, meant to cover the region "below" the arc RP clearly has to deviate from the "free" procedure, described in (3. 7).

This deviation practically consists of covering an arbitrary part RK of the boundary $R T$ with a velocity, given by $\dot{x}=f\left(x, \alpha_{g}, t\right)$, where the ships's course $\alpha_{\mathrm{g}}$ is determined by the direction of RT, the local value of the stream vector and the indicatrix at the point $\mathrm{x}$ (shown in figure 3.9.b).

Having reached $K$, the direction of $\psi$, belonging to the boundary course $\alpha_{\mathrm{g}}$ at that point, can be deduced from the maximum principle. Continuation of the trajectory as a free extremal then generates a curve within the yet unscanned part of G.

When the boundary is covered as far as the corner point $\mathrm{T}$ and the trajectory is continued in the way, just mentioned, the remaining part of G can be covered with free extremals, starting at $\mathrm{T}$ and constructed on the basis of properly 
chosen initial values for the adjoint vector.

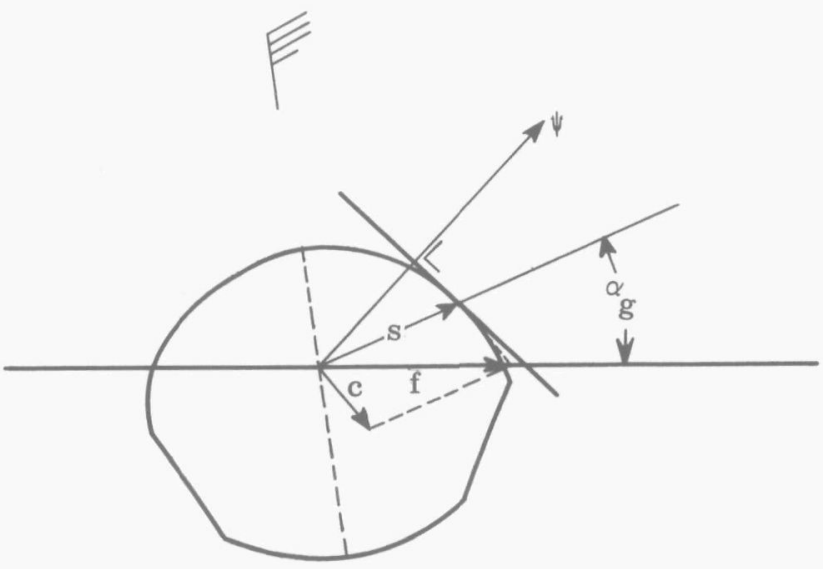

Figure 3. 9.b.

The coincidence of an extremal arc with a part of the boundary will now be briefly investigated.

With

$(3.9 .1)$

$$
\begin{cases}x^{i}\left(t_{0}\right)=x_{0}^{i}, & (i=1,2) \\ \frac{d x^{i}}{d t} & =f^{i}\left(x^{j}, \alpha, t\right) \text { and } \varphi\left(x^{i}\right) \leqq 0,\end{cases}
$$

suppose there is a class A of functions $\alpha(t)$ so that a solution $x^{i}(t)$ of (3.9.1) attains the value $x_{1}^{i}$ for some time $t_{1}$.

Among these control functions there is at least one, say $\widetilde{\alpha}(t)$, that generates a minimal arrival time $\tilde{t}_{1}$.

Suppose $\widetilde{\alpha}(\mathrm{t})$ determines the solutions $\tilde{\mathrm{x}}^{\mathbf{i}}(\mathrm{t})$ of $(3.9 .1)$, where $\varphi\left(\tilde{\mathrm{x}}^{\mathbf{i}}(\mathrm{t})\right)=0$ for $t_{0} \leqslant t \leqslant t_{1}$, meaning that the extremal coincides with the boundary. If $\tilde{\alpha}(t)$ is given a small variation $\delta \alpha(t)$, while $\widetilde{\alpha}(\mathrm{t})+\delta \alpha(\mathrm{t})$ is still a function of class $\mathrm{A}$, this varied control will generate the solutions $x^{i}=\tilde{x}^{i}(t)+\delta x^{i}(t)$ of (3.9.1) and an arrival time $\tilde{t}_{1}+\delta t_{1}$ with $\delta t_{1} \geqq 0$.

Substituting:

$$
\begin{aligned}
& \mathrm{x}^{1}=\mathrm{x} \quad, \quad \mathrm{x}_{\mathrm{o}}^{1}=\mathrm{x}_{0}, \quad \mathrm{x}_{1}^{1}=\mathrm{x}_{1}, \\
& \mathrm{x}^{2}=\mathrm{y}^{1}, \quad \mathrm{x}_{\mathrm{o}}^{2}=\mathrm{y}_{\mathrm{o}}^{1}, \quad \mathrm{x}_{1}^{2}=\mathrm{y}_{1}^{1}, \\
& \mathrm{t}=\mathrm{y}^{2}, \mathrm{t}_{\mathrm{o}}=\mathrm{y}_{\mathrm{o}}^{2}, \mathrm{t}_{1}=\mathrm{y}_{1}^{2}, \\
& 1 / \mathrm{f}^{1}=\mathrm{G}^{2}, \mathrm{f}^{2} / \mathrm{f}^{1}=\mathrm{G}^{1} \text {, }
\end{aligned}
$$


we have:

(3. 9. 3)

$$
\left\{\begin{array}{l}
\frac{d y^{i}}{d x}=G^{i}\left(y^{j}, \alpha, x\right), \\
y^{i}\left(x_{0}\right)=y_{0}^{i}, y^{i}\left(x_{1}\right)=y_{1}^{i},\left(y_{0}^{i} \text { and } y_{1}^{1} \text { are fixed, } y_{1}^{2} \text { is variable }\right)
\end{array}\right.
$$

$$
\varphi\left(\mathrm{x}, \mathrm{y}^{1}\right) \leqq 0, \varphi\left(\mathrm{x}, \mathrm{y}_{\mathrm{o}}^{1}\right)=\varphi\left(\mathrm{x}, \mathrm{y}_{1}^{1}\right)=0 \text {. }
$$

Denoting the minimal solution by $y^{i}=\widetilde{y}^{i}(x)$ and introducing the abbreviative notations

$$
\frac{\partial G^{i}\left(\tilde{y}^{j}, \tilde{\alpha}, x\right)}{\partial y^{k}}=G_{y}^{i} k \quad \text { and } \quad \frac{\partial G^{i}\left(\tilde{y}^{j}, \tilde{\alpha}, x\right)}{\partial \alpha}=G_{\alpha}^{i}
$$

the variations $\delta y^{i}$ and $\delta \alpha$ have to meet the requirement:

$$
\int_{x_{0}}^{x_{1}}\left(G^{2}{ }^{i} \delta y^{i}+G_{\alpha}^{2} \delta \alpha\right) d x \geqq 0 . \quad \begin{aligned}
& \text { (Using the Einstein summation } \\
& \text { convention) }
\end{aligned}
$$

The $\mathrm{x}$-derivatives of $\delta \mathrm{y}^{\mathrm{i}}$ are found to be

$$
\frac{d\left(\delta y^{i}\right)}{d x}=G_{y}^{i} j^{j} y^{j}+G_{\alpha}^{i} \delta \alpha
$$

Introducing a slack variable $\mathrm{z}$, the inequality (3.9.4) can be replaced by:

(3.9.7) $\varphi\left(x, y^{1}\right)+z=0$, where $z \geqq 0$ and $z=0$ for $y^{1}=\tilde{y}^{1}(x)$.

The variations in $\tilde{y}^{i}(x)$ imply slack variations $\delta z(x)$, so

$$
\varphi_{y} \delta y^{1}+\delta z=0
$$

Differentiating this with respect to $\mathrm{x}$ and using (3.9.6) gives:

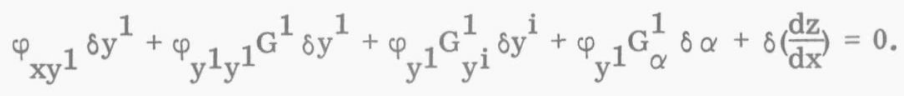

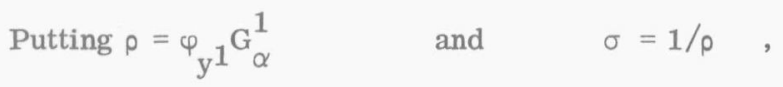

$$
x_{1}=\varphi_{x y}{ }^{+}+\varphi_{y^{1} y^{1}} G^{1}+\varphi_{y}{ }^{1} G_{y^{1}}^{1}, \quad x_{2}=\varphi_{y}{ }^{1} G_{y^{2}}^{1},
$$


equation (3.9.9) becomes:

(3.9.10) $\quad x_{i} \delta y^{i}+\rho \delta \alpha+\delta\left(\frac{d z}{d x}\right)=0 \quad$ or $\quad \delta \alpha=-\sigma x_{i} \delta y^{i}-\sigma \delta\left(\frac{d z}{d x}\right)$.

Considering the minimal time condition (3.9.5), we find:

$$
\int_{x_{0}}^{x_{1}}\left(\left(G_{y^{i}}^{2}-\sigma G_{\alpha}^{2} x_{i}\right) \delta y^{i}-\sigma G_{\alpha}^{2} \delta\left(\frac{d z}{d x}\right)\right) d x \geqq 0 .
$$

I now introduce the adjoint vector $p=\left(p_{1}, p_{2}\right)$ by defining:

$$
\mathrm{G}_{\mathrm{y}}^{2}-\sigma \mathrm{G}_{\alpha}^{2} \mathrm{X}_{\mathrm{i}}=\frac{\mathrm{dp}_{\mathrm{i}}}{\mathrm{dx}}+\mathrm{p}_{\mathrm{j}}\left(\mathrm{G}_{\mathrm{y}^{\mathrm{i}}}^{\mathrm{j}}-\mathrm{G}_{\alpha}^{\mathrm{j}} \sigma \mathrm{x}_{\mathrm{i}}\right) .
$$

Before further development, consider

$$
\begin{aligned}
\frac{d}{d x}\left(p_{i} \delta y^{i}\right) & =\frac{d p_{i}}{d x} \delta y^{i}+p_{i} \frac{d\left(\delta y^{i}\right)}{d x} \\
& =\left(\frac{d p_{i}}{d x}+p_{j} G_{y}^{j}\right) \delta y^{i}+p_{i} G_{\alpha}^{i} \delta \alpha \\
& =\left(\frac{d p_{i}}{d x}+p_{j} G_{y^{i}}^{j}\right) \delta y^{i}+p_{i} G_{\alpha}^{i}\left(-\sigma x_{j} \delta y^{j}-\sigma \delta\left(\frac{d z}{d x}\right)\right) .
\end{aligned}
$$

With $\lambda=\mathrm{p}_{\mathrm{i}} \mathrm{G}_{\alpha}^{\mathrm{i}} \sigma$, this becomes:

$$
\frac{d}{d x}\left(p_{i} \delta y^{i}\right)=\left(\frac{d p_{i}}{d x}+p_{j} G_{y}^{j}-\lambda x_{i}\right) \delta y^{i}-\lambda \delta\left(\frac{d z}{d x}\right)
$$

Now (3.9.11) can be changed to:

$$
\begin{aligned}
& \int_{x_{0}}^{x_{1}}\left(\frac{d}{d x}\left(p_{i} \delta y^{i}\right)+\left(\lambda-\sigma G_{\alpha}^{2}\right) \delta\left(\frac{d z}{d x}\right)\right) d x \geqq 0 \\
& {\left[p_{i} \delta y^{i}\right]_{x_{0}}^{x_{1}}+\int_{x_{0}}^{x_{1}} \mu \delta\left(\frac{d z}{d x}\right) d x \geqq 0 \quad \text { with } \mu=\lambda-\sigma G_{\alpha}^{2}}
\end{aligned}
$$

Remembering that $\delta y^{i}\left(x_{0}\right)=0$ and $\delta y^{1}\left(x_{1}\right)=0$, this leads to: 


$$
p_{2} \delta y^{2}\left(x_{1}\right)+\mu \delta z-\int_{x_{0}}^{x_{1}} \frac{d \mu}{d x} \delta z d x \geqq 0 .
$$

The requirements $\delta y^{2}\left(x_{1}\right)=\delta t_{1} \geqq 0$ and $\delta z \geqq 0$ now mean that

$$
\mathrm{p}_{2} \geqq 0, \quad \mu \geqq 0 \quad \text { and } \quad \frac{\mathrm{d}_{\mu}}{\mathrm{dx}} \leqq 0
$$

The last conclusion means that the "boundary extremal", for which $\mu$ is positive, tends to a free extremal.

Summarizing the result, the variables $y^{i}, \alpha, \mu$ and $p_{i}$ have to be solved from the following equations:

$$
\begin{aligned}
& \frac{d y^{i}}{d x}=G^{i}\left(y^{j}, \alpha, x\right), \\
& \frac{d p_{i}}{d x}=-p_{j} G_{y^{i}}^{j}+\mu x_{i}+G_{y}^{2}, \\
& \varphi\left(x, y^{1}\right)=0, \\
& G_{\alpha}^{2}+\mu \varphi_{y^{1}} G_{\alpha}^{1}-p_{i} G_{\alpha}^{i}=0 .
\end{aligned}
$$

Transforming this set into a system of equations with the time as independent variable and putting $p_{1}=\psi_{2}$ and $\psi_{1}=-\left(\psi_{2} f^{2}+p_{2}-1\right) / f^{1}$, I find:

$$
\begin{aligned}
& \frac{d x^{i}}{d t}=f^{i}\left(x^{j}, \alpha, t\right), \\
& \frac{d \psi_{i}}{d t}=-\psi_{j} f_{x}^{j}+\mu\left(\varphi_{x} j^{j} f_{x}^{j}+\varphi_{x} i_{x} j f^{j}\right),
\end{aligned}
$$

(3.9.16)

$$
\begin{aligned}
& \varphi\left(\mathrm{x}^{\mathrm{j}}\right)=0, \\
& \left(\psi_{\mathrm{i}}-\mu \varphi_{\mathrm{x}^{\mathrm{i}}}\right) \mathrm{f}_{\alpha}^{\mathrm{i}}=0 .
\end{aligned}
$$

The last expression determines $\mu$. This can be geometrically explained by means of figure 3.9. c.

In a point $\mathrm{P}$ of the boundary $\varphi\left(\mathrm{x}^{\mathrm{i}}\right)=0$ the stream vector $\mathrm{c}$ is drawn. The time and the coordinates of $\mathrm{P}$ determine the dimensions of the ship's velocity 
indicatrix. The gradient vector $\nabla \varphi$ is pointed to the outside of $\mathrm{G}$.

The adjoint vector $\psi$ has a direction, so that bare application of the maximum principle would produce a velocity vector $f$, that has a positive inner product with $\nabla \varphi$. This would mean a trespassing into the prohibited region $\mathrm{G}^{\mathrm{C}}$. Subtraction of $\mu \nabla \varphi$ from $\psi$ - with $\mu>0$ - has to deliver a velocity f perpendicular to $\nabla \varphi$. This number $\mu$ can be found as follows:

Determine the ship's velocity s so that $\mathrm{c}+\mathrm{s}$ touches the boundary.

In the endpoint of $s$ draw the tangent to the indicatrix.

The vectors $\psi$ and $\mu \nabla \varphi$ now must have equal projections on this tangent. This determines $\mu$, as long as it is positive. As soon as $\mu$ becomes zero, the extremal leaves the boundary and leads to points with $\varphi\left(x^{i}\right)<0$.

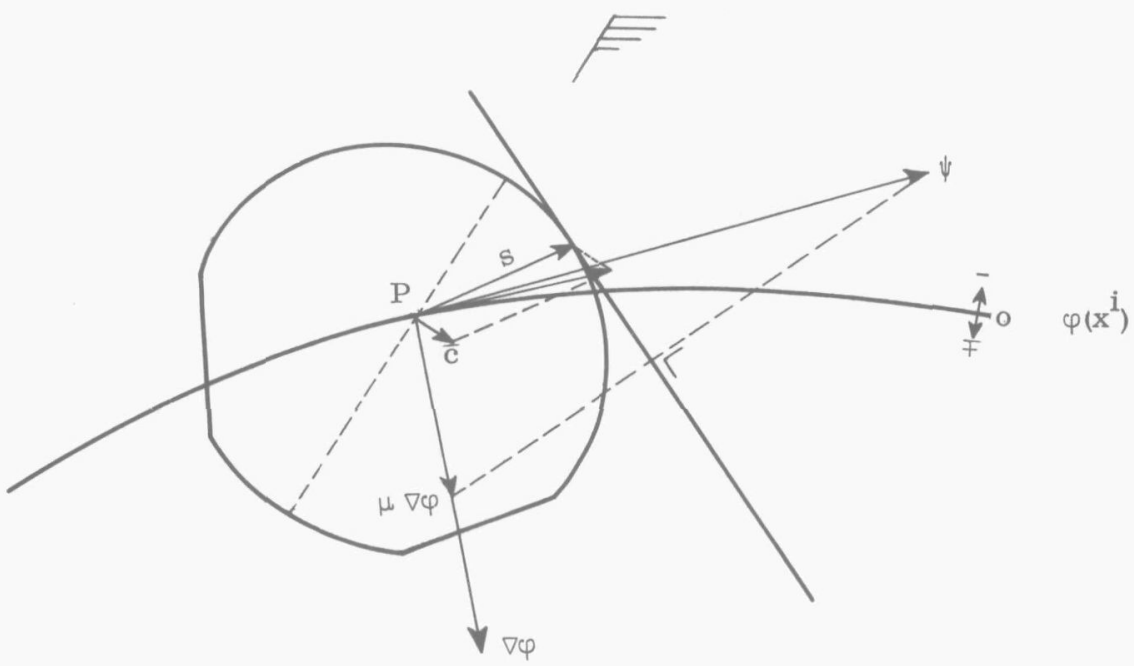

Figure 3.10.c. 


\section{P R A C T I C A L D A T A}

This chapter contains a summary of a few methods of wave prediction from meteorological data, followed by a curse treatment of the possibilities of a ship's response to a given wave pattern.

\subsection{The wave prediction problem}

Let us assume the weather and sea conditions in a region $\mathrm{G}$ to be known exactly at the present time $t_{0}$, while a weather forecast for a time $t_{1}$ can be considered sufficiently reliable to serve as a basis for a wave forecast, to be made up for this future time.

The first serious approach to solve this problem was performed by H. U. Sverdrup and W.H. Munk. As a result of their investigations, a pack of practical directives was compiled by Bretschneider, thus enabling sea navigators to make a fair estimation of the sea conditions to be expected.

Although these forecasts were averagely in fair accordance with practice, the basic mathematical model was a bit incomplete. An important improvement of this model was introduced by W.J. Pierson and a practical method of determination - or rather estimation - of sea conditions was issued as a result. ${ }^{1}$ ) The following three paragraphs contain a brief summary of these theories.

4.2. Some basic elements of ocean wave theory.

Consider a wave train with very long crests in water of constant depth $\mathrm{h}$. Select the $\mathrm{X}, \mathrm{Y}$-plane perpendicular to the crest lines, the $\mathrm{X}^{+}$-direction horizontal torthe right, the $\mathrm{Y}^{+}$-direction upward.

If the fluid is irrotational and incompressible, the velocity components $u$ and $v$ of a fluid particle satisfy the relations:

$$
\begin{array}{ll}
u_{y}-v_{x}=0 & \text { (irrotationality), } \\
u_{x}+v_{y}=0 & \text { (incompressibility). }
\end{array}
$$

This justifies the introduction of a velocity potential $\varphi(x, y, t)$ with the properties:

1) 1955: Practical methods for observing and forecasting ocean waves. U.S. Navy H.O. 603. 
(4.2. 3)

$$
\varphi_{\mathrm{x}}=\mathrm{u}, \quad \varphi_{\mathrm{y}}=\mathrm{v}, \quad \varphi_{\mathrm{xx}}+\varphi_{\mathrm{yy}}=\Delta \varphi=0 .
$$

Let the wave profile be represented by $y=\eta(x, t)$. The free surface boundary condition, with the assumption of a small steepness to permit neglection of higher order terms, means that for $y=\eta$ we must have

$$
\mathbf{v}=\varphi_{\mathrm{y}}=\eta_{\mathrm{t}} .
$$

The Bernoulli equation, with constant pressure and neglection of $2^{\text {nd }}$ order terms, leads to the relation between $\varphi$ and $\eta$ :

$$
\varphi_{t}+g \eta=0 \quad \text { for } \quad y=\eta
$$

At the sea bottom the velocity is purely horizontal so we have the relation:

$$
\mathrm{v}=\varphi_{\mathrm{y}}=0 \quad \text { for } \quad \mathrm{y}=-\mathrm{h}
$$

Solving (4.2. 3) and taking account of $(4.2 .4,5,6)$, we find:

$$
\begin{aligned}
& \varphi=\operatorname{ca} \frac{\cosh (k(y+h))}{\sinh (k h)} \sin (k x-\sigma t) \quad \text { and } \\
& \eta=\frac{\operatorname{coa}}{g} \cos (k x-\sigma t) \frac{\cosh (k(\eta+h))}{\sinh (k h)}
\end{aligned}
$$

where $\quad c=$ phase velocity,

$\mathrm{a}=\mathrm{a}$ constant with the dimension of length,

$\mathrm{k}=$ wave number, (wave length $\mathrm{L}=2 \pi / \mathrm{k}$ )

$\sigma=$ circular frequency, with $\mathrm{c}=\sigma / \mathrm{k}$.

As $\eta \leqq 0.02 * h$ we replace $\eta+\mathrm{h}$ by $\mathrm{h}$, finding:

$$
\mathrm{c}^{2}=(\mathrm{g} / \mathrm{k}) \tanh (\mathrm{kh})
$$

For deep water $-\mathrm{h}>\frac{1}{2} \mathrm{~L}$ - this leads to the approximations

$$
\mathrm{c}^{2}=\mathrm{g} / \mathrm{k} \text { and }
$$

$$
\eta=a \cos (k x-\sigma t)
$$


Introducing the period $\mathrm{T}=2 \pi / \sigma$, we find:

$$
\mathrm{c}=\mathrm{gT} / 2 \pi
$$

Expressing $\mathrm{c}$ in knots and $\mathrm{T}$ in seconds, it appears that

$$
\mathrm{c}=3 \mathrm{~T} \text {. }
$$

The energy of an elementary sinewave per unit surface area can be found to be:

$$
\mathrm{E}=\frac{1}{2} \rho \mathrm{g} \mathrm{a}^{2}
$$

in which $\rho$ is the density of sea water.

The deep water assumption leads to the approximations for the group wave speed $\mathrm{V}_{\mathrm{g}}$ and the speed of energy propagation $\mathrm{V}_{\mathrm{e}}$ :

$$
\mathrm{V}_{\mathrm{g}}=\mathrm{V}_{\mathrm{e}}=\frac{1}{2} \mathrm{c}
$$

4.3. The Sverdrup - Munk wave forecasting method.

In 1943 Sverdrup and Munk introduced a wave prediction method, composed after an assignment by the U.S. Navy Hydrographic Office. The practical results of this method can still fairly well match those of later investigations, especially where the growth of waves is concerned.

With the information, cursely mentioned in the preceding paragraph, one can compute the average rates, at which energy is transmitted from wind to waves by normal pressure and by tangential stress. These rates are denoted by $R_{\nu}$ and $R_{T}$. Their values were adopted as:

$$
\begin{aligned}
& R_{\nu}=\frac{1}{2} S \rho^{1}(U-c){ }^{2} k^{2} a^{2} c \operatorname{sign}(U-c), \\
& R_{T}=\gamma^{2} \pi^{2} \rho^{1} \delta^{2} c U^{2},
\end{aligned}
$$

with $\mathbf{s}=$ sheltering coefficient, $\quad \rho^{1}=$ air density,

$\gamma^{2}=$ resistance coefficient,$\delta=$ wave steepness $=2 \mathrm{a} / \mathrm{L}$. 
As for the growing of waves, the "significant wave" was introduced. Considering a sufficiently large number ( $n$ ) of wave heights, the mean height of the $n / 3$ heighest waves is called the " $\frac{1}{3}$-significant wave height", denoted by $\overline{\mathrm{H}}_{1 / 3}$. The entire composite sea is now (supposed to be) represented by just one classical wave with height $\overline{\mathrm{H}}_{1 / 3}$. This idea meets some objections:

For an elementary wave in deep water the quantities c, $\sigma$ and $L$ can all be written as functions of k. From $c^{2}=g / k$ and $\sigma^{2}=g k$ we see that $\frac{d \sigma}{d k}=\frac{1}{2} c$. The total rate of increase of $\mathrm{L}$ with time is:

$$
\frac{d L}{d t}=\frac{\partial L}{\partial t}+c \frac{\partial L}{\partial x}
$$

Neglecting higher order terms, the wave crest velocity increase over one wave length is $L \frac{\partial c}{\partial x}$, so $\frac{\partial L}{\partial t}+c \frac{\partial L}{\partial x}-L \frac{\partial c}{\partial x}=0$.

Putting $\frac{\partial c}{\partial x}=\frac{d c}{d L} \frac{\partial L}{\partial x}=\frac{d(\sigma / k)}{d(2 \pi / k)} \frac{\partial L}{\partial x}=\frac{k}{2 \pi}\left(c-\frac{d \sigma}{d k}\right) \frac{\partial L}{\partial x}=\frac{c}{2 L} \frac{\partial L}{\partial x}$,

(4.3.1) we get: $\quad \frac{\partial \mathrm{L}}{\partial \mathrm{t}}+\frac{\mathrm{c}}{2} \frac{\partial \mathrm{L}}{\partial \mathrm{x}}=0$.

This relation implies, that a steady state, meaning $\frac{\partial L}{\partial t}=0$, cannot occur if there is a change of $\mathrm{L}$ with distance. Yet it is well known, that a sea in steady state, generated by an offshore wind, has waves with lengths, that increase with the wind fetch.

On the other hand, experience has shown, that ocean waves, being generated in a sufficiently large area, grow independant of their position, while (4.3.1) would suggest, that $\frac{\partial L}{\partial t}=0$ if $\frac{\partial L}{\partial x}=0$.

These difficulties, arising from the assumption to have the sea pattern represented by one "significant wave", were attempted to be overcome by stating, that significant waves are not conservative in a storm area.

Making up the account of energy and neglecting higher order terms, it can be stated that the entire rate of energy gain $\frac{d(E L)}{d t}$ of a crest-to-crest moving waveblock equals the total input by wind, $\left(R_{\tau}+R_{\nu}\right) L$ plus the first order gain of wave power $\frac{\mathrm{cE}}{2}$ over one wave length. This gives the relation

$$
\frac{d(E L)}{d t}=\left(R_{\tau}+R_{\nu}+\frac{\partial}{\partial x}(c E / 2)\right) L
$$


As $\frac{d L}{d t}=\frac{\partial c}{\partial x} L$, so that $\frac{\partial c}{\partial x}=\frac{1}{L} \frac{d L}{d t}$, while the deep water phase speed answers $\mathrm{c}^{2}=\mathrm{gL} / 2 \pi$, so $\frac{2}{\mathrm{c}} \frac{\mathrm{dc}}{\mathrm{dt}}=\frac{1}{\mathrm{~L}} \frac{\mathrm{dL}}{\mathrm{dt}}$, the expression (4.3.2) can be converted into:

$$
\frac{d E}{d t}+\frac{E}{c} \frac{d c}{d t}-\frac{c}{2} \frac{\partial E}{\partial x}=R_{T}+R_{\nu} .
$$

In a free ocean the energy of the significant wave is taken independent of $\mathrm{x}$. Thus follows the "duration equation":

$$
\frac{d E}{d t}+\frac{E}{c} \frac{d c}{d t}=R_{T}+R_{\nu}
$$

This equation is used to compute $\overline{\mathrm{H}}_{1 / 3}$, if the wind fetch is unlimited. To deduce an analogous equation for a steady wave with limited fetch, consider a water sheet of height $\mathrm{h}+\eta$, unit width and length $\delta \mathrm{x}$, fixed in space. In this sheet, potential energy is lost at the amount of $\frac{\partial(\mathrm{cE} / 2)}{\partial \mathrm{x}} \delta \mathrm{x}$, while the gain is again $\left(R_{\tau}+R_{\nu}\right) \delta x$. As the local change of energy is $\frac{\partial E}{\partial t} \delta x$, we have

$$
\frac{\partial E}{\partial t} \delta \mathbf{x}=-\frac{\partial(c E / 2)}{\partial x} \delta \mathbf{x}+\left(R_{\tau}+R_{\nu}\right) \delta \mathbf{x}
$$

For a wave in steady state $\frac{\partial E}{\partial t}=0$, so the "fetch equation" becomes:

$$
\frac{c}{2} \frac{d E}{d x}+\frac{E}{2} \frac{d c}{d x}=R_{T}+R_{\nu} .
$$

Before solving these equations, the dimensionless parameters $\delta \equiv \mathrm{H} / \mathrm{L}$ (wave steepness) and $\beta \equiv c / U$ (wave age) are brought up.

Practical experience has affirmed a univalent functional relation between $\delta$ and $\beta$.

As a result of this, the equations for duration and fetch can subsequently be written in the form

$$
\frac{d \beta}{d t}=f\left(\delta, \beta, \frac{d \delta}{d \beta}\right) \quad \text { and } \quad \frac{d \beta}{d x}=g\left(\delta, \beta, \frac{d \delta}{d \beta}\right) .
$$

The difficulty of determining $\delta$ as a function of $\beta$ was overcome in both cases by assuming a constant partition of energy, $R_{T}+R_{\nu}$ in total, over the energies to contribute to the increase of wave height $\left(\frac{\mathrm{dE}}{\mathrm{dt}}\right.$ and $\left.\frac{\mathrm{c}}{2} \frac{\mathrm{dE}}{\mathrm{dx}}\right)$ and to the increase of phase speed $\left(\frac{E}{c} \frac{d c}{d t}\right.$ and $\left.\frac{E}{2} \frac{d c}{d x}\right)$.

As there is little sense in reconstructing all the details, I shall confine myself 
with the exhibition of the result, given by figure 4.3. a. This figure shows graphs of the dimensionless quantities $\mathrm{gH} / \mathrm{U}^{2}$ and $\mathrm{c} / \mathrm{U}$ for a given value of $\mathrm{gt} / \mathrm{U}$ $(t=$ duration), in the case of an unlimited fetch and a limited duration, and for a given value of $g F / U^{2}$ ( $F=$ fetch length) for the case of a limited wind fetch. Obviously, for a given set of values for $U, t$ and $F$, one should take the smallest of the two values, both for $\mathrm{gH} / \mathrm{U}^{2}$ and for $\mathrm{c} / \mathrm{U}$.

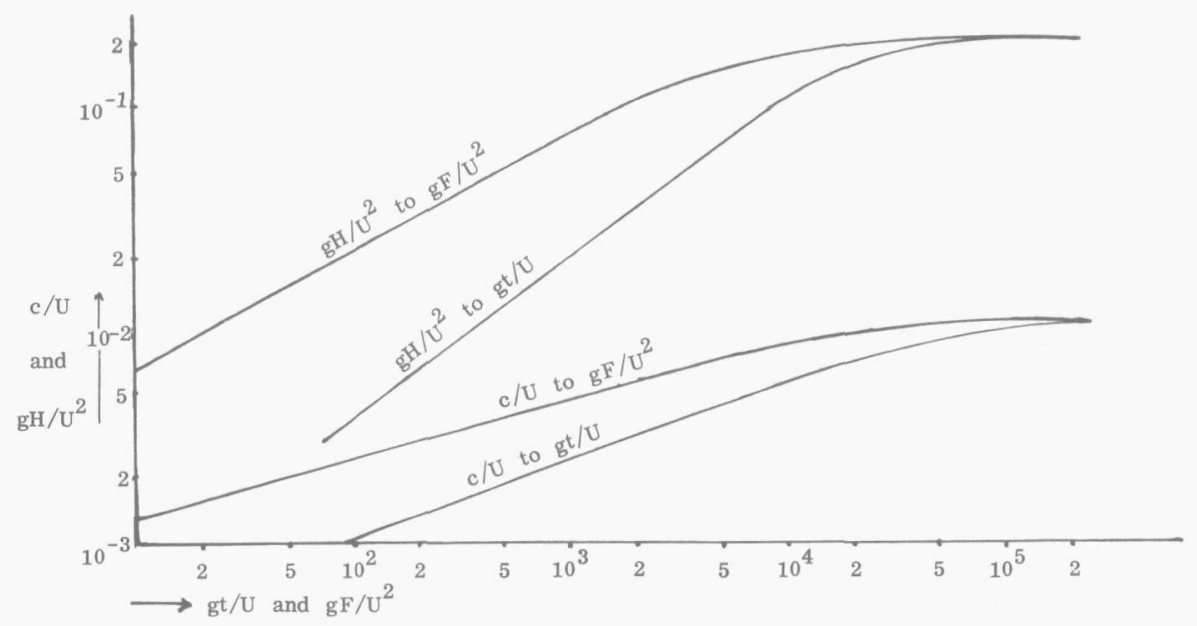

Figure 4.3.a.

4.4. The Pierson - Neumann theory.

It was W.J. Pierson's idea to approach the problem of ocean wind waves by means of stochastics. Therefore this summary of Pierson's theory is preceded by a curse treatment of a few statistical theorems.

A stochastic process $x_{t}(w)$ can be defined as an indexed set of stochastic variables. The set of values of the process is (part of) the real line or the complex plane in most cases. The index set $\mathrm{T}=\{\mathrm{t}\}$ can be the real line, the set of all integers or any other point collection. The points $w$ are elements of a space $\Omega$. A probability measure $\mu$ is defined on a $\sigma$-algebra of subsets in $\Omega$. For a fixed point $w, x_{t}(w)$ is a function of $t$, called a sample function or realization of the process.

Consider now a complex valued stochastic process. The mean value function 
(4. 4. 1)

$$
\mathrm{m}_{\mathrm{t}}=\mathrm{E}\left(\mathrm{x}_{\mathrm{t}}\right)=\int_{\Omega} \mathrm{x}_{\mathrm{t}}(\mathrm{w}) \mathrm{d}_{\mu}(\mathrm{w}) \quad \text { is assumed zero. }
$$

The covariance function, created to give quantitative information on the mutual dependence of the process values at different points of $\mathrm{T}$, is:

$$
r_{s t}=E\left(x_{s} \bar{x}_{t}\right)=\int_{\delta_{b}} x_{s}(w) \overline{x_{t}(w)} d_{\mu}(w) \text {, so } r_{s t}=\bar{r}_{t s} .
$$
If $T=\left\{t_{i}\right\}$ with $i=1(1) n$, then the matrix $\left\{r_{t_{i}}\right\}$ is Hermitian and non negative
definite.

A process, for which $\mathrm{E}\left|\mathrm{x}(\mathrm{t})-\mathrm{x}\left(\mathrm{t}_{\mathrm{o}}\right)\right|^{2} \rightarrow 0$ if $\mathrm{t} \rightarrow \mathrm{t}_{\mathrm{o}}$, is called "continuous in the mean". This property is equivalent to the continuity of $r_{s t}$ for $s=t$.

Let $\mathrm{T}$ be a $\sigma$-field $\mathrm{B} \Lambda$ on a finite dimensional space $\Lambda$.

Suppose a $\sigma$-finite measure $\mu$ is defined on this field. A stochastic set function $\mathrm{z}(\mathrm{s})$ with $\mathrm{s} \in \mathrm{B} \wedge$ is now defined by:

$$
\begin{aligned}
& \mathrm{z}\left(\mathrm{s}_{1} \cup \mathrm{s}_{2}\right)=\mathrm{z}\left(\mathrm{s}_{1}\right)+\mathrm{z}\left(\mathrm{s}_{2} \cap \mathrm{s}_{1}^{\mathrm{c}}\right), \\
& \mathrm{E}(\mathrm{z}(\mathrm{s})) \quad=0 \\
& \mathrm{E}\left(\mathrm{z}(\mathrm{s}) \overline{\left.\mathrm{z( \textrm {s } ^ { \prime } )}\right)}=\mu\left(\mathrm{s} \cap \mathrm{s}^{\prime}\right) .\right.
\end{aligned}
$$

This definition implies, that the process has orthogonal increments. If $f(\lambda)$ is defined on $\Lambda$ so that $\int_{\Lambda}|\mathrm{f}(\lambda)|^{2} \mathrm{~d} \mu(\lambda)<\infty$, a stochastic process can be defined in terms of integrals with respect to this orthogonal set function $\mathrm{z}(\mathrm{s})$. This can be done by selecting a sequence of step functions $f_{n}(\lambda)$, so that

$$
\lim _{n \rightarrow \infty} \int_{\Lambda}\left|f(\lambda)-f_{n}(\lambda)\right|^{2} d \mu=0
$$

Defining $J_{n}=\int_{\Lambda} f_{n}(\lambda) d z(\lambda)$, it can be proved, that $J_{n}$ converges in the mean to a stochastic variable $\mathrm{J}$, where

$$
\mathrm{E}|J|^{2}=\int_{\Lambda}|\mathbf{f}(\lambda)|^{2} \mathrm{~d} \mu
$$
so that $J$ c in bo represented by the expression $\int_{\Lambda} f(\lambda) d z(\lambda)$. These variables have
the propert, 


$$
E\left(J_{f} \overline{J^{\prime}}\right)=\int_{\Lambda} f(\lambda) \overline{g(\lambda)} d \mu(\lambda)
$$

(4. 4.4) The stochastic variable $x_{t}=\int f(t, \lambda) d z(\lambda)$ now has the covariance function

$$
r_{s t}=E\left(x_{s} \overline{x_{t}}\right)=\int_{\Lambda} f(s, \lambda) \overline{f(t, \lambda)} d \mu(\lambda)
$$

Inversely, it is possible to deduce the representation (4.4.4) from the covariance representation (4.4.5).

The stochastic process $x_{t}$ - where $t$ is an $m$-vector - is called strictly stationary if the variables $\mathrm{x}_{\mathrm{t}_{1}}, \ldots \ldots, \mathrm{x}_{\mathrm{t}_{\mathrm{n}}}$ have the same joint probability distribution as $x_{t_{1}+h}, \ldots, x_{t_{n}+h}$, for any $m$-vector $h$.

For a strictly stationary process the covariance function $\mathrm{r}_{\mathrm{st}}$ has the property:

$$
r_{s+h, t+h}=r_{s, t}=r_{s-t, 0}=r(s-t) .
$$

Taking the real line for $\mathrm{T}$, the covariance function $\mathrm{r}(\mathrm{t})$ of a stationary process enables one to construct:

$$
f(\eta)=\frac{1}{2 \pi} \int_{-\infty}^{\infty} e^{-i t \eta} r(t) d t \text { and } F(\lambda)=\int_{-\infty}^{\lambda} f(\eta) d \eta .
$$

From this it follows that $\lim _{\lambda \rightarrow-\infty} F(\lambda)=0$, while

$r(t)=\int_{-\infty}^{\infty} e^{i t \eta} f(\eta) d \eta$, so that $r(0)=\int_{-\infty}^{\infty} f(\eta) d \eta=\lim _{\lambda \rightarrow \infty} F(\lambda)$.

Furthermore $F(\lambda)$ is a bounded, non decreasing function. It is called the "spectral distribution function" of the process.

The covariance function can be found by

$$
r(t)=\int_{-\infty}^{\infty} e^{i t \lambda} d F(\lambda)
$$


But this means that the covariance representation

$$
r_{s t}=r(s-t)=\int_{-\infty}^{\infty} e^{i(s-t) \lambda} d F(\lambda)
$$

can be seen as (4.4.5) with $f(t, \lambda)=e^{i t \lambda}$ and $\mu(\lambda)=F(\lambda)$. So now there is an orthogonal set function $\mathrm{z}(\mathrm{s})$ defined on the Borel sets of the real line, so that $x(t)=\int_{-\infty}^{\infty} e^{i t \lambda} d z(\lambda)$. With $F(\lambda)$ as the probability measure, we have

$$
E\left(z\left(s_{1}\right) \overline{z\left(s_{2}\right)}\right)=\int_{s_{1} \cap s_{2}} d F(\lambda) \quad \text { or } \quad E\left(|d z(\lambda)|^{2}\right)=d F(\lambda) .
$$

The stochastic variable $\mathrm{x}(\mathrm{t})$, just mentioned, is therefore denoted abbreviously by

$$
x(t)=\int_{-\infty}^{\infty} e^{i t \lambda} \sqrt{(d F(\lambda))}
$$

To describe the wave profile of a wind generated sea, Pierson adopted the stochastic model:

(4. 4. 6) $\eta\left(x_{1}, x_{2}, t\right)=\int_{(\sigma, \theta)=(0,-\pi)}^{(\infty, \pi)} \cos \left(\frac{\sigma^{2}}{g}\left(x_{1} \cos \theta+x_{2} \sin \theta\right)-\sigma t+\varepsilon(\sigma, \theta)\right) d z(\sigma, \theta)$.

In this expression, $\epsilon(\sigma, \theta)$ represents a random phase shift, uniformly distributed over $(-\pi, \pi)$ for each element dod $\theta$.

$\mathrm{z}(\sigma, \theta)$ is an orthogonal set function, with

$$
E\left(d z^{2}(\sigma, \theta)\right)=A^{2}(\sigma, \theta) d \sigma d \theta
$$

Figure 4.4. a shows a graph of the spectral function $A^{2}(\sigma, \theta)$ on the $(\sigma, \theta)$-plane.

As $\mathrm{dz}(\sigma, \theta)$ has the dimension of length, the integral

$$
\int_{\sigma_{0}-\frac{1}{2} \Delta \sigma}^{\sigma_{0}+\frac{1}{2} \Delta \sigma}\left\{\int_{\theta_{0}^{-\frac{1}{2} \Delta \theta}}^{\theta_{0}+\frac{1}{2} \Delta \theta} \mathrm{A}^{2}(\sigma, \theta) \mathrm{d} \theta\right\} \text { has the dimension } \mathrm{l}^{2} \text { and }
$$




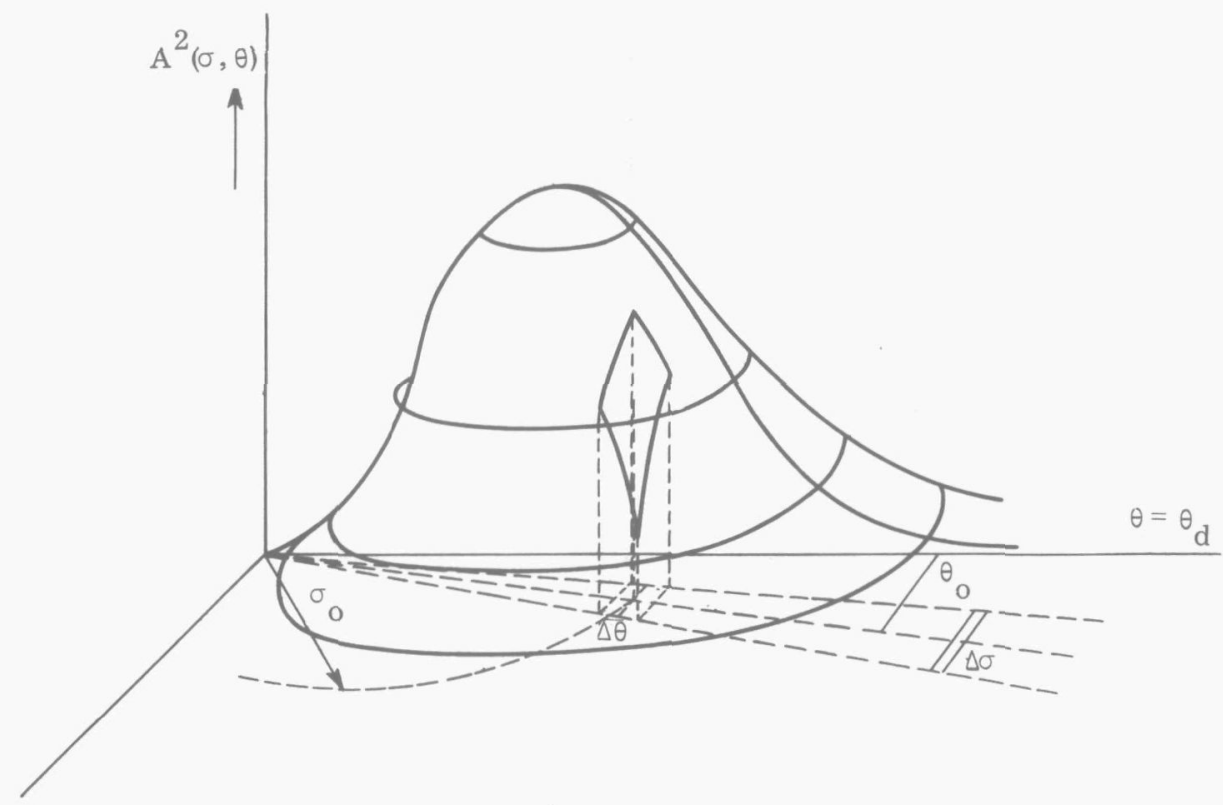

Figure 4.4.a.

is thus proportional to the energy of waves within the frequency band of width $\Delta \sigma$ around $\sigma_{0}$, coming in from directions between $\theta_{0}-\frac{1}{2} \Delta \theta$ and $\theta_{0}+\frac{1}{2} \Delta \theta$. Apart from the question if this model is a good aid to determine as many as possible relations between winds and sea waves - practical experience has so far shown little need for refinement - the kernel of Pierson's problem is to find a proper energy spectrum.

The Neumann spectrum, designed in 1952, has to be considered as a first guess of $\mathrm{A}^{2}(\sigma, \theta)$.

Taking the mean wind direction $\theta_{d}=0$, the dependence of $\mathrm{A}^{2}$ on $\theta$ was assumed to be proportional to $\cos ^{2} \theta$ for $-\pi / 2<\theta<\pi / 2$, and $A^{2}$ was taken zero elsewhere, i.e. in the leeward region. This assumption was based on observations by Arthur (1949), who concluded that the wave height varied approximately proportional to the cosine of the bearing relative to $\theta_{d}$

The adopted expression for the energy spectrum became:

$A^{2}(\sigma, \theta)=C \sigma^{-6} \exp \left(-2 g^{2} \sigma^{-2} U^{-2}\right) \cos ^{2} \theta$ for $-\pi / 2<\theta<\pi / 2 \quad$ and $\mathrm{A}^{2}(\sigma, \theta)=0$ for $-\pi<\theta \leqq-\pi / 2$ or $\pi / 2 \leqq 0 \leqq \pi$.

The frequency interval may be limited by fetch $(\mathrm{F})$ or duration $(\mathrm{t})$. At a given 
wind speed $\mathrm{U}$, the lower bound $\sigma_{0}$ of the frequency interval, over which the spectral function $\mathrm{A}^{2}$ has to be integrated to get the total energy of the wave pattern, is the maximum of two quantities:

1) $\sigma_{f}$, a function of $U$ and $F$,

2) $\sigma_{t}$, a function of $U$ and $t$.

The total energy now follows from

$$
E=\int_{\sigma_{0}}^{\infty} \int_{-\pi / 2}^{\pi / 2} A^{2}(\sigma, \theta) d \sigma d \theta \text {, where } \sigma_{0}=\operatorname{Max}\left(\sigma_{f}, \sigma_{t}\right) .
$$

The $\frac{1}{3}$-significant wave height corresponds with this total energy amount according to $\overline{\mathrm{H}}_{1 / 3}=2.83 \sqrt{\mathrm{E}}$, working with c.g.s. units. Figure $4.4 . \mathrm{b}$ exhibits the results of these formulas.

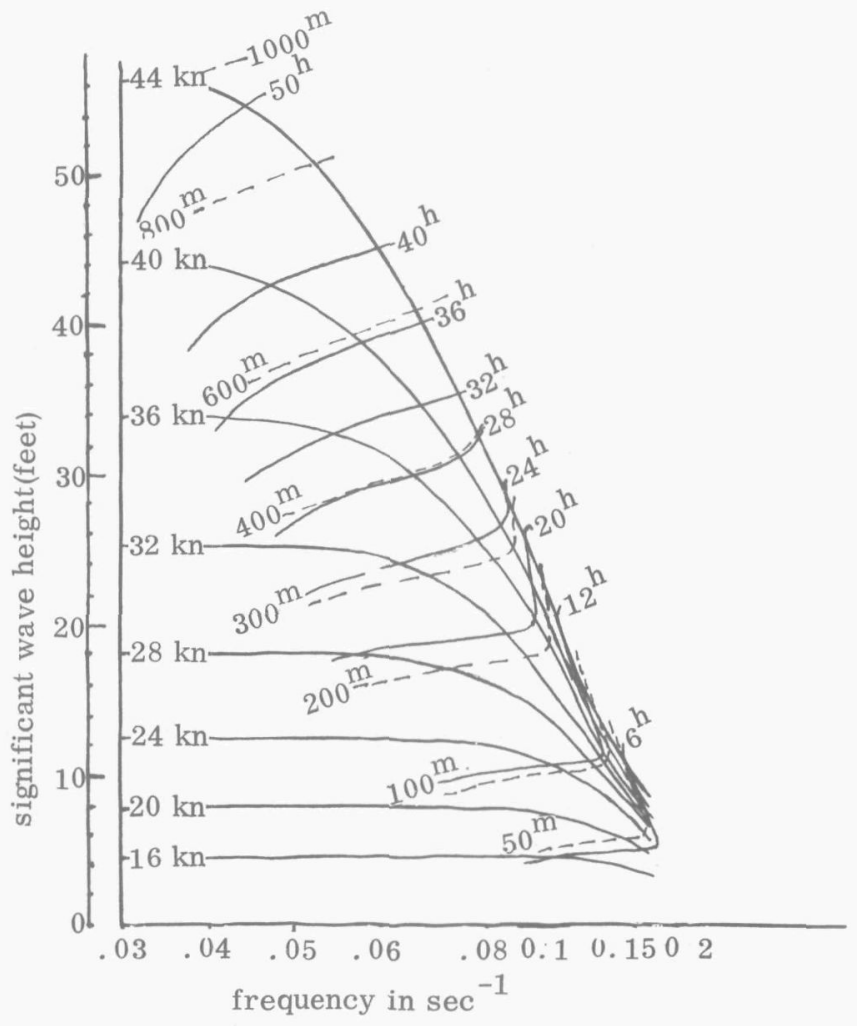

Figure 4. 4. b. 
As an example, take a 28 knots Northerly wind, generating a sea pattern at 200 miles south of Nova Scotia. The diagram shows, that this wind has to be blowing for about 19 hours to generate a fully developed sea. Before that time, the lower frequency bound is determined by the duration, while the 200 miles fetch is a barrier for further development of the waves for a longer duration than 19 hours.

Various attempts were made to improve the Neumann representation of a wind generated sea. Kitaigorodskii paid an important tribute in this respect by introducing his similarity theory.

Writing $\mathrm{A}^{2}(\sigma, \theta)=\mathrm{S}(\sigma) \cos ^{2} \theta$, he assumed that $\mathrm{S}(\sigma)$ was a function of $\sigma, \mathrm{g}, \mathrm{U}$ and $\mathrm{F}$ in case of a limited fetch.

This function can be transformed to a dimensionless spectrum $\overline{\mathrm{S}}$ by putting:

$$
\begin{aligned}
& \overline{\mathrm{S}}=\mathrm{S}(\sigma, \mathrm{g}, \mathrm{U}, \mathrm{F}) \mathrm{g}^{3} \mathrm{U}^{-5}, \\
& \bar{\sigma}=\mathrm{U \sigma g}^{-1}, \\
& \overline{\mathrm{F}}=\mathrm{gFU}^{-2} .
\end{aligned}
$$

According to Kitaigorodskii, this function $\overline{\mathrm{S}}$ only depends on the dimensionless quantities $\bar{\sigma}$ and $\overline{\mathrm{F}}$. In addition, the spectral function for a fully developed sea has to have a couple of properties, like

$$
\begin{gathered}
\overline{\mathrm{H}}_{1 / 3} \sim \mathrm{U}^{2}, \\
\sigma_{\max } \mathrm{Ug}^{-1}=\text { constant }, \\
\mathrm{S}\left(\sigma, \mathrm{g}, \mathrm{U}_{2}\right) \geqq \mathrm{S}\left(\sigma, \mathrm{g}, \mathrm{U}_{1}\right) \text { for } \mathrm{U}_{2}>\mathrm{U}_{1} \text {. and all } \sigma .
\end{gathered}
$$

An attempt to construct a spectral function $\mathrm{S}$ with these properties was made by L. Moskowitz in $1963^{1)}$.

His proposal not only met the above mentioned requirements, but it was also found to be in satisfactory accordance with data, collected from practical measurements.

Denoting $\omega=2 \pi \sigma$ and $\omega_{0}=\mathrm{gU}^{-1}$, the proposed spectral function was:

$$
\begin{gathered}
\mathrm{S}(\omega)=\alpha \mathrm{g}^{2} \omega^{-5} \exp \left(-\beta \omega_{0}^{4} \omega^{-4}\right), \quad \text { where } \\
\alpha=8.10^{*} 10^{-3}, \quad \beta=0.745 \quad \text { for c.g.s. units. }
\end{gathered}
$$

\footnotetext{
1) Pierson, Moskowitz. - Proposed spectral form for fully developed wind seas, N. Y. University, Geophysical Sciences Laboratory, Report 63-12.
} 
As for the propagation of windwaves outside a storm area, consider an area with fully developed waves of length $\mathrm{L}$ and width $\mathrm{W}$.

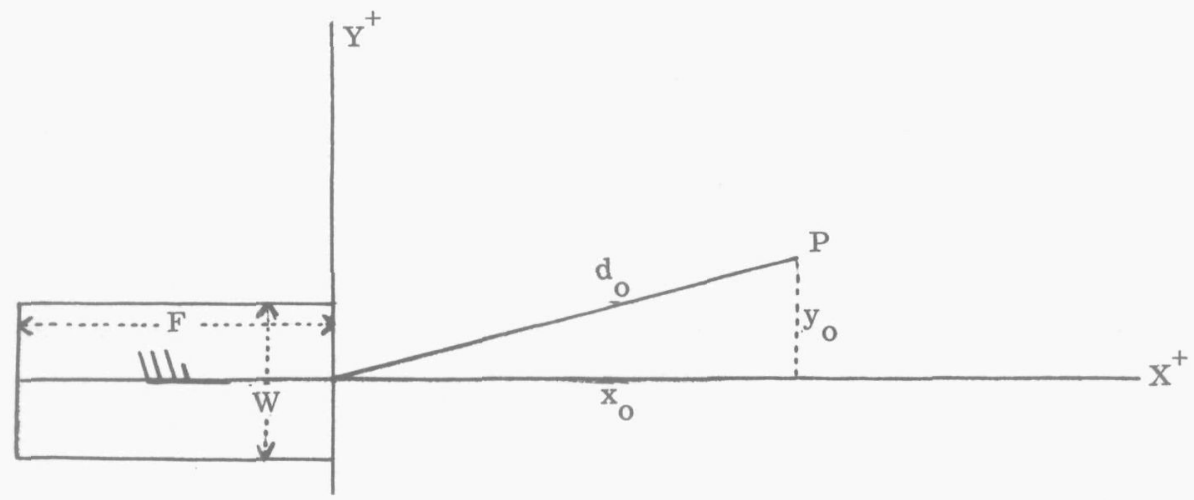

Figure 4.4.c.

Assume the windwave pattern in this area to be a linear composition of waves of all sorts of frequencies and directions. In that case, the waves that leave the storm area, will all propagate with their own group velocity.

In a point $\mathrm{P}\left(\mathrm{x}_{\mathrm{o}}, \mathrm{y}_{\mathrm{o}}\right)$ at a time $\mathrm{t}_{\mathrm{o}}$, the sea will only contain part of all the frequencies and part of all the directions that the sea in the source area consisted of. These frequency and direction intervals may have widths $\Delta \sigma$ and $\Delta \theta$.

The bounds of these frequency and direction bands are

$\frac{\mathrm{gt}_{\mathrm{o}}}{2\left(\mathrm{~d}_{\mathrm{o}}+\mathrm{F}\right)}<\sigma<\frac{\mathrm{gt}_{\mathrm{o}}}{2 \mathrm{~d}_{\mathrm{o}}}$ and $\arctan \left(\left(\mathrm{y}_{\mathrm{o}}-\mathrm{W} / 2\right) / \mathrm{x}_{\mathrm{o}}\right)<\theta+\pi<\arctan \left(\left(\mathrm{y}_{\mathrm{o}}+\mathrm{w} / 2\right) / \mathrm{x}_{\mathrm{o}}\right)$

These bands determine, what part of the entire spectrum is observed in $\mathrm{P}$ at tirne $t_{0}$.

Approximating $\Delta \sigma$ and $\Delta \theta$ by $\Delta \sigma=\frac{\mathrm{gFt}_{\mathrm{o}}}{2 \mathrm{~d}_{\mathrm{o}}\left(\mathrm{d}_{\mathrm{o}}+\mathrm{F}\right)}$ and $\Delta \theta=\mathrm{W} / \mathrm{d}_{\mathrm{o}}$,

it is clear that these bands become smaller as $d_{0}$ and $t_{0}$ increase, while $d_{0} / t_{0}$ is constant. This is a remarkable affirmation of practical experience: The further one gets from a storm area, the more the waves look like elementary waves with small frequency band an parallel wave crests. 
4.5. The performance of a ship in a given wave field.

\subsubsection{Practical approach}

For a given $\frac{1}{3}$-significant wave height $\mathrm{H}$ and a mean wave direction $\theta_{\mathrm{d}}$, experience has shown that the maximum ship's speed $r$ for a course $\alpha$ is a function of $\mathrm{H}$ and of $\alpha_{d}=\left|\alpha-\theta_{d}\right|$. The problem of finding this function $r\left(\alpha_{d}, H\right)$ is at this moment far from being completely solved. Attempts to determine $r$ for $\alpha_{d}=0, \pi / 2, \pi$ on a strictly experimental basis have been made - among several others - by G. Verploegh of the K. N. M. I. -routeing office and by R. W. James of the U.S. Naval Hydrographic Office. Mainly based on ship's log data, they composed graphs of $\mathrm{r}$ as a function of $\mathrm{H}$ for head, beam and following seas. One of these graphs is shown in figure 4.5.a.

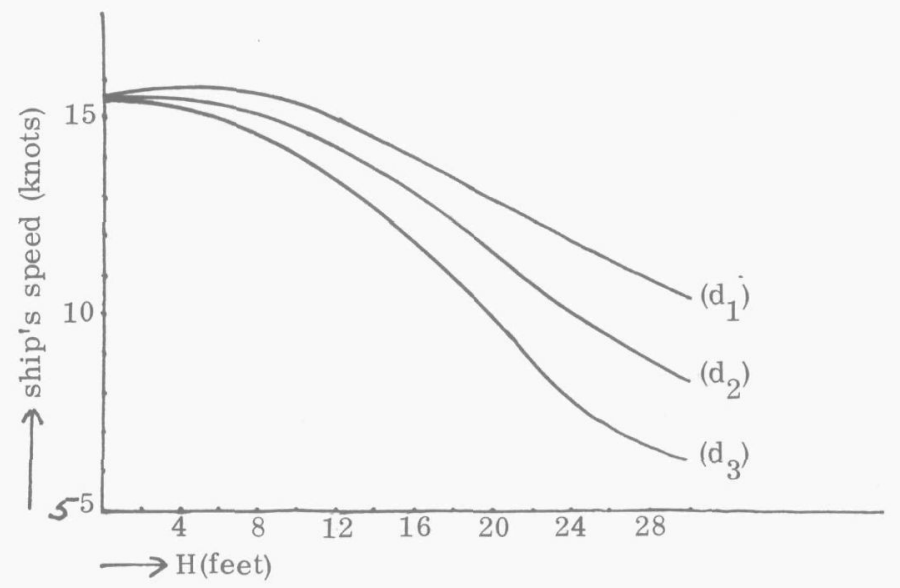

Figure 4.5.a.

In addition to this, the K. N.M.I. discovered a curious policy of ships in the case of quarterly incoming waves, i.e. $\pi / 2<\alpha_{\mathrm{d}}<\pi$.

Practically all ship's masters avoided too heavy rolling in these courses by either reducing speed or altering course. This means that $\mathrm{H}$ may determine a prohibited sector $\left(g_{1}, g_{2}\right)$ for $\alpha_{d}$, so that the choice of $\alpha_{d}$ is limited by the constraints

$$
0 \leqq \alpha_{\mathrm{d}} \leqq \mathrm{g}_{1} \quad \text { or } \quad \mathrm{g}_{2} \leqq \alpha_{\mathrm{d}} \leqq \pi, \text { with } \quad \mathrm{g}_{1} \leqq \mathrm{~g}_{2}
$$


With the experimentally found values for $r(0, H), r(\pi / 2, H), r(\pi, H), g_{1}$ and $g_{2}$ at hand, I assumed the effective indicatrix of that ship to be an ellipse for admissible values of $\alpha_{d}$ and a straight line segment for the prohibited sector. This is shown in figure 4.5 . b.
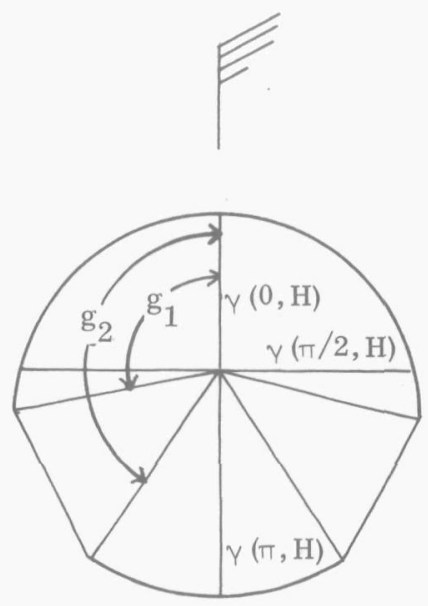

Figure 4.5.b.

\subsubsection{Scientific approach.}

In this country, a scientific research of various aspects of a ship's behaviour in sea waves is being coordinated by the Netherlands Ship Research Centre T.N.O. This institution has issued reports of investigations, carried out at the Shipbuilding Laboratory of this technological university and at the Netherlands Ship Model Basin (N.S. P.) in Wageningen.

A brief summary of the results of this work will now be given.

If a ship is moving through a wave field at an average speed s with respect to the water, the sea waves work as an input for several oscillatory ship movements, the most important of them being:

1. Heaving: Vertical oscillation of the ship's gravity centre G.

2. Swaying: Horizontal thwartships oscillation of $\mathrm{G}$.

3. Pitching: Angular oscillation about a thwartships axis through G.

4. Rolling: Angular oscillation about a longships axis through G.

5. Yawing: Angular oscillation about an axis, perpendicular to the axes of 
rolling and pitching. Yawing can also be identified with an oscillatory alteration of the ship's compass course.

In an attempt to analyse these movements, the principle of linear superposition was adopted:

a. The sea wave pattern is assumed to be a linear combination of sinewaves with frequencies varying from zero to infınity, each with its own amplitude and phase.

The Pierson-Moskowitz model was selected as the most appropriate one to work with.

b. The ship's movement as a response to this composite sea can be regarded as a linear combination of sinussoidal responses to the various sine components of the wave pattern, each response with its own amplitude gain and fase lag with respect to the sinussoidal input oscillation.

Although these assumptions may make the impression of being somewhat hazardous, the results have so far proved to be rather useful. The ship's responses can be characterized by complex numbers with a module equal to the amplitude ratio (output/input) and with an argument equalling the fase lag of the output oscillation relative to the wave input.

In an attempt to enlighten the use of these complex numbers by means of a few examples, let us adopt the following notations:

$$
\begin{aligned}
& \eta, \eta_{a} \quad: \text { Wave height and amplitude, } \\
& \sigma, \sigma * \quad \text { : True and apparent wave circular frequency, } \\
& \mathrm{z}_{\mathrm{a}}, \mathrm{y}_{\mathrm{a}} \quad \text { : Heaving and swaying amplitudes, } \\
& \beta, \beta_{\mathrm{a}} \quad \text { : Pitching angle and amplitude, } \\
& \varphi, \varphi_{\mathrm{a}} \quad \text { : Rolling angle and amplitude, } \\
& \alpha, \alpha_{\mathrm{a}} \quad \text { : Yawing angle and amplitude, } \\
& A_{z}^{2}, A_{\eta}^{2} \text { etc. : Spectral functions of the corresponding quantities, } \\
& \mathrm{H}_{\mathrm{z}}^{\eta}, \mathrm{H}_{\beta}^{\eta} \text { etc. : Frequency responses of } \mathrm{z}, \beta \text { etc. } \\
& \varepsilon_{\mathrm{z}}^{\eta} \text {, etc. : Arguments of the complex numbers } \mathrm{H}_{\mathrm{z}}^{\eta} \text { etc. , } \\
& \mathrm{m}_{\mathrm{z}}, \mathrm{m}_{\mathrm{y}} \text { etc. : Mean squares of } \mathrm{z}, \mathrm{y} \text { etc. }
\end{aligned}
$$

The quantities $\sigma$ and $\sigma^{*}$ are related by 


$$
\sigma^{*}=\sigma+\sigma^{2} \mathrm{~s} \cos \left(\theta-\theta_{\mathrm{d}}\right) / \mathrm{g} \text {. }
$$

(Without loss of generality the ship's course is taken zero)

Furthermore, put $\theta^{*}=\theta-\theta_{d}$.

Let $A_{\eta}^{2}$ be known as a function of $\sigma$ and $\theta$. Then use (4.5.2.1) to transform $\mathrm{A}_{\eta}^{2}$ to a function of $\sigma^{*}$ and $\theta^{*}$.

The other spectral functions can now be found from

$\mathrm{A}_{\mathrm{z}}=\left|\mathrm{H}_{\mathrm{z}}^{\eta}\right| \mathrm{A}_{\eta}, \quad \mathrm{A}_{\mathrm{y}}=\left|\mathrm{H}_{\mathrm{y}}^{\eta}\right| \mathrm{A}_{\eta}, \quad \mathrm{A}_{\beta}=\left|\mathrm{H}_{\beta}^{\eta}\right| \mathrm{A}_{\eta} \mathrm{k} \cos \theta \quad$ and

$\mathrm{A}_{\varphi}=\left|\mathrm{H}_{\varphi}^{\eta}\right| \mathrm{A}_{\eta} \mathrm{k} \sin \theta$

Regarding the last two expressions it can be remarked that the input amplitudes for pitching and rolling oscillations are $\mathrm{k} \eta_{a} \cos \theta$ and $\mathrm{k} \eta_{a} \sin \theta$ respectively. As for the yawing response $\mathrm{H}_{\alpha}^{\eta}$ it can be noted that this complex number is dependent of both $\sigma^{*}$ and $\theta$, probably like

$$
\mathrm{H}\left(\sigma^{*}, \theta\right)=\mathrm{K}_{\alpha}^{\eta}\left(\sigma^{*}\right) \sin 2 \theta
$$

For the rest, little or nothing is known about this quantity numerically.

For the heaving we can now give the stochastic representation

$$
\mathrm{z}=\int_{-\pi / 2}^{\pi / 2} \int_{0}^{\infty} \mathrm{A}_{\mathrm{z}} \cos \left(\sigma * \mathrm{t}+\epsilon+\epsilon_{\mathrm{z}}^{\eta}\right) \sqrt{(\mathrm{d} \sigma * \mathrm{~d} \theta *)}
$$

where $€$ is a stochastic variable with a uniform distribution over $(0,2 \pi)$.

The mean square follows from $m_{z}=\int_{-\pi / 2}^{\pi / 2} \int_{0}^{\infty} A_{z}^{2}\left(\sigma^{*}, \theta^{*}\right) d \sigma^{*} d \theta^{*}$

The probability for an amplitude to exceed a given value can be found from Rayleigh's formula

$$
\mathrm{P}\left[\beta_{\mathrm{a}} \geqq \mathrm{B}\right]=\frac{1}{\mathrm{~m}_{\beta}} \int_{\mathrm{B}}^{\infty} \mathrm{x} \exp \left(-\frac{\mathrm{x}^{2}}{2 \mathrm{~m}_{\beta}}\right) \mathrm{dx}=\exp \left(-\frac{\mathrm{B}^{2}}{2 \mathrm{~m}_{\beta}}\right)
$$

For the other quantities we have analogous expressions. Concentrating now on the case $\theta_{d}=0$ (ship's head to wind), we can evaluate the chance that the ship makes water on deck and hatches. To do this, we have to find an expression 
for the total water height at the ship's stem. Denoting this quantity by $S$, we have $S=\operatorname{Re}\left\{\eta_{b}-z+\frac{L}{2} \beta\right\}$, where $L$ is the ship's length and $\eta_{\mathrm{b}}=\eta_{\mathrm{a}} \exp \left(\mathrm{i}\left(\sigma * \mathrm{t}+\frac{1}{2} \mathrm{~kL} \cos \theta\right)\right)$.

With $\mathrm{z} / \eta_{\mathrm{a}}=\mathrm{H}_{\mathrm{z}}^{\eta} \exp (\mathbf{i} \sigma * \mathrm{t}), \quad \beta /\left(\eta_{\mathrm{a}} \mathrm{k} \cos \theta\right)=\mathrm{H}_{\beta}^{\eta} \exp (\mathrm{i} \sigma * \mathrm{t})$ and $\eta_{\mathrm{b}} / \eta_{\mathrm{a}}=\exp \left(\mathrm{i}\left(\frac{1}{2} \mathrm{~kL} \cos \theta+\sigma * \mathrm{t}\right)\right)=\mathrm{H}_{\eta}^{\eta} \exp (\mathrm{i} \sigma * \mathrm{t})$ we find:

$$
\mathrm{S}=\operatorname{Re}\left\{\eta_{\mathrm{a}}\left(\mathrm{H}_{\eta}^{\eta}-\mathrm{H}_{\mathrm{z}}^{\eta}+\frac{1}{2} \mathrm{~kL} \cos \theta \mathrm{H}_{\beta}^{\eta}\right) \exp (\mathrm{i} \sigma * \mathrm{t})\right\}
$$

Denoting this by $\mathrm{S}=\operatorname{Re}\left\{\eta_{\mathrm{a}} \mathrm{H}_{\mathrm{S}}^{\eta} \exp \left(\mathrm{i} \sigma^{*} \mathrm{t}\right)\right\}$, we can find the mean square of this value by taking

$$
\mathrm{m}_{\mathrm{s}}=\int_{-\pi / 2}^{\pi / 2} \int_{0}^{\infty}\left|\mathrm{H}_{\mathrm{s}}^{\eta}\right|^{2} \mathrm{~A}_{\eta}^{2} \mathrm{~d} \sigma * \mathrm{~d} \theta
$$

If the ship makes water on deck, the amplitude $\mathrm{S}_{\mathrm{a}}{ }^{\mathrm{f}} \mathrm{S}$ exceeds the freeboard's height at the stem. The probability that this occurs, can now be evaluated by using Rayleigh's distribution formula. On the other hand the frequency responses of $\beta$ and $z$ enables one to calculate the speed $S$, at which the probability of making water does not exceed a desired upper bound.

The avoidance of slamming - the ship's hull rises above the sea and then slams the sea surface, causing a short, but rather frightening vibration of the ship's structure - can be treated in an analogous way.

Stated very briefly and generally, a captain's set of wishes with regard to the avoidance of various undesired phenomena and the knowledge of the ship's responses can thus lead to the evaluation of a best possible speed for various courses in a given wave field. The knowledge of the ship's responses can also serve to compute the ship's resistance increase in waves. This resistance increase has been found to be determined by the wave amplitude, the ship's dimensions and the values of the heaving and pitching responses. Thus one can get a fair idea about the ship's speed in a given wave pattern, if the engines are working at maximal power capacity. 
5.1. Oceangraphic and meteorological data.

In the Kahn projection of the concerned area - I suggest to concentrate on the North Atlantic from now on - the $\mathrm{X}$-axis is taken to be the mapping of the central great circle from Bishop Rock, starting point of ocean navigation for West bound merchant craft, to Providence Channel near the Bahama Islands. The origin is the mapping of a point on the earth with coordinates $49^{\circ} \mathrm{N}, 7^{\circ} \mathrm{W}$. The mapping of a stretch of 200 nautical miles, i.e. $\frac{200 \pi R}{180 * 60}$, is taken as a unit of length, where $\mathrm{R}$ is the radius of the sphere on which the ellipsoid was conformally mapped. The points with integer coordinates are now taken as data grid points. This implies that the sea current and sea wave data are introduced as an array, like sxr, syr, hzr, $\operatorname{tzr}[0: 18,-3: 5]$.

The array sxr, syr gets the values of the ocean current components for time stretches of 12 hours. The elements hzr and tzr are the significant wave heights and the mean directions these waves come from. The $200 * 200 \mathrm{~m}^{2}$ grid is sufficiently dense to serve as a basis for computing the current components and the wave direction for arbitrary coordinates by means of linear interpolation. As for the wave heights, the grid is occasionally liable to neglect small areas of exceptionally high waves. To meet this imperfection, the partial derivatives of the wave heights with respect to $\mathrm{x}$ and $\mathrm{y}$ were also taken into account. The wave data can be taken from wave prediction charts, constructed by the K. N. M.I. routeing office. These charts are still made up manually, taking account of wind velocity, duration and fetch. Automation of this procedure is being studied, but results fit for practical use have not yet been attained.

As the meteorological situation seldom or never can be taken stationary, it is necessary to calculate the wave heights and directions and to have them read in by the computer at the beginning of each step of integration, which is a 12 hours time stretch.

Weather forecasts and weather maps have until now never been produced for more than five days ahead. This means that for the future time, that exceeds this period, - a North Atlantic crossing takes a merchant ship some 7 to 11 days - an estimation of the weather situation has to be made up. This could be done, for instance, by assuming that the periodicity with regard to wind 
velocity and direction, concluded from the 3-to-5-days-ahead weather forecasts, is being extrapolated over the rest of the crossing time. As for the wave heights to be deduced from these rough weather estimations, it seems reasonable to assume a fully aroused sea, thus simplifying the calculation of wave heights for those areas, where one guess is just as good as any other one.

The uncertain area, implied by the limitation in forecasting period, has the advantage of being further away than the area, the ship is going to cross first and it reduces to zero as soon as the ship is so close to its destination, that the reliable weather forecasting period is greater than the rest of the trip's duration.

The data for the ocean current components can be taken from statistical issues like the U.S. Hydrographic Office Pilot Charts. Because of their small magnitude they can be taken constant for a trip's duration.

\subsection{Evaluating the timefronts.}

Suppose the coordinates of a number of points of a timefront $S_{j}$ - for a time $t_{j}=t_{0}+j^{*} 12^{h}-$ are known. Denote these coordinates by $x[i, 0]$ and $y[i, 0]$, with $i=i k(1) i m$.

The timefront gradient's direction (a) can now be approximated:

aa: $=\arctan ((\mathrm{x}[\mathrm{i}+1,0]-\mathrm{x}[\mathrm{i}, 0]) /(\mathrm{y}[\mathrm{i}, 0]-\mathrm{y}[\mathrm{i}+1,0])) \quad$ and

$b b:=\arctan ((x[i, 0]-x[i-1,0]) /(y[i-1,0]-y[i, 0]))$.

If $\mathrm{i}=\mathrm{ik}$ then $\mathrm{a}:=\mathrm{aa}$, if $\mathrm{ik}<\mathrm{i}<\mathrm{im}$ then $\mathrm{a}:=(\mathrm{a} a+b b) / 2$ and

if $\mathrm{i}=\mathrm{im}$ then $\mathrm{a}:=\mathrm{bb}$. This process can be executed by calling a previously declared procedure "normaal".

The first (Euler-) approximation of points of $\mathrm{S}_{\mathbf{j}+1}$ is now computed by calling the procedure "optistep", which will now be briefly described. The wave height and direction are determined as indicated in 5.1. The ship's response to these waves is characterized by five parameters $d_{1}, d_{2}, d_{3}, g_{1}, g_{2}$, shown in figure 5.2.a.

Given the timefront gradient's direction relative to the mean wind direction:

$$
\psi=\mathrm{a}-\mathrm{tz}
$$

the problem of determining the ship's $12^{\mathrm{h}}$-displacement vector that has a maximal inner product with the vector $(\cos \psi, \sin \psi)$ can now be solved. As for the curvilinear parts of the $12^{\mathrm{h}}$-position indicatrix this amounts to determining the polar line of the point with homogeneous coordinates $(-\sin \psi, \cos \psi, 0)$ 


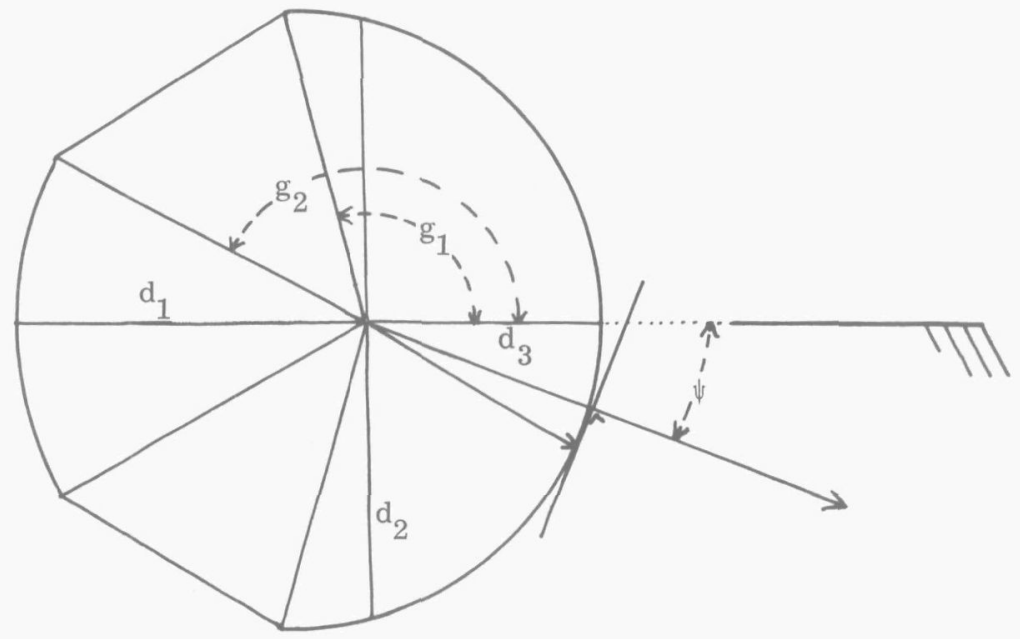

Figure 5.2, a.

with respect to the ellipse. Denoting this "conjugate gradient direction" by $\varphi$, the angle $\varphi+$ tz can be taken as the ship's course, provided $|\varphi| \leqq g_{1}$ or $|\varphi| \geqq g_{2}$.

If $\mathrm{g}_{1}<|\varphi|<\mathrm{g}_{2}$, the maximum principle would prescribe to take either $+\mathrm{g}_{1}+\mathrm{tz}$ or $\pm \mathrm{g}_{2}+\mathrm{tz}$ as the ship's course, depending on which of the corresponding velocity vectors has the greatest inner product with (cos $\psi, \sin \psi)$. However, on account of the $12^{\mathrm{h}}$-step integrating procedure, this policy might cause an unpractical accumulation and even a coincidence of points of the next timefront. Therefore, the ship's displacement (relative to water) is taken in the "course" $\varphi+t z$, from the centre of the indicatrix to a point on the rectilinear part. This point can be reached by steering courses $\pm g_{1}+t z$ and $\pm g_{2}+t z$ in a proper time ratio.

In both cases - free and bounded courses - the vector of the ship's indicatrix, obtained in the just described way, gives the ship's displacement for 12 hours, relative to the water. This vector $(\mathrm{dx}, \mathrm{dy})$ is now, together with the sea current components, added to the ship's starting position $(\mathrm{x}[\mathrm{i}, 0], \mathrm{y}[\mathrm{i}, 0])$, which gives the Euler approximation of the point of $S_{j+1}$ with index $i$.

A Heun approximation of these points is now obtained by carrying out the "optistep"-procedure once more for this first approximation $(x[i, 1], y[i, 1])$, using wave heights expected at a time $t_{0}+(j+1)^{*} 12^{h}$. This results in another displacement (dx, dy), including sea current. 
The point of $\mathrm{S}_{\mathbf{j}+\mathbf{1}}$ with index $\mathrm{i}$ is now taken:

$$
x[i, 2]:=(x[i, 0]+d x+x[i, 1]) / 2 \text { and } y[i, 2]:=(y[i, 0]+d y+y[i, 1]) / 2 \text {. }
$$

The Euler approximations of points of the first timefront are obtained by taking:

$$
\mathrm{a}:=\pi^{\prime}(25-\mathrm{i}) / 180 \text { with } \mathrm{i}=0(1) 40 .
$$

This way the area is scanned by a sector of $40^{\circ}$ width, which produces a timefront of some 1600 miles length after 7 days. Selecting the initial values of a with $1^{\circ}$ intervals, the mutual distance between consecutive points of a timefront is liable to become too large. To prevent this, a refining procedure is declared, adding half-way-between points to the timefront points, as soon as they are more than 40 miles apart.

Special precautions must be taken in the event that the region's boundary prevents free extremals from covering part of the area. This is actually the case after passing the New-Foundland bank. With Northerly winds off the New-England coast, the free extremals are even inclined to bend Southward, so that an area with favourable navigating conditions because of its position close to a windward coast may remain uncovered. This can be avoided by the addition of a sector of "subextremals", as described in the last paragraph of the 3rd chapter.

\subsection{Revision of the timefronts.}

When passing regions of high waves or regions with considerable vorticity in the field of wind vectors - these phenomena frequently coincide - the field of extremals is liable to be split up into three families (as described in 3.8), one of which is irrelevant for the solution of the problem. Therefore the trajectories with ultimate points for a time $t$, that are not located at the very border of $\mathrm{H}_{\mathrm{t}}$, have to be eliminated. Because of the various possibilities of configurations, this eliminating process is carried out by two procedures, called "ontlussen" and "schoonmaak".

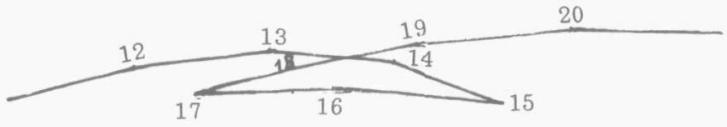

Figure 5.3.a. 
In the event of overlapping timefronts, like shown in figure 5. 3.a., the points with indices 14(1)18 are deleted. This kind of configuration is traced by seeing if a timefront segment between points with indices $i$ and $i+1$ has an intersection with any of the following segments. Another possible configuration is shown in figure 5. 3. b.

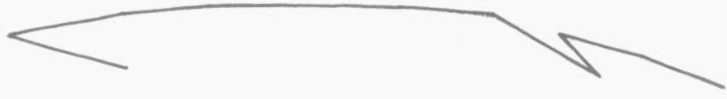

Figure 5.3.b,

This situation is checked for by seeing if the extension of the segment of a trajectory from $S_{j-1}$ to $S_{j}$ has an intersection with any of the segments between two consecutive points of timefront $\mathrm{S}_{\mathrm{j}}$.

A procedure "rand" cancels points of a timefront, that lie outside of $G$, the navigating area.

Data regarding stream and sea in gridpoints just outside of $\mathrm{G}$ are not changed. Assumption of extremely high wave heights in those points might work as a prevention of coming outside of $\mathrm{G}$, but this trick has the disadvantage that trajectories with arcs close to a coastline are thus being eliminated, while these routes can be favourable, especially in case of an off shore wind.

\subsection{Determination of the trajectory and the time gain.}

As soon as the destination is estimated to be less than 48 hours away, a search is started to see, if the destination $B$ is located between $S_{j}$ and $S_{j-1}$. This is executed by starting with tracing the index " $\mathrm{i}_{0}$ " of the point of $\mathrm{S}_{\mathrm{j}-1}$ closest to $\mathrm{B}$. Then B is checked on lying in one of the quadrangles, formed by the points with indices $\left[i_{0}, 0\right],\left[i_{0}, 2\right],\left[i_{0}-1,2\right]$ and $\left[i_{0}-1,0\right]$ or

$$
\left[i_{0}, 0\right],\left[i_{0}, 2\right],\left[i_{0}+1,2\right] \text { and }\left[i_{0}+1,0\right] \text {. }
$$

As soon as this is found to be true, the arrival time and the initial value of the timefront gradient can be evaluated. The least time track can then be constructed.

A fair idea about the time gain of the optimal track can be obtained by comparing it with the time, needed for the same ship to cross the same composition of 


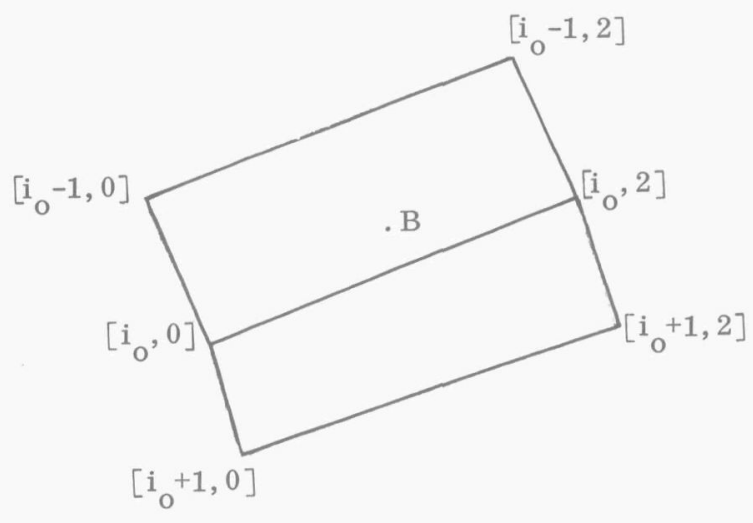

Figure 5.4.a.

obstacles when steering a great circle's course. Replacing this great circle by a straight line in the Kahn projection - which is allowable on account of the very slight scale alteration in this chart - the positions on this line at the end of each 12 hours interval can be computed by calling a procedure named "stap".

\subsection{The Algol program to compute the least time track.}

This paragraph mainly contains a program in Algol code, to compute the least time track between two arbitrary points. The program was used to execute this for a ship, starting from a point near Bishop Rock on March 1st ' $67,00^{\mathrm{h}}$ G. m.t. and bound for a point near Nantucket Shoals, from where it can navigate to New York without further routeing support.

The result of the computation, carried out on an I. C. T. -1905 computer, operating at the mathematical department of this technical university, is exhibited on the North Atlantic chart, folded in at the inside back cover. The, yet unrevised, timefronts $\mathrm{S}_{0.5}, \mathrm{~S}_{1}$ etc. and the extremal trajectory were copied from a Calcomp plotter, which is attached to the I. C. T. -computer.

To illustrate the - time dependent - wave field, arrows are drawn near the timefronts, indicating the mean wave direction at the corresponding time and position. The adjoint numbers give the significant wave heights in meters. Fully drawn arrows indicate wind driven sea waves, while dashed arrows represent swell.

The dotted line from $(0,0)$ to $(13,-1)$ is the great circle track. The small crosses on this line are the positions on this track after a half day, one day etc. 
FI $A \times A L E \# D I S C \uparrow \star$

GO\#XALE2O^*

- SENDTO' (ED, SEMICOMPFILE, .PRDGRAM WO12)

- PROGRAM" (WO12)

- INPUT $\cdot O=C R O$

- OUTPUT' $0=L P O$

-CREATE ' 15=MTO(PLOTTAPE $(1,0))$

- BEGIN' 'INTEGER'I, J,H,K, IK, IM, F, G, I 0, I 1, I0, J1, IK 1, IM 1 ;

'PROCFDURE'PLOTSTART; 'ALGOL';

- PROCEDURE'PLOT (I, A,B); 'INTEGEP' I; 'RE AL'A,B; 'EXTERNAL';

CWO 12000

CW012001

CW01201A

- PROCEDURE'PLOTFRAME (XMIND, XMAXD, YMIND, YMAXD, XMAXP, YMAXP,SCX,SCY); CWO1201B

-REAL - XMIND, XMAXD, YMIND, YMAXD, SCX, SCY;

- INTEGER ' XMAXP, YMAXP;'ALGOL';

CW01201C

CW01201D

- BOOLEAN'ALFA, BETA; REAL'A,B,PI, DX, DY, XO, YO, XB, YB, GR, L, M, N, O,P, Q, R, S, CWO12002 GK, SGK, XGK, YGK, COSGK, SINGK,

CW01202A

$T, X I I, Y I I, X H I, Y H I, X H H, Y H H, D E T, D M I N, P P, Q Q, R R, S S, X K, Y K$;

- INTEGER' 'ARRAY ' NU, MU $[1: 20,1: 17], 1 B, I \in[1: 17]$;

CW012003

CW012004

- ARRAY.SXR, SYR, HZR, HRX, HRY, TZR[0:14,-2: 7$], X, Y[0: 60,0: 2], U, V[0: 60,0: 17], C W 012005$ D, COSPSIG[ $1: 3,0: 30], D E, \operatorname{COSGR} 1: 3], D X G R, D Y G R, S I N G[1: 2] ;$

CW 12006

-PROCEDURE. NORMAAL $(X, Y, I I, J J, A A)$; ARRAY'X,Y; INTEGER'II,JJ;'REAL'AA; CWOI2OOT

'BEGIN' 'REAL'DH,EH,DT, ET, BB; 'IF' I I <IM. THEN'

- BEGIN,DH: =X[II+1, JJ]-X[II, JJ];EH:=Y[II,JJ]-Y[II+1,JJ];

' IF'ABS(DH) $\angle A B S(E H)$ 'THEN'AA: = ARCTAN(DH/EH) 'ELSE' $A A:=P I \star S I G N(D H) \star S I G N(E H) / 2-\triangle R C T A N(E H / D H)$

'END';'IF'II I IK' THEN"

- BEGIN'DT: $=X[I I, J J]-X[I I-1, J J] ; E T:=Y[I I-1, J J]-Y[I I, J J] ;$

' IF'ABS(DF) $<A B S(E T)$ THEN'BB: = ARCTAN (DT/ET)

- ELSE $B B:=P I$ \&IGN(DT) $B$ SIGN(FT)/2-ARCTAN(ET/DT)

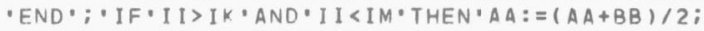

- IF $I I=I M \cdot T H E N \cdot A A:=B B$

CW012008

CW012009

CWO12010

CWO12011

CWO12012

CWO12013

CWO12014

CW012015

CWO12016

CWO12017

- END.NORMAAL;

- PROCEDURE' OPT ISTEP(XS, YS, A); 'REAL' XS, YS, A;

- BEGIN. REAL 'FP, FPC, FQ,FQC, TZ, HZ, TZO, TZ1, TZOO, TZO1,TZ10,

$T Z 11, H Z 1, H Z 2, A I, B I, E I, C O P S I, S I D S I, D X 1, D Y 1, C O S T Z, S I N T Z$;

$H:=E N T I E R(X S) ; K:=E N T I E R(Y S) ; F P:=X S-H ; F P C:=1-F P$;

CW012018

CW012019

CW012020

CWO12021

CW012022

$F Q:=Y S-K ; F Q C:=1-F Q$;

$D X:=F Q C \star(F P C \star S \times R[H, K]+F P \star S X R[H+1, K])$

$+F Q \star(F P C \star S X R[H, K+1]+F P \star S X R[H+1, K+1]) ;$

$D Y:=F Q C \star(F P C \star S Y R[H, K]+F P \star S Y R[H+1, K])$

$+F Q \star(F P C \star S Y R[H, K+1]+F P \star S Y R[L+1, K+1]):$

$H Z 1:=F P C *(H Z R[H, K]+F P * H R \times[H, K])+F P \star(H Z R[H+1, K]$ $-F P C \star H R \times[H+1, K])$;

$H Z 2:=F P C \star(H Z R[H, K+1]+F P \star H R x[H, K+1])$

$+F P \star(H Z R[H+1, K+1]-F P C \star H R \times[H+1, K+1]) ;$

$H Z:=F Q C \star(H Z 1+F Q \star(F P C \star H R Y[H, K]+F P \star H R Y[H+1, K]))$

$+F Q \star(H Z 2-F Q C \star(F P C \star H R Y[H, K+1]+F P \star H R Y[H+1, K+1])) ;$

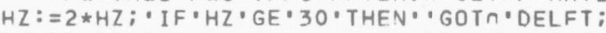

$T Z 00:=T Z R[H, K] ; T Z 01:=T Z R[H, K+17:$

$T Z 10:=T Z R[H+1, K] ; T Z 11:=T Z R[H+1, K+1] ;$

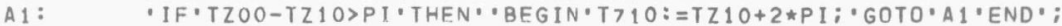

CW012023

CW012024

CWO12025

CWO12026

CW012027

CW012028

CWO12029

CW012030

CWO 12031

CWO12032

CW012033

CWO12034

CWO 12035

CWO12036

CW012037

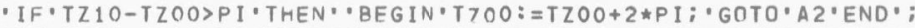

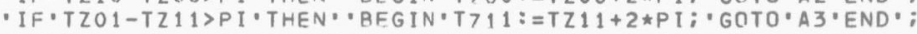

CW012038

CWO 12039

CW012040

$T Z O:=F P C \star T Z O O+F P \star T Z 10 ; T Z 1:=F P C \star T Z O 1+F P \star T Z 11 ;$

- IF' TZO-TZ1>PI ' THEN ' BEGIN 'TZ1: $=T Z 1+2 \star P I ; \cdot G O T O \cdot A 5$ 'END';

CW012041

CW012042 
A6

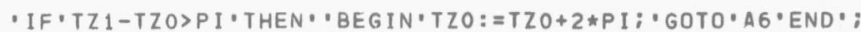

CW012043

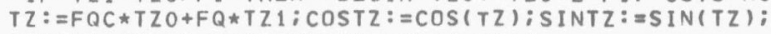

COPSI $:=\operatorname{COS}(A-T Z) ; \operatorname{SIPSI}:=\operatorname{SIN}(A-T Z) ;$

$H:=E N T I E R(H Z) ; F P:=H Z-H ; F P C:=1-F P$;

- $F O R \cdot K:=1,2,3 \cdot D O \cdot D E[K]:=D[K, H] \star F P C+D[K, H+1] \star F P$;

CWO12044

CW012045

CW012046

CW012047

- FOR $K:=1,2 \cdot D O \cdot \operatorname{COSG}[K]:=F P C * \operatorname{COSPSIG}[K, H]+F P * \operatorname{COSPSIG}[K, H+1] ; \quad C W \quad 12048$

$A I:=(D E[1]+D E[3]) / 2 ; E I:=D E[1]-A I ; B I:=A I * D E[2] / S Q R T(D E[1] \star D E[3]) C W 012049$

; 'IF ' COPSI GE ' COSG[1] OR ' COPSI I E' $\operatorname{COSG}[2] \cdot$ THEN '

- BEGIN?P:=AI*COPSI; $Q:=B I * S I P S I ; R:=S Q R T(P \star P+Q \star Q)$;

$D \times 1:=A I \star P / R-E I ; D Y I:=B I \star Q / R$ :

CW012050

CW012051

CW012052

$D X:=D X+D X 1 * \operatorname{COSTZ} Z-D Y 1 * S I N T Z ;$

DY: $=D Y+D X 1 * S I N T Z+D Y 1 * \operatorname{COSTZ;\cdot GOTO\cdot DELFT}$

- END'; $, F O R \cdot K:=1,2 \cdot D O \cdot$

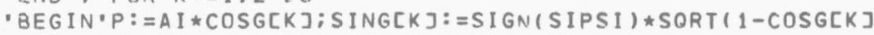

$\star \operatorname{COSG}[K]) ; Q:=B I \star S I N G[K] ; R:=S Q R T(P \star P+Q \star Q) ;$

CWO 12053

CW012054

CW012055

CW012056

CW012057

DXGR[K]: =AI

-END ; FP: $=(\operatorname{COSG}[1]-\operatorname{COPS} 1) /(\operatorname{COSG}[1]-\operatorname{COSG}[2]) ; F P C:=1-F P ;$

CW012058

$D \times 1:=F P \star D X G R[2]+F P C \star D X G R[1]-E I ; D Y 1:=F P \star D Y G R[2]+F P C \star D Y G R[1] ;$

CW012059

CWO12060

$D X:=D X+D X 1 * C O S T Z-D Y 1 * S I N T Z ; D Y:=D Y+D X 1 * S I N T Z+D Y 1 * C O S T Z ;$

CWO12063

DELFT : $\quad S:=P I *(Y S+D Y / 2) / 54 ; S:=(E X P(S)+E X P(-S)) / 2 ; D X:=S * D X ; D Y:=S * D Y$

CW012064

- END- OPT ISTEP;

- PROCEDURE' ONTLUSSEN:

- BEGIN I $:=I K ; H:=I+2$;

LL1: $\quad X I I:=X[I+1,2]-X[I, 2] ; Y I I:=Y[I+1,2]-Y[I, 2] ;$

CW012065

CWO12066

CW012067

CW012068

LL2: $\quad X H I:=X[H+1,2]-X[I, 2] ; Y H I:=Y[H+1,2]-Y[I, 2] ;$

CW012069

$X H H:=X[H+1,2]-X[H, 2] ; Y H H:=Y[H+1,2]-Y[H, 2] ; D E T:=X I I * Y H H-Y I I * X H H ; C W 012070$

$\mathrm{L}:=(X H I * Y H H-Y H I * X H H) / D E T ; M:=(X I I * Y H I-Y I I * X H I) / D E T$;

CW012071

' IF'L>O'AND'L'LE' $1 \cdot A N D \cdot M>0 \cdot A N D \cdot M \cdot L E \cdot I \cdot T H E N \cdot$

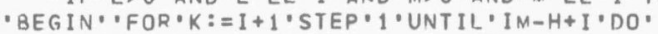

- BEGIN'X[K,O]: =X[K+H-I,O];Y[K,O]: $=Y[K+H-I, 0] ;$

CW012072

CW012073

CW012074

$X[K, 2]:=X[K+H-I, 2] ; Y[K, 2]:=v[K+H-I, 2]$

- END'; IM: $=I M-H+I ; I:=I+1 ; H:=I+2 ; \cdot I F \cdot H<I M \cdot T H E N \cdot G O T O \cdot L L 1$

-ELSE'-GOTO'LO

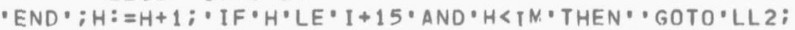

$I:=I+1 ; H:=I+2 ;$ ' IF'H $\angle I M$ ' THEN' 'GNTO'LL 1 ;

CW012075

CW012076

CW012077

CW012078

CW012079

LO: - ENDי ONTLUSSEN:

- PROCEDURE'SCHOONMAAK;

'BEGIN' 'FOR'I : =IK'STEP' 1 'UNTIL'IM D DO

L1: $\quad$ BEGIN'XII: $=X[1,2]-X[1,0] ; Y I I:=Y[1,2]-Y[1,0] ;$

'FOF'H: $=I K \cdot S T E P \cdot 1 \cdot U N T I L \cdot I M \cdot D O \cdot$

CW012080

CW012081

CW 12083

CWO12084

CW012085

-BEGIN ' IF'H=I-1 OR ' H=I 'THEN 'GOTO'L 2 ;

$X H I:=X[H, 2]-X[1,0] ; Y H I:=Y[H, 2]-Y[I, 0] ;$

$X H H:=X[H, 2]-X[H+1,2] ; Y H H:=Y[H, 2]-Y[H+1,2] ;$

DET: $=X I I * Y H H-Y I I * X H H ; L:=(X H I * Y H H-Y H I * X H H) / D E T ;$

$M:=(X I I * Y H I-Y I I * X H I) / O E T ; \cdot I F \cdot L>I \cdot A N D \cdot M>0 \cdot A N D \cdot M<1 \cdot$ THEN

CW012086

CWO12087

CW012088

CWO12089

CW012090

'BEGIN' 'FOR'K: =I'STEP' 1 'UNT IL'IM-1'DO'

- BEGIN'X[K,O]: $=X[K+1,0] ; \forall[K, 0]:=Y[K+1,0]$;

$x[K, 2]:=x[K+1,2] ; y[K, 2]:=y[K+1,2]$

$\cdot$ ENO':

- END, ; IM: $=I M-1 ; \cdot$ GOTO $L 1$

CW012091

CWO12092

CWO12093

CW012094

CW012095

L2:

- ENDי

106

107

108

109

110

'END'; IF' IM-IK>20 'THEN ' H: $=20$. ELSF, H: $=I M-I \mathrm{~K}$;

- FOR'I $:=I K+1$ 'STEP' 1 'UNTIL'IK+H'DO'

CW012096

CW012097

CW012098

- BEGIN. L $3:$ IF'Y[I, 2]>Y[IK, 2] THEN .

CW01 2099

-BEGIN ' FOR' $K:=I$ 'STEP' 1 'UNTIL'IM-1'DO'

CW01299A 

- END.

- END';IM:=IM-1; GOTO'L3

'END'; FOR'I: =IM-H'STEP' 1 'UNTIL'IM-1 D D '

CWO $1299 \mathrm{C}$

CWO 12990

CWO1299E

CWO $1299 F$

- BEGIN' L4: IF' Y[I, 2]<Y[IM, 2]'THEN'

- BEGIN ' FOR'K: = I'STEP' 1 'UNTIL'TM-1'DO

- BEGIN $X[K, 0]:=X[K+1,0] ; Y[K, 0]:=Y[K+1,0]$; $X[K, 2]:=X[K+1,2] ; Y[K, 2]:=Y[K+1,2]$

CWO1299G

CWO1299H

CWO 12100 'END';IM: =IM-1;'GOTO'L 4

CWO12101

CW012102

'END.

CWO12103

- END.

- END. SCHOONMAAK:

-PROCEDURE'RAND;

CWO12104

CWO12105

CW012106

- BEGIN.

A 7 :

' IF, Y $[I K, 2]>2.5$ ' THEN 'BEGIN'IK: $=I K+1 ; \cdot G O T O \cdot A 7$ ' FND' ;

IF, X[IM, 2]<8.8. THEN

- BEGIN. AB: 'IF' Y IIM, 2]<-1.5 THFN'

- BEGIN'IM: =IM-1; 'GOTO'A 8

- END'

CW012108

CW012109

CWO12110

CW012111

CW012112

'END'; 'IF'X[IM, 2]'GE'8.8'AND'X[IM, 2$]<9.7 \cdot$ THEN

CWO12113

- BEGIN.

A9: IF. Y[IM, 2]<-0.9.THEN

- BEGIN'IM: $=I M-1 ; \cdot G O T O \cdot A 9$

- END';

CWO12114

CWO12115

CWO12116

CWO12117

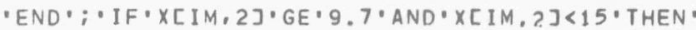

CW012118

- BEGIN. A10:,$I F \cdot Y[I M, 2]<-1.4 \cdot$ THEN.

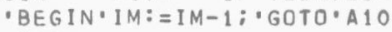

'END.

'END'; 'IF'X[IM, 2] 'GE' 15 'THEN'

CW012119

CWO12120

CWO12121

CW012122

- BEGIN. A11: 'IF.Y[IM, 2]<-1 THFN. CW012123

- BEGIN I IM: = IM-1; • GOTO'A11 CWO12124

- END.

CWO 12125

CW012126

CW012127

IEND'RAND;

CW012500

- PROCEDURE'STAP ;

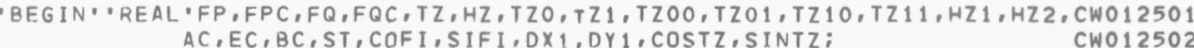

$H:=E N T I E R(X G K) ; K:=E N T I E R(Y G K) ; F P:=X G K-H ; F P C:=1-F P ; F O:=Y G K-K ; F Q C:=C W 012503$

$1-F Q ; S T:=(F Q C *(F P C \star S \times R[H, K]+F P \star S X R[H+1, K])+$

CW012504

\section{$F Q \star(F P C \star S X R[H, K+1]+F P \star S X R[H+1, K+1])) \star \operatorname{COSGK}$}

$+(F Q C \star(F P C \star S Y R[H, K]+F P \star S Y R[H+1, K])+$ $F Q \star(F P C \star S Y R[H, K+1]+F P \star S Y R[H+1, K+1])) \star S I N G K$

CW01254A

CW01254B

CWO $1254 \mathrm{C}$

$H Z 1:=F P C \star(H Z R[H, K]+F P \star H R \times[H, K]+O)+F P \star(H Z R[H+1, K]-F P C \star H R \times[H+1, K]) ; C W 012505$

$H Z 2:=F P C \star(H Z R[H, K+1]+F P \star H R \times[H, K+1])+F P \star(H Z R[H+1, K+1]-F P C \star H R \times[H+1, C W 012506$

$K+1]): H Z:=F Q C \star(H Z 1+F Q \star(F P C \star H R Y[H, K]+F P \star H R Y[H+1, K]))+$ $F Q \star(H Z 2-F Q C \star(F P C \star H R Y[H, K+1]+F P \star H R Y[H+1, K+1])) ; H Z:=2 \star H Z ;$

' IF'HZ'GF'30'THEN ' 'BEGIN'L: $=0 ; \cdot$ GOTO'ZWET'END' ;

CW012507

CW012508

CWO12509

$T Z 00:=T Z R[H, K] ; T Z 01:=T Z R[H, K+1] ; T Z 10:=T Z R[H+1, K] ; T Z 11:=T Z R[H+1, K+1] ; C W 012510$ AS1: IIF'TZOO-TZ10>PI'THEN'-BEGIN'TZ10:=TZ10+2*PI; GOTO'ASI'END';

CW 12511

AS2: 'IF'TZ10-TZOOOPI'THEN' BEGIN'TZO0: $=T Z 00+2 \star P 1 ; \cdot G 0 T 0 \cdot A S 2$ 'END';

CWO12512

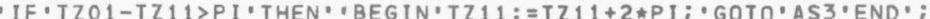

CWO12513

CWO12514

CWO12515 $T Z 0:=F P C * T Z 00+F P \star T Z 10 ; T Z 1:=F P C \star T Z \cap I+F P \star T Z 11 ;$

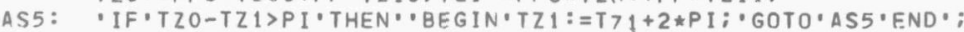


AS6: 'IF'TZ1-TZO>PI 'THEN -BEGIN 'TZO: $=T 70+2 \star P I ; \cdot G O T O \cdot A S 6$ 'END';

CWO12517

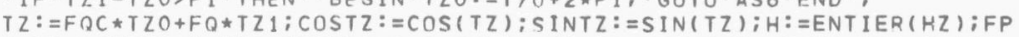
$:=H Z-H ; F P C:=1-F P ; \cdot F O R \cdot K:=1,2,3 \cdot D O \cdot N E[K]:=F P C \star D[K, H]+F P \star D[K, H+1] i$ - $F O R \cdot K:=1,2 \cdot D O \cdot \operatorname{COSG}[K]:=F P C \star C O S P S I \approx[K, H]+F P \star C O S P S I G[K, H+1] ; A C:=$ $D E[1]+D E[3]) / 2 ; E C:=D E[1]-A C ; B C:=A C \star D E[2] / S Q R T(D E[1] \star D E[3]) ; C O F I$

$=C O S(G K-T Z) ; S I F I:=S I N(G K-T Z) ; P:=R L \star B C \star C O F I ; Q:=A C \star A C \star S I F I ; R:=E C \star$

CWO 12522

$S I F I ; R:=R \star R ; S:=P \star C O F I ; T:=Q \star S I F I ; L:=(-P \star E C+A C \star B C \star S Q R T(T-R+S)) /(T+S) C W O 12523$ ;DXI: $:=L \star C O F I ; D Y 1:=L \star S I F I ; \cdot F O R \cdot I:=1,2 \cdot D 0^{\circ}$

CWO 12524

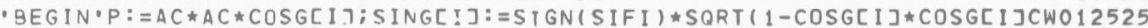
); $Q:=B C \star B C \star S I N G[I] ; R:=S Q R T(P \star C O S G[1]+Q \star S T N G[I]) ; D \times G R[I]:=P / R ; D Y G R$

CWO 12526

$[I]:=Q / R ; \cdot E N D \cdot ; \cdot I F \cdot D \times G R[2]<D \times 1+E C \cdot A N D \cdot D \times 1+F C<D \times G R[1] \cdot T H E N \cdot$

$L:=((D \times G R[1]-E C) \star D Y G R[2]-(D \times G R[2]-F C) * D Y G R[1]))$

$((D Y G R[2]-D Y G R[1]) \star C D F I+\vdots D \times G R[1]-D \times G R[2]) \star S I F I)$;

ZWET: $\quad D X:=(L+S T) \star C O S G K ; D Y:=(L+S T) \star S I N F K ;$ $S:=P I *(Y G K+D Y / 2) / 54 ; S:=(\operatorname{EXP}(S)+E X P(-S)) / 2 ;$

CW012527

CWO12528

CWO12529

CW012531

CWO12532

$D X:=S \star D X ; D Y:=S \star D Y ; \cdot E N D \cdot S T A P ;$

-PROCEDURE.FUIK;

- BEGIN?REAL, D;DMIN $:=1000 ; I 0:=0 ; \cdot F O R \cdot I:=I K \cdot S T E P \cdot 1 \cdot$ UNTIL'IM:DO - BEGIN.DX: $=X[I, O]-X B ; D Y:=Y[I, O]-Y R ; D:=S Q R T(D X * D X+D Y * D Y)$; 'IF'D'LE'DMIN'THEN *BEGIN'DMIN: =D; IO: =I'END'

CWO12533

CWO12128

CWO12129

CWO 12130

CWO12131

- END'; I1 $:=10-1 ; R R:=(X B-X[10,0]) \star(Y[10,2]-Y[10,0])-$ $(Y B-Y[10,0]) *(X[10,2]-X[10,0])$;

CONTROLE : $\quad P P:=(X B-X[I 0,0]) *(Y[I 1,0]-Y[T 0,0])$ $-(Y B-Y[10,0]) *(X[11,0]-X[10,0]) ;$ $Q Q:=(X B-X[10,2]) \star(Y[I 1,2]-Y[[0,2])$ $-(Y B-Y[I 0,2]) *(X[11,2]-X Y[0,2]) ;$ $S S:=(X B-X[I 1,0]) *(Y[I 1,2]-Y[I 1,0])$ $-(Y B-Y[I 1,0]) *(X[I 1,2]-X[I 1,0]) ;$

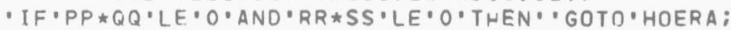
' IF' I $1=I 0-1$ ' THEN ' BEG IN' I $1:=10+1 ; \cdot$ GOTO ' CONTROLE'END' ;

CWO 12132 CWO12133

CWO12134

CWO12135

CW012136

CW012137

CWO 12138

CWO12139

CWO12140

CW012141

SELFCT OUTPUT $(0) ; \cdot$ GOTO'NOG NIET;

HOERA: J1:=J-1; ALFA: =-TRUE ; F : =IO;SELECT OUTPUT $(0)$;

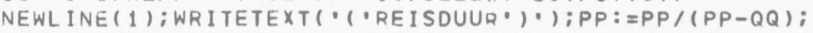
$K:=E N T I E R(J 1 / 2) ; D:=(J 1-2 \star K+P P) * 12 ; \operatorname{PRINT}(K, 3,0) ;$

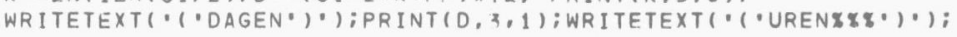

CWO12142 CWO12144 CWO12152 CWO12153 CWO 12154

WRITETEXT(' ('EINDINDEX \&BAANKROMME ') '); PRINT $(0,2,0) ;$ ' GOTO'L BB; NOG NIET: NEWLINE( 1$)$; WRITETEXT $(\cdot(\cdot R E I$ ISDUUR $>,) \cdot)$; PRINT $(J / 2,2,1)$; WRITETEXT( ( 'DAGEN $) \cdot)$;

LBB : 'END'FUIK; 'PROCEDURE' VERFYN ; - BEGIN'I : = IK;

CW012155 CW012159 CWO12160 CW012161 CW01261A

20: XII $:=X[I, 0]-X[I+1,0] ; Y I I:=Y[I, 0]-Y[I+1,0] ;$ . IF $X_{I I} I * X I J+Y I I * Y I I>0.04 \cdot T H E N$.

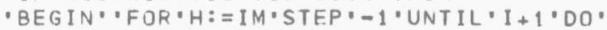
- BEGIN $X[\mathrm{H}+1,0]:=X[\mathrm{H}, 0] ; Y[\mathrm{H}+1,07:=Y[\mathrm{H}, 0]$

- END ' $X[I+1,0]:=X[I, 0]-X I I / 2 ; Y[I+1,0]:=Y[I, 0]-Y I I / 2$;

CWO1261B CW01261C CW01261D CW01261E CW01261F

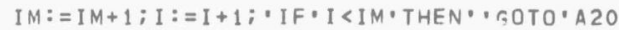
'ELSE' - GOTO'A21

- END' 'ELSE'

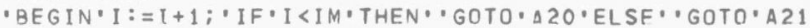
- END. ;

21 : 'END'VERFYN:PI $:=3.141592653590 ; G R:=P 1 / 180 ; B E T A:=$ 'TRUE';

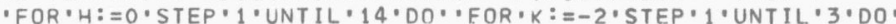
- BEGIN'SXR[H,K]:=READ; SYR[H,K]:=READ;

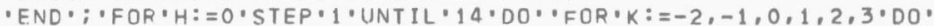

- BEGIN.HZR[H,K]:=READ; HRX[H,K]:=READ; HRY[H,K]: =READ;

CW01261G CW01261H CW012611 CW01261K CWO1261L

CW01261M CW012162 CWO12163 CW012164 CWO12165 
PLOTSTART; PLOTFRAME $(0,14,-1.5,2.5,4370,1248,0,0)$; PLOT $(1,0,-1.5) ; P L O T(2,0,2.5) ; P L O T(2,14,2.5) ; P L O T(2,14 .-1.4):$ $\operatorname{PLOT}(2,9.7,-1.4) ; \operatorname{PLOT}(2,9.7,-0.9) ; \operatorname{PL} \cap T(2,8.8,-0.9) ; \operatorname{PL} 0 T(2,8.8,-1.5) ;$ PLOT $(2,0,-1.5) ; \operatorname{PLOT}(1,0,0) ; \operatorname{PLOT}(2,14,0)$;

GK: = ARCTAN $(Y B-Y 0) /(X B-X 0)) ; U[0,0]:=X G K:=X O ; V[0,0]:=Y G K:=Y O ;$

CWO 12698

CWO $1269 C$

CWO 12690

CWO $1269 E$

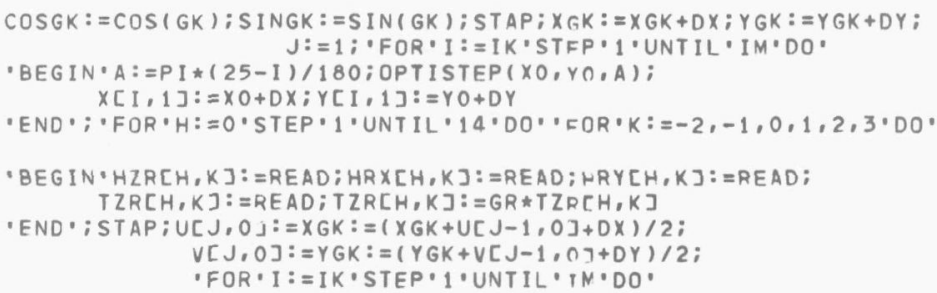

CWO1269F

CWO 12170

CWO12171

CWO12172

CWO 12173

CWO12174

CWO12175

CWO 12176

CWO12176

CWO1276A

- BEGIN-NORMAAL $(X, Y, I, 1, A)$; OPTISTEP $(X[I, 1], Y[I, 1], A)$; $X[I, 2]:=(X[I, 1]+X(0+D X) / 2 ; Y[I, 2]:=(Y[I, 1]+Y 0+D Y) / 2 ;$

- END'; SELECT OUTPUT $(15) ; P L O T(1, X[I K, 2], Y[I K, 2])$; 'FOR'I $:=I K \cdot S T E P \cdot 1$ 'UNTIL'IM'DO'

- BEGIN.PLOT $(2, X[1,2], Y[I, 2]) ; x[I, 0]:=U[I, J]:=x[I, 2]$;

CWO12177

CWO12178

CWO 12179

CWO12180

CWO12181

$Y[1,0]:=V[1, J]:=Y[1,2] \cdot E N D \cdot ; P L O T(1, X G K, Y G K+0.02) ; P L 0 T(2, X G K, Y G K-0.02) C W O 12182$ ;PLOT $(1, X G K-0.02, Y G K) ; P L \cap T(2, X G K+0.02, Y G K)$;

TYDFRONT: $J:=J+1$; ALFA: = 'FALSE ; SELECT OUTPUT 15 ; ; STAP: XGK: =XGK+DX;YGK: $=Y G K+D Y ;$ 'FOR'I: =IK'STEP'I.UNTIL'IM・DO*

CWO12183

CWO 12187

CWO1287A

CWO 12188

- BEG IN - NORMAAL $(X, Y, I, 0, A) ; O P T I S T E P(X[I, 0], Y[I, 0], A)$; $X[I, 1]:=X[I, 0]+D X ; Y[1,1]:=Y[1,0]+D Y$

'END, ; IG[J-1]:=100; IF:X[IM, 0]>9.3'AND'BETA THEN *

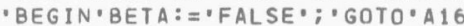

- END.; IF'A $>-5 \star G R \cdot A N D \cdot X[I M, 0]>9.3 \cdot T H F N \cdot$

A 16 : 'BEGIN'F: $=15 ;$ 'IF'IM>45'THEN $\mathrm{IM}:=60-I M ; I G[J-1]:=I M$; 'FOR'I: $=I M+1$ 'STEP' 1 'UNTIL'IM+F, DO'

- BEGIN'A: =A-GR;X[I,O]: =X[IM,O];Y[I,0]: =Y[IM,O]: OPT ISTEP $(X[1,0], Y[I, 0], A) ; X[1,1]:=X[I, 0]+D X ; Y[I, 1]:=Y[I, 0]+D Y$ - END'; IM: =IM+F

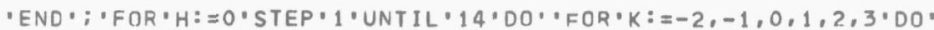

'BEG IN ' HZR $[H, K]:=R E A D ; H R \times[H, K]:=R E A D ; H R Y[H, K]:=R E A D$; $T Z R[H, K]:=R E A D ; T Z R[H, K]:=G R * T Z R[H, K]$

- END';STAP;U[J,O]: $=X G K:=(U[J-1,0]+X G K+D X) / 2$; $V[J, O]:=Y G K:=(V[J-1,0]+Y G K+D Y) / 2 ;$

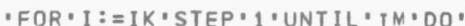

CW012189

CWO12190

CWO12191

CWO12192

CWO12193

CW012194

CWO 12195

CWO 12196

CWO1296A

CWO $1296 \mathrm{~B}$

CWO 12197

CWO12198

CWO12199

CWO12200

CWO 12200

CWO $1200 \mathrm{~A}$

CWO12201

CWO12202

CWO1202A

CWO12203

$V[I, J]:=Y[I, 2]:=(Y[I, 1]+Y[I, 0]+D Y) / 2$

'END'; PLOT $(1, X[I K, 2], Y[I K, 2]) ; \cdot F O R \cdot I:=I K \cdot S T E P \cdot 1 \cdot U N T I L \cdot I M \cdot D O \cdot$

CW01203A

CWO $1203 B$

CWO $1203 \mathrm{C}$

CWO12204

CWO 12205 


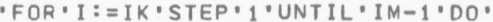

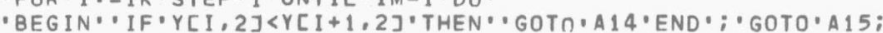

A 14: ONTLUSSEN; SCHOONMAAK; A 15:RAND; IKI: $=I K ; I M 1:=I M ;$ 'FOR'I $:=I K \cdot S T E P \cdot I \cdot U N T I L \cdot I M \cdot D O$.

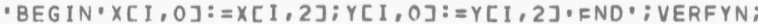

- END'; IF' $X[H, 1] \# \times[1,2] \cdot A N D \cdot X[I, 2] \# \times[K, 0] \cdot T H E N \cdot$

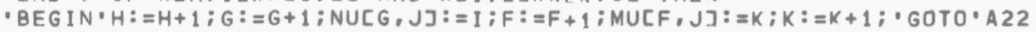

'END'; 'IF'X[H,1]=X[I,2]'AND'X[I,2]\#XIK,0]'THEN

- BEGIN'F: $: F+1 ; M U[F, J]:=K ; K:=K+1 ; \cdot G O T \cap \cdot A 22$

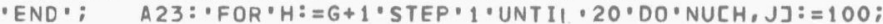

CW012210

CWO12211

CWO12212

CWO12213

CWO12214

CWO12215

CW012216

CWO12217

CWO12218

CWO12219

CWO12220

-FOR $\cdot H:=F+1$ 'STEP 1 - UNTII $20 \cdot D O \cdot M U[H, J]:=100 ;$

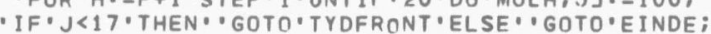

AFGELOPEN $: J 0:=J:=J-1 ;$ IB[J]: $=10 ;$

CCO: IF'IB[J]>IG[J]'THEN'IB[J]:=IG[J];F: $=20$ :

CE1: 'IF'IB[J]'GE'MU[F,J]'THEN.

CWO12221

CWO12222

CWO12223

CWO12224

CW012225

- BEGIN'IBLJ]:=IB[J]-F; 'GOTO'CC2,END', ELSE'

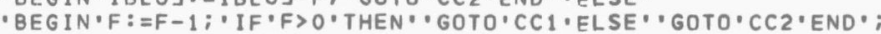

CC2: $G:=20 ; \quad C C 3:$ IF'IB[J]'GE'NU[G,J].THEN'

-BEGIN I I [ J J : =IB[J]+G; • GOTO'CC4 'END' 'FLSE'

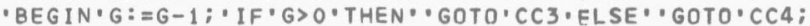

CW012226

CWO12227

CW012228

CWO12229

CWO12230

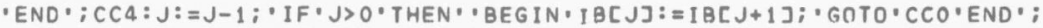
SELECT OUTPUT $(0)$; NEWLINE $(1)$;

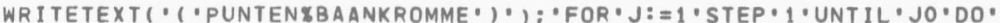

- BEGIN - NEWL INE (1); PRINT (UIIB $[J], J], 2,3)$; PRINT ( V [ IB $[J], J], 2,3)$

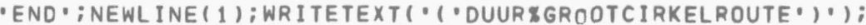

CW012231

CW01231A

CW012232

CWO12233

CW012234

$P:=(J 0+(X B-U[J 0,0]) /(U[J 0+1,0]-U[J 0,0])) / 2 ; K:=E N T$ IER $(P) ;$

$Q:=(P-K) * 24 ;$ PRINT $(K, 2,0)$; WR ITETEXT $(\cdot(\cdot \operatorname{DAGEN} \cdot))$; PRINT $(0,2,1)$;

CW01234A

CWO1234B

WRITETEXT ( $(\cdot$ UREN $))$; $)$ SELECT OUTPMT $(15) ; P L O T(1,0,0) ;$

CWO1234C

CWO12235

$\operatorname{PLOT}(2,13,-1)$

CW012236

EINDE: -END'DIEPE ZUCHT;

CW012237

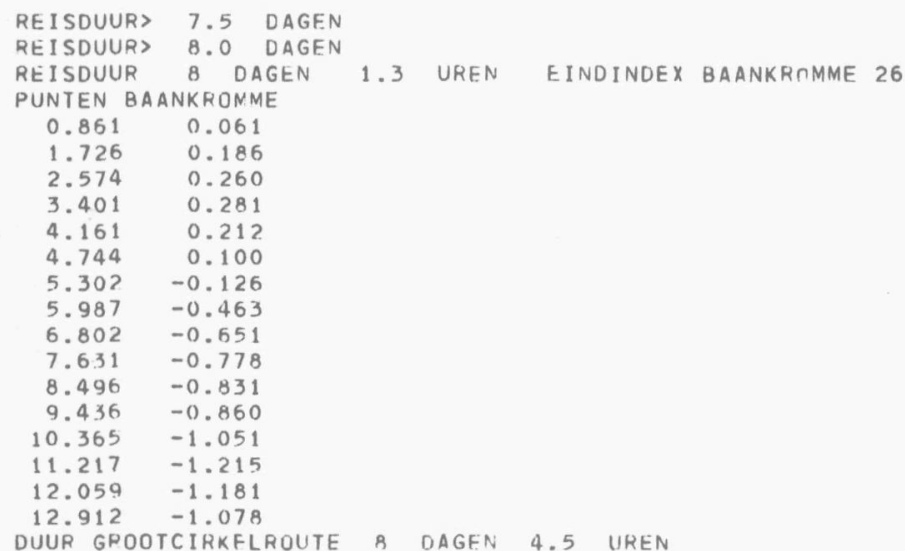


5.6. Considerations regarding data incertainties and practical use.

As noted before, the reliability of weather predictions can be taken inversely proportional to the time last ahead, the prediction is given for. This means, that the least time track, constructed on the basis of weather and sea estimations for a time, from 0 to 8 days ahead, can only be taken as a real extremal for the next one or two days to come. A change in the predicted data would mean, that the track has to be revised. If a ship would thus follow a day-byday corrected extremal, the entire track will consist of parts, that are extremal arcs from day to day, but the composition of these extremals arcs will in general not be an extremal.

It seems rather precarious to make a numerical estimation of the error, that is made this way. A possibility to collect statistical data on this matter would be to simulate ship's crossings in the past, based on weather and sea predictions that were really made at that time, and then compare this with the real extremal, that should have been taken.

Considering the efficiency it can be stated, that the past seven years of experimental and "manual" ship routeing have shown a comparatively small average time gain of about three hours per trip. It can be noted however, that the cost decrease is more than would be expected from this bare figure. This can be made plausible by noting, that considerable time gains are booked in cases where a great circle track would have lead through regions with very high waves. In those regions there is a greater probability of damage to ship or cargo. These damage peaks are very unwanted because of the high costs they imply, while the time loss on account of necessary repairs can disturb the entire sailing schedule.

Another advantage of ship routeing has appeared to be the better predictability of the arrival time. For cargo ships, carrying big unit loads, this is liable to become even more important. The rather short holding time in ports for these vessels as well as the expensive loading installations necessitate a minimizing of the time, during which these terminals stand still. Therefore the schematizing of a container terminal's working procedure has to be done with a minimal tolerance on account of arrival time incertainties. 
Chapter 2:

L. Driencourt, J. Laborde,

Traité des Projections des Cartes Géographiques,

Hermann et Cie, Paris, 1932.

J. van Roon,

Leerboek der Zeevaartkunde III,

C. de Boer, Hilversum, 1949.

Chapter 3:

L.S. Pontryagin c.s.,

The Mathematical Theory of Optimal Processes,

Pergamon Press, 1964.

I. M. Gelfand, S. V. Fomin,

Calculus of Variations,

Prentice Hall, Englewood Cliffs, N. J., 1963.

H. Halkin,

On the necessary conditions for optimal control of nonlinear systems, Journal d'Analyse Mathématique, Jerusalem, 1964.

H. M. de Jong,

Theoretical Aspects of Aeronavigation and its Application in Aviation Meteorology,

Staatsdrukkerij- en Uitgeverijbedrijf, The Hague, 1956.

Chapter 4:

Blair Kinsman,

Wind waves, their generation and propagation on the ocean surface, Prentice Hall, 1965.

U. Grenander, M. Rosenblatt,

Statistical analysis of stationary time series,

Almqvist \& Wiksell, Stockholm, 1956.

W. J. Pierson, G. Neumann, R.W. James,

Practical Methods for Observing and Forecasting Ocean Waves, U.S. Hydrographic Office Pub. No. 603, Washington, 1955. 
P. Groen, R. Dorrestein,

Zeegolven,

Staatsdrukkerij- en Uitgeverijbedrijf, The Hague, 1958.

J. Gerritsma,

Het gedrag van een schip in zeegang,

Vakantieleergang "Het moderne koopvaardijschip", voordr. VII, Delft, 1965.

J. Gerritsma, J.J. van den Bosch, W. Beukelman,

Propulsion in regular and irregular waves,

Shipbuilding Laboratory, Techn. Univ. Delft, Pub. No. 17, 1961.

G. van Leeuwen,

The lateral damping and added mass of a horizontally oscillaring shipmodel,

Neth. Research Centre TNO for Shipbuilding and Navigation, Delft, 1964.

J. Gerritsma, W. Beukelman,

Analysis of the modified strip theory for the calculation of ship motions and wave bending moments,

Neth. Ship Research Centre TNO, Delft, 1967.

R. Wahab,

Amidships forces and moments on a "series $60 "$ model in waves from

various directions,

Neth. Ship Research Centre TNO, Delft, 1967.

J.H. Vugts,

The hydrodynamic coefficients for swaying, heaving and rolling cylinders in a free surface,

Neth. Ship Research Centre TNO, Delft, 1968.

Chapter 5:

F. D. Faulkner,

Numerical methods for determining optimum ship routes,

Journal of the Institute of Navigation, Vol. 10, No. 4, U.S.A., 1964.

W. E. Bleick, F.D. Faulkner,

Minimal-Time Ship Routing,

Journal of Applied Meteorology, U.S.A., April 1965.

F.W. Nagle,

Ship Routing by Numerical Means,

U.S. Navy Weather Research Facility, Report 32-0361-042,

Norfolk, Virg., 1961.

G. J. Haltiner, W. E. Bleick, F.D. Faulkner,

Use of Long-Range Weather Forecasts in Ship Routing,

U.S. Navy Weather Resarch Facility, Norfolk, Virg. , 1967. 
In dit proefschrift wordt aangegeven, op welke wijze men voor een gegeven schip de oceaanroute met de kortste reisduur tussen twee plaatsen kan berekenen.

De, met de tijd veranderende, toestand van de zee wordt overal in het te bevaren gebied G bekend verondersteld, evenals de - stationair genomen zeestroom. Tevens wordt aangenomen, dat het gedrag van het schip in een zee met gegeven golfspectrum geheel bekend is.

Ter vereenvoudiging van afstandsberekeningen wordt G conform en met minimale schaalverandering afgebeeld in een plat vlak. Deze afbeelding wordt in hoofdstuk 2 behandeld.

In hoofdstuk 3 wordt het gestelde probleem besproken als toepassing van Pontryagin's theorie betreffende optimaal geregelde processen. Hierbij worden tijdfronten geïntroduceerd en wordt nagegaan, hoe de gradientvector van zo'n front zich gedraagt bij het volgen van een baankromme. Ook wordt aandacht besteed aan de mogelijke structuur van zo'n front en aan de modificaties, die moeten worden aangebracht als een deel van de baankromme langs de rand van het te bevaren gebied valt.

Hoofdstuk 4 bevat een summiere behandeling en samenvatting van diverse methoden van voorspelling van golfhoogten, alsmede een kort relaas van wat tot nu toe bekend is betreffende het gedrag van een schip in zeegang.

In hoofdstuk 5 wordt een rekenmachineprogramma behandeld, waarmee de routeberekening kan worden uitgevoerd. Als voorbeeld wordt dit programma toegepast voor berekening van de kortste zeeweg van de Westelijke uitgang van het Kanaal naar de kust van Nieuw Engeland.

In de slotparagraaf wordt aandacht geschonken aan de gevolgen van onzekerheden in de gegevens en worden enkele praktische voordelen van meteorologische scheepsroutering besproken. 


\section{S U M M A R Y}

In this thesis a method is described to evaluate the least time track for a given ship to cross an ocean.

The sea conditions - changing with time - and the stationary sea currents are assumed to be known everywhere in the navigated region G. Also the ship's resistance and response in a given wave pattern are supposed to be given. In order to avoid metric difficulties, $G$ is conformally mapped onto a plane, keeping the scale alteration as small as possible. This mapping is treated in chapter 2 .

In the 3rd chapter the minimal time problem is discussed as an application of Pontryagin's theory on optimally controlled processes. The concept of a timefront is then introduced and the behaviour of the timefront gradient along a trajectory is analyzed. Some attention is given to possible structures of these fronts, while modifications of the general theory in case part of a trajectory coincides with the boundary are being discussed.

The 4th chapter contains a curse treatment of wind wave prediction methods as well as a brief report on what is known so far about a ship's behaviour in sea waves.

The fifth chapter gives a treatment of a computer program to evaluate the optimal trajectory. This program serves to determine a ship's shortest track from the Western entrance of the English Channel to the New England coast. As a conclusion, the consequences of data incertainties and the practical use of meteorological ship routeing are briefly discussed. 
The author of this thesis was born in Rotterdam in 1923. After finishing highschool there, he took a two years steersman's apprentice course at the Nautical School, followed by a year of practical training at the Rotterdam Llóyd Navigation Cy.

After the war he sailed four years on Dutch merchant vessels of the Halcyon Line as an apprentice and as a third and second mate. In 1949 he was compelled to stop his active sailing career because he was rejected medically on account of short-sightedness. He became a teacher of navigation and mathematics at the Nautical School at Scheveningen and obtained the legal qualification to prosecute this profession in 1952.

While teaching at the nautical schools of Scheveningen ('49 - '56) and Rotterdam ('56 - '62), he studied mathematics and astronomy at the university of Leiden, where he did his doctoral examination in 1962.

From 1962 until this date he has been working at the Technical University of Delft as an instructor of mathematics. 
Teneinde het minimale tijdprobleem voor een gestuurd niet autonoom systeem onder te kunnen brengen in de klasse van optimaal gestuurde processen, is het noodzakelijk, deze klasse te definiëren op de wijze van Halkin, d.w. z. : Gegeven:

$$
\begin{aligned}
& \frac{d x^{i}}{d t}=f^{i}\left(x^{1}, \ldots, x^{n}, u^{1}, \ldots, u^{m}, t\right) \text { voor } i=1(1) n, \\
& x^{i}\left(t_{0}\right)=x_{0}^{i} \text { voor } i=1(1) n, \\
& x^{i}\left(t_{1}\right)=x_{1}^{i} \text { voor } i=1(1) n-1, \\
& \left(u^{1}, \ldots, u^{m}\right) \in U\left(x^{1}, \ldots ., x^{n}, t\right),
\end{aligned}
$$

$\mathrm{U}$ is een gesloten en begrensde deelruimte van $\mathrm{R}^{\mathrm{m}}$.

Gevraagd: $u^{k}(t)$ zo te bepalen $-k=1(1) m-$ dat $x^{n}\left(t_{1}\right)$ minimaal wordt.

(L.S. Pontryagin c.s., Mathematical Theory of Optimal Processes;

H. Halkin, On the necessary conditions for optimal control of nonlinear systems)

II

Indien men van een schip bij gegeven golfspectrum en gemiddelde golfrichting de kosten per afgelegde mijl als functie van de koers en vaart kent, dan kan men tussen twee plaatsen de baankromme berekenen, waarvoor de totale kosten minimaal zijn.

In Pontryagin's boek over optimaal geregelde processen wordt in hoofdstuk 1, paragraaf 7 verzuimd te bewijzen, dat de eigenschap: "Elk stuk van een optimale baankromme is zelf optimaal" ook geldt voor niet autonome systemen. 
Het veelvuldige gebruik van onbemande ruimtevaartuigen voor doeleinden als meteorologische waarnemingen, communicatie, plaatsbepaling, ruimte-onderzoek, tegenover het slechts incidenteel plaats vinden van bemande ruimtereizen betekent een bevestiging van de ideeën van wijlen Prof. Dr. G. van den Bergh. (Stelling 9 bij dissertatie H.K. Kuiken, T.H. Delft, 1 november 1967)

\section{V}

Bij Noordzoekende gyrokompassen, gebruikt aan boord van koopvaardijschepen, is het systeem, waarbij de koers - en vaartfout niet bij het hoofdkompas wordt gecompenseerd, te prefereren boven het systeem, waarbij dit wèl gebeurt, ook als men in het eerste geval de slingertijd iets verkleint en de demping opvoert.

\section{VI}

Tegen het artikel van Bleick en Faulkner, getiteld "Minimal-Time Ship Routing" in de Journal of Applied Meteorology, april '65, zijn een drietal bezwaren aan te voeren:

1. Indien men over vaartgrafieken van schepen beschikt, verdient bepaling van de vaart bij gegeven golfhoogte door middel van lineaire of kwadratische interpolatie de voorkeur boven vaartbepaling door approximatie van die vaartgrafiek met een analytische functie.

2. De aanname van een convexe vaartindicatrix zonder koersrestricties voor een stoom - of motorschip is niet in overeenstemming met de practijk.

3. Indien men, werkend met een convexe indicatrix, met behulp van een "probeer-en-corrigeer-methode" (trial \& error) een locale extremaal van A naar B heeft geconstrueerd door te werken met de vergelijkingen van Euler - Lagrange, dan behoeft deze extremaal nog niet de absolute extremaal van A naar B te zijn.

\section{VII}

Het invoeren van zeer grote golfhoogten in punten buiten het navigatie-gebied geeft in het algemeen geen juist beeld van de navigatiemogelijkheden. 
In het vierde deel van "Traité des Projections des Cartes Géographiques" van Driencourt en Laborde wordt bij het bewijs van de formule voor de verandering van de geodetische kromming bij conforme afbeelding onnodig slordig gewerkt met het begrip "differentiaal".

\section{IX}

In de, in 1962 verschenen bewerking van de Zeevaartkundige Tafels werd de vergrotende breedte voor de bol vervangen door de vergrotende breedte voor de ellipsoide. Voor loxodromische verheidsberekeningen is deze maatregel alleen zinvol, indien men tevens de mogelijkheid opent, een correctie aan te brengen ter compensatie van het verschil tussen de lengte van één (elliptische) meridiaanminuut en één zeemijl.

\section{$\mathrm{X}$}

Teneinde de doelmatigheid van het routeren van schepen te bevorderen, is het gewenst, dat de routeringsdienst van het K. N.M.I. meer gebruik maakt van de resultaten van het onderzoek naar het gedrag van een schip in zeegang, uitgevoerd door het scheepslaboratorium van deze Technische Hogeschool en door het Nederlands Scheepsbouwkundig Proefstation en gecoördineerd door het Nederlands Scheepsstudiecentrum T. N.O.

\section{XI}

In Nederland bestaat grote behoefte aan een onafhankelijk adviesbureau ter bepaling van doelmatige navigatie-apparatuur voor koopvaardijschepen.

\section{XII}

Gelet zowel op de historische groei als op de recente technische ontwikkelingen is het dringend gewenst, dat bij de behandeling van gewone differentiaalvergelijkingen in technische wiskundeboeken allereerst de existentie van de oplossing van zo'n vergelijking constructief wordt bewezen, terwijl numerieke integratie als belangrijkste oplossingsmethode dient te worden aangemerkt.

(Dr. B. Meulenbeld, Dr. W.K. Baart, Analyse 2, Hfdst. VIII;

Handboek der Wiskunde, Hfdst. VIII, door Dr. S.C. van Veen)

20 november 1968.

C. de Wit. 